UNIVERSIDADE DE SÃO PAULO

INSTITUTO DE PSICOLOGIA

PROGRAMA DE PÓS-GRADUAÇÃO EM PSICOLOGIA EXPERIMENTAL

HELOÍSA CURSI CAMPOS

Procedimento go/no-go com estímulos compostos e relações emergentes em pombos 


\title{
Procedimento go/no-go com estímulos compostos e relações emergentes em pombos ${ }^{1}$
}

\begin{abstract}
Dissertação de mestrado apresentada ao Programa de Pós-Graduação em Psicologia Experimental da Universidade de São Paulo como parte dos requisitos necessários à obtenção do título de Mestre em Psicologia Experimental.
\end{abstract}

Área de concentração: Psicologia Experimental Orientadora: $\operatorname{Prof}^{\mathrm{a}}$ Dr $^{\mathrm{a}}$ Paula Debert

\section{São Paulo}

2009

\footnotetext{
${ }^{1}$ Trabalho financiado pela Coordenação de Aperfeiçoamento de Pessoal de Nível Superior (CAPES) sob a forma de Bolsa de Mestrado.
} 
AUTORIZO A REPRODUÇÃO E DIVULGAÇÃO TOTAL OU PARCIAL DESTE TRABALHO, POR QUALQUER MEIO CONVENCIONAL OU ELETRÔNICO, PARA FINS DE ESTUDO E PESQUISA, DESDE QUE CITADA A FONTE.

Catalogação na publicação

Biblioteca Dante Moreira Leite

Instituto de Psicologia da Universidade de São Paulo

Campos, Heloísa Cursi.

Procedimento go/no-go com estímulos compostos e relações emergentes em pombos / Heloísa Cursi Campos; orientadora Paula Debert. -- São Paulo, 2009.

$75 \mathrm{p}$.

Dissertação (Mestrado - Programa de Pós-Graduação em Psicologia. Área de Concentração: Psicologia Experimental) Instituto de Psicologia da Universidade de São Paulo.

1. Procedimento go/no-go 2. Estímulos compostos 3. Equivalência de estímulos 4. Simetria 5. Pombos I. Título. 


\title{
FOLHA DE APROVAÇÃO
}

\author{
Heloísa Cursi Campos
}

Procedimento go/no-go com estímulos compostos e relações emergentes em pombos

Dissertação de mestrado apresentada ao

Programa de Pós-Graduação em Psicologia

Experimental da Universidade de São Paulo como parte dos requisitos necessários à obtenção do título de Mestre em Psicologia Experimental.

Área de concentração: Psicologia Experimental

Aprovado em:

Banca examinadora

$\operatorname{Prof}(\mathrm{a}) . \operatorname{Dr}(\mathrm{a})$ :

Instituição: Assinatura:

Prof(a). Dr(a).:

Instituição: Assinatura:

Prof(a). Dr(a).:

Instituição: Assinatura: 


\section{AGRADECIMENTOS}

Ainda que eu conste como autora deste trabalho, ele não teria sido possível se não fosse a participação de muitas pessoas. Por isso, agradeço:

À Prof ${ }^{a}$ Paula, pelas diversas oportunidades de aprendizado, pela confiança e pela sempre presença em todos os momentos dessa pesquisa.

Ao $\operatorname{Prof}^{\circ}$ Gerson, por ter cedido o equipamento e os pombos para a coleta e pelos valiosos comentários durante as reuniões de laboratório e o Exame de qualificação.

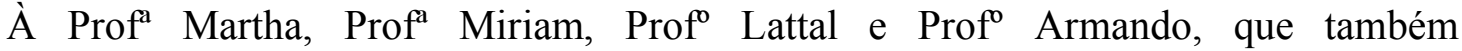
enriqueceram com comentários essa pesquisa.

À Prof ${ }^{a}$ Deisy, pelos valiosos comentários durante o Exame de qualificação.

Aos meus professores de graduação na PUCSP, que me formaram analista do comportamento.

Aos colegas de laboratório(s): Marcelo, Vivi, Cássia, Rafa, Luiza, Ariene, Candido, Saulo, Edson, Eliana, Nathalí, Arturo, Peter, Will, Pri, Fê e Paola, pela convivência diária e pelas discussões.

Ao Marcelo, à Vivi e à Prof ${ }^{a}$ Miriam, pelos cuidados e dedicação com os pombos e a montagem do equipamento.

À Paola, pela doçura, pelas conversas nos corredores do IP, pela torcida para que o equipamento sempre funcionasse e pelas caronas aos domingos.

À Édila, por cuidar dos nossos pombos e pela incrível paciência no dia em que eu tentava pegar um pombo pela primeira vez.

Aos demais funcionários do biotério e da USP, principalmente à Sonia e ao Marcelo, pela competência impecável.

Ao Marcio Bandeira pela ajuda com a montagem inicial do equipamento.

À Jô, que também participou disso tudo.

Ao Pibe, pela companhia, pelas caronas e pelos cuidados nos momentos iniciais desse trabalho.

Ao Vi, o programador, pelas quase setenta versões do Pigeon System e que agora terá que voltar a trabalhar!

Ao Vi, o amigo, e às amigas Dê, Dani, Ana e Dri, somente posso me desculpar pela minha ausência.

Ao Will, entre muitos outros pontos, por ter preenchido com a sua presença os vazios corredores do IP nos finais de semana e feriados durante toda a coleta. 
Ao meu pai, à minha mãe, à Má, ao meu vô Octávio e a toda a minha família, também somente posso me desculpar pela minha ausência diária.

À CAPES, pelo auxílio concedido. 
Toda a nossa ciência, comparada com a realidade, é primitiva e infantil - e, no entanto, é a coisa mais preciosa que temos.

Albert Einstein (1879 - 1955) 


\section{RESUMO}

CAMPOS, H. C. Procedimento go/no-go com estímulos compostos e relações emergentes em pombos. 2009. 75 f. Dissertação (Mestrado) - Instituto de Psicologia, Universidade de São Paulo, São Paulo, 2009.

A emergência de relações não diretamente treinadas e a formação de classes de estímulos equivalentes têm sido demonstradas após treinos com o procedimento matching-to-sample em humanos. Entretanto, estudos com não-humanos têm encontrado dificuldade em demonstrálas. Estudos que utilizaram procedimentos alternativos ao matching-to-sample com pombos sugerem a emergência de relações de identidade e simetria a partir do procedimento go/no-go. O presente estudo pretendeu avaliar se o procedimento go/no-go com estímulos compostos produziria relações emergentes de simetria, transitividade e equivalência, que atestam a formação de classes de equivalência, utilizando pombos como sujeitos. Três pombos passaram por um treino $(\mathrm{AB}$ e $\mathrm{BC})$ de discriminação sucessiva, no qual responder aos compostos A1B1, A2B2, B1C1 e B2C2 foi consequenciado com alimento em VI60 e responder aos compostos $\mathrm{A} 1 \mathrm{~B} 2, \mathrm{~A} 2 \mathrm{~B} 1, \mathrm{~B} 1 \mathrm{C} 2$ e $\mathrm{B} 2 \mathrm{C} 1$ não foi seguido de consequência programada. Os testes envolveram compostos formados pelas recombinações dos elementos dos compostos de treino: BA e CB (simetria), AC (transitividade) e CA (equivalência). Todos os pombos apresentaram desempenhos indicativos de emergência de simetria, mas não de transitividade e equivalência. Esses resultados sugerem que testes de simetria com o procedimento go/no-go com estímulos compostos podem avaliar repertórios diferentes dos testes de simetria com o procedimento matching-to-sample, uma vez que no caso desse último procedimento a literatura indica maiores dificuldades de se estabelecer simetria do que transitividade. Outra possibilidade é que o procedimento go/no-go com estímulos compostos seria mais eficaz para testar emergência de simetria. Futuros estudos poderão investigar quais parâmetros do procedimento go/no-go com estímulos compostos poderiam favorecer a emergência também das relações de transitividade e equivalência.

Palavras-chave: Procedimento go/no-go; estímulos compostos; equivalência; pombos. 


\begin{abstract}
CAMPOS, H. C. Go/no-go procedure with compound stimuli and emergent relations in the pigeon. 2009. 75 p. Dissertation (Master's degree) - Instituto de Psicologia, Universidade de São Paulo, São Paulo, 2009.

Emergence of not directly trained relations and formation of stimulus equivalence classes have been shown using matching-to-sample procedure in humans. However, studies found difficulties to demonstrate these relations in nonhumans. Studies with alternative procedures suggest the emergence of identity and symmetry relations with the go/no-go procedure in pigeons. The present study aimed to evaluate if the go/no-go procedure with compound stimuli would produce symmetry, transitivity and equivalence relations with pigeons as subjects. Three pigeons were submitted to a successive discrimination training in which responding in the presence of the compounds $\mathrm{A} 1 \mathrm{~B} 1, \mathrm{~A} 2 \mathrm{~B} 2, \mathrm{~B} 1 \mathrm{C} 1$ and $\mathrm{B} 2 \mathrm{C} 2$ was followed by food and responding to $\mathrm{A} 1 \mathrm{~B} 2, \mathrm{~A} 2 \mathrm{~B} 1, \mathrm{~B} 1 \mathrm{C} 2$ and $\mathrm{B} 2 \mathrm{C} 1$ was not followed by programmed consequence. During tests, the compounds were formed by recombination of the elements of training compounds: BA and $\mathrm{CB}$ (symmetry), $\mathrm{AC}$ (transitivity) and CA (equivalence). All pigeons showed emergence of symmetry, but not transitivity and equivalence. These results suggest that symmetry tests with go/no-go procedure with compound stimuli would evaluate different repertories than the symmetry tests with matching-to-sample procedure because studies with matching-to-sample procedure indicate difficulties in establishing symmetry but not to establish transitivity. Another possibility is that the go/no-go procedure with compound stimuli would be more efficient to test emergence of symmetry. Future studies could investigate which parameters in a go/no-go procedure with compound stimuli would favor the emergence of transitivity and equivalence relations.
\end{abstract}

Key-words: Go/no-go procedure; compound stimuli; equivalence; pigeons. 


\section{SUMÁRIO}




Em um procedimento de discriminação simples, geralmente, na presença de um estímulo, respostas são seguidas de reforço e, na presença de outro estímulo, as mesmas respostas não são seguidas de reforço (Skinner, 1953). O efeito sobre o comportamento do organismo é que determinadas respostas terão maior probabilidade de ocorrência na presença dos estímulos correlacionados com reforço e menor probabilidade de ocorrência na presença do estímulo não correlacionado com reforço. Dessa maneira, pode-se alterar a probabilidade de ocorrência de uma resposta pela apresentação ou remoção desses estímulos que são chamados de estímulos discriminativos (Skinner, 1953).

Diferentemente, o procedimento de discriminação condicional envolve no mínimo quatro estímulos. Na presença de dois dos quatro possíveis pares formados por esses quatro estímulos, uma resposta emitida será seguida de reforço. Na presença dos demais pares, a mesma resposta não será seguida de reforço (Cumming \& Berryman, 1965). O efeito sobre o comportamento consiste na maior ou menor probabilidade de ocorrência de uma classe de respostas a depender dos pares de estímulos.

O procedimento comumente aplicado nos estudos de discriminação condicional é chamado matching-to-sample (Cumming \& Berryman, 1965) ou, traduzido para o português, emparelhamento com o modelo. Alguns estímulos apresentados por meio do procedimento matching-to-sample são chamados de estímulo "modelo" e outros são chamados de estímulo “escolha”. Cada tentativa se inicia com a apresentação do estímulo modelo. É requerido que o sujeito emita uma resposta de observação ao modelo (por exemplo, bicar ou apontar) que produz dois ou mais estímulos escolha. Em seguida, a resposta de escolher um desses estímulos é seguida de reforço ou não, a depender do modelo apresentado.

O procedimento matching-to-sample empregado para estabelecer relações de identidade entre estímulos é conhecido por matching de identidade (Cumming \& Berryman, 1965). Nesse procedimento é apresentado um modelo e dois ou mais estímulos escolha. Um dos estímulos escolha é igual ao modelo e os demais são diferentes. Respostas de escolha do estímulo igual ao modelo são seguidas de reforço. Respostas de escolha do estímulo diferente ao modelo não são seguidas de reforço.

Outro tipo de procedimento matching-to-sample é chamado de matching de singularidade (Cumming \& Berryman, 1965). Nesse procedimento, um dos estímulos escolha é idêntico ao modelo e o outro estímulo escolha é diferente do modelo. Respostas de escolha do estímulo diferente ao modelo são seguidas de reforço. Respostas de escolha do estímulo igual ao modelo não são seguidas de reforço. 
O procedimento matching-to-sample também pode ser utilizado para estabelecer relações condicionais arbitrárias entre estímulos. Nesse caso, são utilizados, por exemplo, os estímulos A1 e A2 (estímulos do Conjunto A) e B1 e B2 (estímulos do Conjunto B). No treino da relação $\mathrm{AB}$, na presença do modelo $\mathrm{A} 1$ e dos estímulos escolha $\mathrm{B} 1$ e B2, escolher B1 será seguido de reforço e escolher B2 não. Diante do modelo A2 e dos estímulos escolha B1 e B2, escolher B2 será seguido de reforço e escolher B1 não. Como resultado desse treino, verificase que o responder está sob controle condicional se, sistematicamente, perante A1 o organismo escolher B1 e perante A2 o organismo escolher B2.

Se além das relações condicionais $\mathrm{AB}$ forem ensinadas as relações $\mathrm{BC}^{2}$, é possível produzir outras relações condicionais arbitrárias entre estímulos, as relações de reflexividade, simetria, transitividade e equivalência, sem que essas novas relações sejam diretamente ensinadas. Essas relações são chamadas de relações emergentes (Sidman \& Tailby, 1982).

Considerando o treino hipotético $\mathrm{AB}$ e $\mathrm{BC}$, a propriedade reflexividade é verificada quando um modelo exerce controle sobre a resposta de escolher um estímulo escolha idêntico a ele. Por exemplo, na presença do modelo A1 e dos estímulos escolha A1 e A2, o estímulo A1 é escolhido e o estímulo A2 não. Na presença do modelo A2 e dos estímulos escolha A1 e A2, o estímulo A2 é escolhido e o estímulo A1 não. O mesmo deverá ser válido quando os estímulos $\mathrm{B}$ e $\mathrm{C}$ forem empregados no teste.

A propriedade de simetria é demonstrada quando o estímulo que foi apresentado como modelo durante o treino é apresentado como estímulo escolha nos testes e o responder permanece consistente com o que foi ensinado. Em função do treino $\mathrm{AB}$ mencionado, na presença do modelo B1 e dos estímulos escolha A1 e A2, o estímulo A1 é escolhido e o A2 não. Na presença do modelo B2 e dos estímulos escolha A1 e A2, o estímulo A2 é escolhido e o A1 não. Em função do treino $\mathrm{BC}$, na presença do modelo $\mathrm{C} 1$ e dos estímulos escolha $\mathrm{B} 1$ e B2, o estímulo B1 é escolhido e o B2 não. Na presença do modelo C2 e dos estímulos escolha B1 e B2, o estímulo B2 é escolhido e B1 não.

A propriedade de transitividade é verificada quando os estímulos A como modelo e $\mathrm{C}$ como estímulo escolha passam a ser relacionados no teste de forma consistente com o que foi ensinado devido ao fato de terem sido relacionados ao mesmo estímulo B. Por exemplo, na presença do modelo $\mathrm{A} 1$ e dos estímulos escolha $\mathrm{C} 1$ e $\mathrm{C} 2$, o estímulo $\mathrm{C} 1$ é escolhido e o $\mathrm{C} 2$

\footnotetext{
${ }^{2}$ No ensino da relação $\mathrm{BC}$, por exemplo, na presença do modelo $\mathrm{B} 1$ e dos estímulos escolha $\mathrm{C} 1$ e C2, escolher C1 será seguido de reforço e escolher C2 não. Diante do modelo B2 e dos estímulos escolha $\mathrm{C} 1$ e C2, escolher C2 será seguido de reforço e escolher C1 não.
} 
não. Na presença do modelo A2 e dos estímulos escolha $\mathrm{C} 1$ e C2, o estímulo C2 é escolhido e o C1 não.

A relação de equivalência é verificada quando o estímulo $\mathrm{C}$ como modelo passa a ser relacionado no teste com os estímulos A como escolha de forma consistente com o que foi ensinado. Por exemplo, na presença do modelo $\mathrm{C} 1$ e dos estímulos escolha A1 e A2, o estímulo A1 é escolhido e o A2 não. Na presença do modelo C2 e dos estímulos escolha A1 e A2, o estímulo A2 é escolhido e o A1 não.

A partir da aquisição das relações condicionais ensinadas e da emergência das relações condicionais de reflexividade, simetria, transitividade e equivalência, pode-se inferir que os estímulos condicionalmente relacionados no treino formam o que foi denominado de classe de estímulos equivalentes. Isso porque resultados positivos nos testes mencionados indicam que os estímulos se tornaram substituíveis pelos estímulos da mesma suposta classe (Sidman \& Tailby, 1982). Por exemplo, quando se ensinam as relações $\mathrm{AB}$ e as relações $\mathrm{BC}$, conforme exemplificado anteriormente, provavelmente, serão formadas duas classes de estímulos: a Classe 1, formada pelos estímulos A1, B1 e C1 e a Classe 2, formada pelos estímulos A2, B2 e $\mathrm{C} 2$.

Comportamentos que envolvem o que costuma ser chamado de linguagem, cognição e comportamento simbólico têm sido explicados por meio da formação de classes de estímulos equivalentes (Sidman, 1994). Estudos que investiguem características de procedimentos que permitem a produção mais rápida e efetiva de relações condicionais emergentes, tanto simbólicas quanto de identidade, podem permitir a formulação de tecnologias de ensino para o estabelecimento dos comportamentos mencionados em indivíduos com desenvolvimento típico e atípico (Sidman, 1994). O desenvolvimento dessas tecnologias pode se beneficiar especialmente dos resultados de estudos com sujeitos não-humanos criados em laboratório na medida em que esses estudos possibilitam uma melhor avaliação das condições necessárias e suficientes para a produção de classes de estímulos equivalentes.

Apesar de relações condicionais emergentes terem sido extensivamente verificadas após treinos com o procedimento matching-to-sample em humanos (Sidman, 1994), estudos com sujeitos não-humanos têm demonstrado dificuldade em produzi-las por meio do mesmo procedimento (e.g., Sidman, Rauzin, Lazar, Cunningham, Tailby, \& Carrigan, 1982).

Um dos parâmetros do procedimento matching-to-sample que provavelmente dificulta a emergência de relações e/ou o estabelecimento de desempenhos em discriminação condicional em não-humanos é o uso de diferentes localizações para a ocorrência das respostas (e.g., Iversen, Sidman, \& Carrigan, 1986; Kamil \& Sacks, 1972). Isso pode permitir 
o desenvolvimento de controle pela localização do responder em detrimento da relação condicional entre estímulo modelo e estímulo escolha (Iversen, 1997; Iversen et al., 1986; Kamil \& Sachs, 1972; Sidman, 1992; Sidman et al., 1982). A expressão "controle pela localização" indica que o responder está sob controle da localização na qual o estímulo escolha é apresentado, independentemente de qual estímulo escolha seja apresentado nessa localização e de qual seja o modelo. Esse tipo de controle que se estabelece sem planejamento pelo experimentador, diferentemente, do responder que está sob controle da relação entre estímulo modelo e escolha, não produz classes de estímulos equivalentes.

O primeiro estudo a investigar a possibilidade de se estabelecer controle pela localização do responder por meio do procedimento matching-to-sample em sujeitos nãohumanos foi Kamil e Sachs (1972). O objetivo do Experimento 1 foi investigar se, após um treino de relações de identidade com o matching-to-sample apresentando três configurações de estímulos, o responder dos sujeitos estaria sob controle da relação de identidade em uma quarta configuração, não ensinada. Quatro pombos foram submetidos a uma tarefa na qual três chaves de resposta eram dispostas horizontalmente e cada uma iluminada com uma cor (vermelho, R, ou verde, G). Durante o treino, eram apresentadas as seguintes configurações ${ }^{3}$ : $\mathrm{R} * \mathrm{RG}, \mathrm{GRR}^{*}$ e RGG*. Cada tentativa se iniciava com a apresentação do estímulo modelo na chave central. Uma resposta de bicar o modelo era consequenciada com a remoção deste estímulo e a apresentação dos dois estímulos escolha, cada um em uma chave lateral. Respostas ao estímulo idêntico ao modelo eram seguidas de alimento. Respostas ao estímulo diferente do modelo eram seguidas de 10 segundos de escurecimento da caixa. Cada configuração de estímulos era apresentada 40 vezes, totalizando 120 tentativas por sessão. O critério de encerramento dessa fase era o desempenho do sujeito atingir $90 \%$ de acertos em três sessões consecutivas. Na fase de teste eram apresentadas as três configurações de estímulos do treino e também a configuração $G^{*} \mathrm{GR}$, que não havia sido apresentada durante a fase de treino. Cada configuração era apresentada 30 vezes. O critério de encerramento da fase de teste era atingir a porcentagem de acertos de $90 \%$ ou a ocorrência de 15 sessões. Os resultados mostraram desde o início do treino, para todos os sujeitos, a porcentagem de acertos esteve próxima a 100\% quando eram apresentadas as configurações GRR* e RGG*, indicando que os sujeitos respondiam ao estímulo escolha localizado à direita. Na presença de

\footnotetext{
${ }^{3}$ Para a descrição das relações apresentadas, será convencionado aqui que o primeiro estímulo se refere ao estímulo escolha na localização esquerda, o segundo estímulo se refere ao modelo na localização central e o terceiro estímulo se refere ao estímulo escolha na localização direita. O asterisco aponta qual era o estímulo escolha na presença do qual respostas eram seguidas de reforço (estímulo escolha idêntico ao modelo).
} 
$\mathrm{R} * \mathrm{RG}$, a porcentagem de acertos foi nula durante as primeiras sessões de treino, o que indica que os sujeitos respondiam ao estímulo escolha verde localizado à direita. Nas sessões seguintes, a porcentagem de acertos atingiu valores próximos a 100\% nessa configuração. Esses dados sugerem que, no início do treino, havia se estabelecido um controle discriminativo simples pela localização do responder aos estímulos escolha na chave direita que parece ter sido substituído por um controle pela relação condicional entre estímulos modelo e escolha nas sessões seguintes. Durante o teste, as porcentagens de acertos estiveram, aproximadamente, entre 70 e $100 \%$, desde o início dessa fase para as três configurações que haviam sido apresentadas no treino. No caso da nova configuração, G*GR, a porcentagem de acertos esteve, aproximadamente, entre 0 e $50 \%$ nas primeiras cinco sessões. Isso indica que os sujeitos respondiam ao estímulo escolha vermelho localizado à direita. Nas demais sessões de teste, as porcentagens de acertos na presença de $\mathrm{G}^{*} \mathrm{GR}$ variaram entre, aproximadamente, 75 e 100\% para todos os sujeitos, indicando que foi estabelecido o responder sob controle da relação condicional entre estímulo modelo e escolha. Segundo Kamil e Sacks (1972), a cor e a localização do responder escolha podem ter controlado o responder dos sujeitos no início do treino e não a relação de identidade entre os estímulos.

Com o objetivo de verificar essa hipótese, Kamil e Sacks (1972) conduziram um segundo experimento. Para isso, durante a fase de teste, os dois estímulos escolha apresentados eram da mesma cor. Seis pombos ingênuos foram submetidos ao mesmo treino conduzido durante o Experimento 1 (R*RG, GRR* e RGG*). Em seguida, os Sujeitos 1 e 2 foram submetidos à fase de teste em que foram apresentadas duas configurações novas, em que os estímulos escolha da direita e da esquerda eram ambos da cor branca (W). O objetivo dessa manipulação era verificar se um controle pela localização do responder seria apresentado durante o teste, mesmo quando os estímulos apresentados como estímulos escolha fossem iguais entre si e não mantivessem qualquer relação com o estímulo modelo estabelecida pelo experimentador. As configurações apresentadas eram: WRW e WGW. A sessão de teste continha 120 tentativas, 60 de cada uma dos novos estímulos. Para os demais quatro sujeitos foi empregado o mesmo procedimento, exceto que as configurações apresentadas eram RGR e GRG. Na terceira fase os seis sujeitos foram submetidos a uma sessão na qual cada uma das configurações WRW, WGW, RGR e GRG eram apresentadas 30 vezes. Como resultados, a porcentagem de acertos, em geral, esteve próxima a $100 \%$ durante o treino, desde o início, quando eram apresentadas as configurações GRR* e RGG*. Na presença da configuração $\mathrm{R}^{*} \mathrm{RG}$, a porcentagem de acertos foi nula nas 20 primeiras sessões. Em conjunto, esses resultados sugerem controle pela localização direita nessas primeiras 
sessões. Nas sessões seguintes, a porcentagem de acertos atingiu valores próximos a 100\%. Durante a segunda fase, na qual os dois estímulos escolha eram idênticos e diferentes do modelo, dois sujeitos responderam sob controle da localização direita na maior parte das tentativas. Para os outros dois sujeitos, quando foram apresentadas as configurações GRG e RGR, a porcentagem de respostas variou entre 23 e $31 \%$ na chave direita quando o modelo era a cor vermelha e entre 92 e $98 \%$ de respostas na chave direita quando o modelo era a cor verde. Esses resultados sugerem que para esses sujeitos se estabeleceu um controle pela localização esquerda quando o modelo era a cor vermelha e um controle pela localização direita quando o modelo era a cor verde, ainda que os estímulos escolha fossem idênticos. Durante a terceira fase, todos os sujeitos apresentaram porcentagens de acertos que variaram entre 0 e $23 \%$ diante da configuração $G^{*} \mathrm{GR}$, a nova configuração, indicando que havia se estabelecido um controle pela localização do responder na direita, ao invés do estabelecimento de controle pela relação de identidade.

Sidman (1992) também apresentou uma análise que permitiu verificar estabelecimento de controle pela localização do responder, em sujeitos não-humanos, por meio do procedimento matching-to-sample em um estudo anterior (Sidman et al., 1982). Este último estudo teve o objetivo de avaliar se, após uma tarefa com o procedimento matching-to-sample, relações de simetria seriam produzidas em macacos.

No estudo de Sidman et al. (1982), um macaco rhesus foi submetido a um treino de matching de identidade e matching arbitrário com as cores vermelha e verde e linhas verticais e horizontais como estímulos. O modelo era apresentado na localização central de um painel (Localização 3) e os dois estímulos escolha eram apresentados em duas localizações laterais de quatro possíveis (Localização 1, 2, 4 e 5), equidistantes da localização central. A cada tentativa, era variada a localização do responder aos estímulos escolha nas localizações laterais. Havia seis pares possíveis de apresentação dos estímulos escolha nas localizações laterais (Localizações 1 e 2; 1 e 4; 1 e 5; 2 e 4; 2 e 5; e 4 e 5). Cada par de estímulos escolha e cada estímulo escolha tinha a mesma probabilidade de ser apresentado em cada localização. Cada tentativa se iniciava com a apresentação do estímulo modelo. Após o sujeito responder ao modelo, os dois estímulos escolha eram apresentados. Nas tentativas de matching de identidade, escolher o estímulo escolha idêntico ao modelo era seguido de reforço. Escolher o estímulo escolha diferente do modelo não era seguido de consequência programada. Nas tentativas de matching de singularidade, escolher o estímulo escolha diferente do modelo era seguido de reforço. Escolher o estímulo escolha idêntico ao modelo não era seguido de consequência programada. Cada sessão continha 300 tentativas e foram conduzidas 39 
sessões. Durante as 20 primeiras sessões, a porcentagem de acertos esteve em torno de $50 \%$. A partir da sessão 21 até a sessão 33 , a porcentagem de acertos esteve em torno de $70 \%$. A partir da sessão 34 , a porcentagem de acertos aumentou gradativamente até atingir $100 \%$ de acertos na sessão 39.

Sidman (1992) sistematizou alguns desses resultados de forma que as porcentagens de escolha da linha vertical diante do modelo linha vertical e diante do modelo horizontal foram apresentadas separadamente para cada um dos seis pares de apresentação dos estímulos nas localizações laterais nas sessões 34 a 39. Se as porcentagens de escolha da linha vertical fossem diferentes a depender da localização dos estímulos escolha, isso indicaria que a localização do responder controlou as respostas do sujeito antes de se estabelecer um controle condicional pela relação de identidade entre os estímulos. A seguir são apenas apresentadas as porcentagens de escolha da linha vertical quando os estímulos escolha eram apresentados nas Localizações 1 e 2 e Localizações 4 e 5 já que, nas demais localizações, os controles estabelecidos seguem um dos dois padrões descritos a seguir. Quando os estímulos eram apresentados nas Localizações 1 e 2 , a porcentagem de escolha da linha vertical foi de $80 \%$ diante da linha vertical e 50\% diante do modelo linha horizontal. Nas sessões seguintes, a porcentagem de escolha da linha vertical aumentou e a porcentagem de escolha da linha horizontal decresceu, de forma que na maior parte das vezes o sujeito deixou de escolher a linha vertical apenas quando o modelo era linha horizontal. Esses dados indicam que quando os estímulos escolha eram apresentados nessas localizações ocorreu inicialmente controle pela linha vertical. Nas Localizações 4 e 5, diante do modelo linha vertical, a porcentagem de escolha da linha vertical foi de $45 \%$. Isso indica que o sujeito escolheu, em um maior número de tentativas, a linha horizontal e que havia se estabelecido um controle pelo estímulo linha horizontal. Diante do modelo linha horizontal, a porcentagem de escolha da linha vertical foi $10 \%$, nas mesmas sessões, o que também indica que o sujeito escolheu, em um maior número de tentativas, a linha horizontal. A partir desses dados, verificou-se que durante a aquisição das relações de identidade (controle pela linha vertical ou pela linha horizontal) o controle de estímulos estabelecido foi diferente a depender da localização ocupada pelos estímulos escolha. Isso indica que a localização do responder se constituiu uma propriedade controladora e o sujeito respondeu sob controle das localizações ocupadas pelos estímulos. Portanto, mesmo um procedimento que variou a localização de apresentação dos estímulos escolha em quatro possíveis localizações não preveniu que esse controle inadvertido se estabelecesse ao longo do treino. 
Outra manipulação realizada e que não parece ter sido suficiente para prevenir o estabelecimento de controle pela localização do responder em não-humanos consistiu na variação da localização do estímulo modelo e foi realizada por Iversen et al. (1986) com macacos.

O estudo de Iversen et al. (1986) pretendeu verificar se os desempenhos acurados produzidos por um treino de matching de identidade em que o modelo fosse apresentado sempre na mesma localização permaneceriam com altas porcentagens de acertos se o modelo e, portanto, os estímulos escolha, passassem a ser apresentados em diferentes localizações. Dois macacos rhesus, R47 e R50, foram submetidos a uma tarefa na qual três chaves de resposta eram apresentadas horizontalmente. Durante os treinos, em cada tentativa, o modelo era apresentado sempre na localização central. Após o sujeito pressionar o modelo, cada um dos dois estímulos escolha era apresentado nas duas localizações laterais e o modelo permanecia na chave central. Escolher o estímulo escolha idêntico ao modelo era seguido de alimento e do término da tentativa. Escolher o estímulo escolha diferente do modelo era consequenciado com o término da tentativa. Cada combinação dos dois estímulos escolha apresentados em cada tentativa e cada estímulo escolha tinha a mesma probabilidade de ser apresentado em cada uma das localizações. Foram ensinadas relações de identidade com os estímulos vermelho, verde, linha vertical e linha horizontal. Após atingir 95\% de acertos em pelo menos duas sessões consecutivas, os sujeitos eram submetidos à fase de treino seguinte, de mudança do estímulo modelo. Nessa fase, em cada tentativa, o modelo poderia ser apresentado em qualquer uma das três localizações e os estímulos escolha, portanto, nas localizações restantes. Durante a última sessão de treino, com linhas ou cores, na qual o estímulo modelo era apresentado na localização central, a porcentagem de acertos esteve próxima a $100 \%$. Durante a primeira sessão de treino na qual o modelo poderia ser apresentado em qualquer localização, a porcentagem de acertos se manteve ao redor de $100 \%$ quando os estímulos consistiam em cores e decresceu para aproximadamente $66 \%$ para o Sujeito R50 e 73\% para o Sujeito R47 nas tentativas envolvendo linhas. Essa deterioração da porcentagem de acertos indica que o responder diante das cores não estava relacionado às localizações ocupadas pelos estímulos modelos, ao passo que na presença da linha, o responder estava sob controle das linhas em conjunto com as localizações nas quais os modelos eram apresentados. Segundo Iversen et al. (1986), a localização do modelo também deve ser vista como uma possível fonte de controle do responder em procedimentos de discriminação condicional. 
Em conjunto, os trabalhos de Iversen et al. (1986), Kamil e Sacks (1972) e Sidman (1992) mostram que, ao empregar o procedimento matching-to-sample com sujeitos nãohumanos, a possibilidade de o responder ocorrer em mais de uma localização pode estabelecer um controle pela localização do responder. Mesmo procedimentos de treino que envolvam apresentação ou variação dos estímulos em mais de duas localizações não previnem o estabelecimento de um controle pela localização do responder (Iversen et al., 1986) ou demandam sessões adicionais de treino para corrigir esse controle inadvertido (e.g., Barros, Galvão, \& McIlvane, 2002). Procedimentos que apresentassem apenas uma localização para o responder poderiam prevenir que a localização do responder se tornasse uma propriedade controladora do responder de sujeitos não-humanos e poder-se-iam constituir alternativas ao procedimento matching-to-sample para a produção de relações emergentes.

Um procedimento por meio do qual era exigido que o responder fosse emitido em uma única localização foi empregado no estudo de Frank e Wasserman (2005). Esse estudo parece ter produzido a emergência da relação de simetria em pombos a partir do procedimento matching-to-sample sucessivo go/no-go ("successive go/no-go matching-to-sample procedure") no qual os estímulos eram apresentados em apenas uma localização.

Nesse procedimento, primeiramente era apresentado um estímulo (S1). A primeira resposta após 10 segundos tinha como consequência a remoção do S1 e a apresentação, na mesma localização, de outro estímulo (S2). A apresentação sucessiva de cada estímulo caracteriza o procedimento matching-to-sample sucessivo. Responder ao S2 que, de acordo com as contingências programadas, fosse da mesma classe do S1, era seguido de alimento. Responder ao S2 que, de acordo com as contingências programadas, fosse de classe diferente do S1, não era seguido de reforço, o que caracteriza o procedimento go/no-go. Foram realizados três experimentos. Cada um deles contou com dois pombos ingênuos. Os estímulos utilizados consistiram em uma imagem de uma borboleta, uma flor, um caracol e uma planta que eram apresentados em uma tela sensível às bicadas dos pombos. Entre o sujeito e a tela havia a parede da caixa experimental. Na parede havia uma abertura de sete centímetros centralizada que dava acesso à tela e ao local de apresentação dos estímulos. Durante o treino, cada tentativa se iniciava com a apresentação do símbolo +. Após uma resposta de bicar, o símbolo + deixava de ser apresentado e era apresentado o S1 sorteado para aquela tentativa. Respostas de bicar após 10 segundos do início da apresentação do S1 eram seguidas da remoção do estímulo e da apresentação de uma tela branca por 3,5 segundos. Em seguida, era apresentado o S2. Caso o S2 fosse o estímulo designado arbitrariamente pelo experimentador como relacionado ao S1 (combinação positiva), após 10 segundos da apresentação do S2, 
respostas de bicar eram seguidas de alimento. Caso o estímulo S2 não fosse o designado como relacionado ao S1 (combinação negativa), após os 10 segundos, a tela escurecia. No Experimento 1, foram apresentadas as combinações A1B1 e A2B2 (positivas de matching arbitrário), A1B2 e A2B1 (negativas de matching arbitrário), A1A1, A2A2, B1B1 e B2B2 (positivas de matching de identidade) e A1A2, A2A1, B1B2 e B2B1 (negativas de matching de identidade). A justificativa para a apresentação de tentativas de matching de identidade foi impedir que a ordem temporal dos estímulos S1 e S2 se estabelecesse como uma propriedade controladora do responder. Isso porque apenas nas tentativas de matching de identidade todos os estímulos eram apresentados como S1 e S2. As combinações de matching arbitrário e de identidade eram randomicamente apresentadas durante o treino. Em cada sessão, eram apresentadas 192 tentativas, distribuídas em oito blocos de 24 tentativas (duas de cada combinação positiva e negativa). Eram calculadas três razões de discriminação. A razão das combinações de matching arbitrário era calculada pelo número de respostas a A1B1 e A2B2 dividido pelo número de respostas a A1B1, A2B2, A1B2 e A2B1. A razão das combinações de matching de identidade dos estímulos do Conjunto A era calculada pelo número de respostas a A1A1 e A2A2 dividido pelo número de respostas a A1A1, A2A2, A1A2 e A2A1. A razão das combinações de matching de identidade do Conjunto $B$ era calculada pelo número de respostas a B1B1 e B2B2 dividido pelo número de respostas a B1B1, B2B2, B1B2 e B2B1. Inicialmente todas as tentativas eram seguidas de um intervalo entre tentativas (IET) randomizado entre 5 e 10 segundos. Se, durante três sessões de treino, o sujeito não respondesse diferencialmente entre as combinações positivas e negativas, o IET era aumentado apenas após as combinações negativas, em 5 segundos. As sessões de treino terminavam quando as três razões de discriminação atingiam 0,80 em uma sessão. Depois de atingido o critério, foi conduzido o teste de simetria. Em cada sessão, eram apresentadas as quatro combinações de matching arbitrário e as oito combinações de matching de identidade apresentadas durante o treino, acrescidas de quatro combinações de teste de simetria. No teste de simetria, o estímulo apresentado como S1 durante o treino passava a ser apresentado como $\mathrm{S} 2$ e o estímulo apresentado como S2 durante o treino passava a ser apresentado como S1. As combinações do teste de simetria foram: B1A1, B2A2, B1A2 e B2A1. Não havia apresentação de alimento nas tentativas de teste, somente nas de treino. As sessões do teste de simetria totalizavam 224 tentativas. Cada sessão se iniciava com um bloco que continha cada uma das quatro combinações de matching arbitrário e cada uma das oito combinações de matching de identidade apresentadas durante o treino de forma que não havia a possibilidade de iniciar o teste com tentativas nas quais o responder não seria seguido de alimento. Em 
seguida, eram apresentados sete blocos, cada um com 28 tentativas. Em cada bloco havia duas tentativas de cada uma das oito combinações de matching de identidade e de cada uma das quatro combinações de matching arbitrário apresentadas durante o treino e quatro tentativas de teste de simetria, uma de cada combinação de teste. A justificativa para intercalar tentativas de treino com tentativas de teste era manter baixa a frequência de tentativas de teste (sem a apresentação de alimento) ao longo das sessões de teste de simetria. Por fim, era apresentado um bloco com 16 tentativas, uma de cada combinação de matching arbitrário e de identidade apresentada durante o treino (12 tentativas) e uma de cada combinação de teste (quatro tentativas). Da mesma maneira que as razões de discriminação do treino, foi calculada uma razão de discriminação nas tentativas do teste de simetria: número de respostas a B1A1 e B2A2 dividido pelo número de respostas a B1A1, B2A2, B1A2 e B2A1. Foram realizadas duas sessões de teste de simetria, cada uma separada por sessões de treino, em número necessário até que os sujeitos atingissem razões de discriminação de 0,80 em cada uma das três razões calculadas de treino para passar pelo segundo teste de simetria. Os resultados, entretanto, foram apresentados por meio de taxas de respostas. Os resultados mostraram que para um sujeito, ao final do treino, a taxa média de respostas de bicar por segundo diante das combinações positivas de matching de identidade era 0,99 e diante das combinações negativas de matching de identidade era 0,25 . Na presença das combinações positivas de matching arbitrário era 1,02 e das combinações negativas de matching arbitrário era 0,30. No teste de simetria, a taxa era 1,08 nas combinações positivas e 0,27 nas combinações negativas. Para o outro sujeito, ao final do treino, a taxa média de respostas diante das combinações positivas de matching de identidade era 1,52 e diante das combinações negativas de matching de identidade era 0,18 . Na presença das combinações positivas de matching arbitrário era 1,57 e das combinações negativas de matching arbitrário era 0,21 . No teste de simetria, a taxa média era 1,44 nas combinações positivas e 0,40 nas combinações negativas. As diferenças entre as taxas diante das combinações positivas e negativas de matching arbitrário e de identidade durante os treinos e testes indicam que os sujeitos aprenderam as relações ensinadas e que emergiram as relações de simetria.

Frank e Wasserman (2005) planejaram o Experimento 2 com o objetivo de verificar se apenas o treino de matching arbitrário, sem o treino de matching de identidade, permitiria a emergência de simetria. Foi empregado o mesmo procedimento utilizado no Experimento 1. Contudo, no Experimento 2, durante o treino e o teste de simetria, não havia tentativas de matching de identidade. Em cada sessão de treino eram apresentadas 160 tentativas, divididas em oito blocos de 20 tentativas. Em cada bloco havia cinco tentativas de cada uma das quatro 
combinações de matching arbitrário. Cada sessão do teste de simetria se iniciava com um bloco que continha cinco tentativas de cada uma das quatro combinações de matching arbitrário apresentadas durante o treino (total de 20 tentativas). A seguir, eram apresentadas as tentativas de treino junto com as tentativas de teste de simetria. Em cada bloco havia cinco tentativas de cada uma das quatro combinações de matching arbitrário apresentadas durante o treino (total de 20 tentativas) e quatro de cada uma das quatro combinações de tentativas de teste de simetria (total de 4 tentativas). Foram apresentados sete blocos (cada um com 24 tentativas), totalizando 188 tentativas nas sessões de teste. Para um sujeito, ao final dos treinos, a taxa média de respostas diante das combinações positivas de matching arbitrário era 2,12 e diante das combinações negativas de matching arbitrário era 0,31. Nos testes de simetria, a taxa média era 0,89 na presença das combinações positivas e 0,78 na presença das combinações negativas. Para o outro sujeito, ao final dos treinos, a taxa média de respostas diante das combinações positivas era 1,02 e diante das combinações negativas era 0,55 . Nos testes de simetria, a taxa era 0,48 na presença das combinações positivas e 0,46 na presença das combinações negativas. Esses resultados mostraram uma diferença entre as taxas diante das combinações positivas e negativas durante os treinos. Porém, a diferença entre as taxas nas combinações positivas e negativas nos testes de simetria foi muito pequena. Isso indica que, ainda que os sujeitos tenham demonstrado desempenhos acurados durante os treinos, a relação de simetria não emergiu. Como conclusão, Frank e Wasserman (2005) sugerem que a emergência de simetria durante o Experimento 1 poderia estar relacionada com o uso de tentativas de matching de identidade no treino.

Para verificar se a ausência de tentativas de matching de identidade seria responsável por resultados negativos no teste de simetria do Experimento 2, Frank e Wasserman (2005) delinearam o Experimento 3. Foi utilizado, primeiramente, um procedimento similar ao procedimento do Experimento 2, que apresentava tentativas de matching arbitrário, e, em seguida, um procedimento similar ao do Experimento 1, que apresentava tentativas de matching arbitrário e matching de identidade. Outras alterações consistiram na diminuição do intervalo de troca do estímulo S1 pelo S2 de 3,5 segundos para 1 segundo e no cálculo das razões de discriminação que serviram como critério para mudança de fase. Durante o treino de matching arbitrário foram calculadas duas outras razões de discriminação. Um dos cálculos era realizado a partir do número de respostas a A1B1 dividido pelo número de respostas a A1B1 e A2B1 e o outro cálculo era realizado a partir do número de respostas a A2B2 dividido pelo número de respostas a A2B2 e A1B2. 
Da mesma forma que no experimento anterior, foram apresentadas apenas as taxas de respostas. Para um sujeito, ao final dos treinos de matching arbitrário, a taxa média de respostas diante das combinações positivas de matching arbitrário era 0,88 e diante das combinações negativas era 0,19 . Nos testes de simetria seguintes aos treinos de matching arbitrário, as duas taxas médias atingiram o valor 0,7. Esses resultados mostraram que, ainda que o sujeito tenha demonstrado desempenho acurado durante os treinos, ele não demonstrou a emergência de simetria. Esses resultados replicaram os resultados do Experimento 2. Para o mesmo sujeito, quando submetido à fase seguinte, treino de matching arbitrário e de identidade, ao final dos treinos de matching arbitrário e de identidade, a taxa média diante das combinações positivas de identidade era 0,52 e diante das combinações negativas de 0,1 . A taxa média diante das combinações positivas de matching arbitrário era 0,54 e diante das combinações negativas de matching arbitrário era 0,06 . Nos testes de simetria posteriores aos treinos de matching arbitrário e de identidade, a taxa média era 0,32 na presença das combinações positivas e 0,14 na presença das combinações negativas. Segundo Frank e Wasserman (2005), esses resultados mostraram uma diferença entre as taxas diante das combinações positivas e negativas de matching arbitrário e de identidade e uma modesta, mas confiável diferença entre as taxas diante das combinações positivas e negativas durante os testes de simetria. Isso indicaria que a relação de simetria emergiu após os treinos de matching arbitrário e de identidade. Contudo, a diferença entre as taxas diante das combinações positivas e negativas durante o teste de simetria do Experimento 3 foi menor do que a diferença entre as mesmas taxas obtidas no Experimento 1. Para o outro sujeito, ao final dos treinos de matching arbitrário, a taxa média de respostas diante das combinações positivas de matching arbitrário era 1,05 e diante das combinações negativas era 0,31. Nos testes de simetria realizados após os treinos de matching arbitrário, a taxa média era 0,22 na presença das combinações positivas e 0,17 na presença das combinações negativas. Esses resultados mostraram que, ainda que o sujeito tenha demonstrado desempenho acurado durante os treinos de matching arbitrário, ele não demonstrou a emergência de simetria. Isso replica os resultados do Experimento 2. Para o mesmo sujeito, ao final os treinos de matching arbitrário e de identidade, a taxa média diante das combinações positivas de identidade era 1,33 e diante das combinações negativas era 0,23. A taxa média diante das combinações positivas de matching arbitrário era 1 e diante das combinações negativas de matching arbitrário era 0,27. Nos testes de simetria seguintes aos treinos de matching arbitrário e de identidade, a taxa média era 0,82 na presença das combinações positivas e 0,77 na presença das combinações negativas. Esses resultados mostraram uma diferença entre as taxas diante das combinações 
positivas e negativas de matching arbitrário e de identidade durante os treinos de matching arbitrário e de identidade. Contudo, não houve diferença entre as taxas diante das combinações positivas e negativas durante os testes. Isso indica que a relação de simetria não emergiu após os treinos de matching arbitrário e de identidade. Os resultados do Experimento 3 indicam que um procedimento que envolve inicialmente treinos de matching arbitrário e em seguida treinos de matching arbitrário e de identidade não é tão eficiente para produzir a emergência de simetria quanto um procedimento que envolve treinos de matching arbitrário e de identidade misturados desde o início do treino (Experimento 1). Provavelmente, a inclusão das tentativas de matching de identidade desde o início do Experimento 1 preveniu, ou não permitiu, que o responder ficasse sob controle da ordem temporal de apresentação dos estímulos. Os resultados do Experimento 3 podem ter ocorrido, provavelmente, porque sem as tentativas de matching de identidade apresentadas desde o início do treino a ordem temporal de apresentação dos estímulos se estabeleceu como uma propriedade controladora do responder.

Outro estudo que empregou um procedimento com uma única localização para o responder e que parece ter produzido relações emergentes em pombos foi o estudo de Zentall e Hogan (1975). O procedimento utilizado por Zentall e Hogan (1975), diferentemente do procedimento empregado por Frank e Wasserman (2005), não permitiu que se estabelecesse um controle pela ordem temporal de apresentação dos estímulos. Isso porque os estímulos, a cada tentativa, eram apresentados simultaneamente.

Zentall e Hogan (1975) tiveram o objetivo de verificar a emergência das relações de identidade e singularidade em pombos por meio do procedimento go/no-go e verificar a transferência dessas relações para novos estímulos com e sem propriedades ortogonais às propriedades dos estímulos do treino ${ }^{4}$. Se um treino fosse realizado apresentando cores como estímulos, os testes com estímulos com propriedade ortogonal referir-se-iam a estímulos com brilho ou com linhas, por exemplo. Assim, esses estímulos teriam menor similaridade com os estímulos do treino.

\footnotetext{
${ }^{4} \mathrm{O}$ estudo de Mallot, Mallot, Svinicki, Kladder e Ponicki (1971) foi o primeiro a avaliar se um procedimento go/no-go com chave única de resposta, dividida ao meio por uma linha vertical, geraria controle pela relação de identidade entre os estímulos nos treinos e pela relação de identidade entre novos estímulos nos testes, trabalhando com pombos como sujeitos. Zentall e Hogan (1975) estenderam os resultados de Malott et al. (1971) porque realizaram testes também com estímulos com propriedade ortogonal à propriedade dos estímulos do treino. Em função disso, privilegiou-se a descrição do estudo de Zentall e Hogan (1975) e não a de Malott et al. (1971) no presente projeto.
} 
No Experimento 1, oito pombos ingênuos foram submetidos a um treino no qual cada metade de uma chave de resposta, dividida ao meio por uma linha vertical, era iluminada independentemente com cores. A Fase 1 tinha o objetivo de modelar a resposta de bicar a chave. A Fase 2 tinha o objetivo de fortalecer a resposta de bicar na presença das duas configurações de matching (duas metades vermelhas ou duas metades verdes na chave, que se referem à relação de igualdade) para quatro sujeitos (Grupo M) e na presença das duas configurações de não matching (metade esquerda vermelha e metade direita verde ou metade esquerda verde e metade direita vermelha, que se referem à relação de singularidade) para outros quatro sujeitos (Grupo N). Era apresentada uma das duas configurações de cada grupo. Respostas de bicar eram reforçadas em esquema de reforçamento contínuo (CRF) até que fossem apresentados quinze reforços. A Fase 3 tinha o objetivo de fortalecer as respostas de bicar em esquema VI 60 segundos. As mesmas configurações apresentadas na fase anterior eram apresentadas randomicamente por 30 segundos e as respostas de bicar eram reforçadas em VI 60 segundos. A apresentação das configurações era separada por um IET de 10 segundos. Cada configuração era apresentada trinta vezes, totalizando sessenta apresentações. A Fase 4 (treino discriminativo) tinha o objetivo de ensinar os sujeitos do Grupo $\mathrm{M}$ a responder na presença das configurações de matching e não responder na presença das configurações de não matching e ensinar os sujeitos do Grupo $\mathrm{N}$ a responder na presença das configurações de não matching e não responder na presença das configurações de matching. Respostas de bicar eram reforçadas em VI 60 na presença das configurações de matching para o Grupo $\mathrm{M}$ e na presença das configurações de não matching para o Grupo N. Não havia consequência programada para as respostas de bicar as configurações de não matching para o Grupo $\mathrm{M}$ e as configurações de matching para o Grupo N. Eram apresentadas quinze tentativas de cada configuração em uma sessão, totalizando 60 tentativas por sessão. Nesta fase, foram realizadas 24 sessões. As durações de apresentação dos estímulos e do IET eram idênticas em relação à fase anterior. A Fase 5 (teste) tinha o objetivo de verificar se haveria transferência do responder para estímulos novos (cores azul e amarela). Quatro novas configurações eram apresentadas: duas metades amarelas e duas metades azuis (configurações de matching) e metade esquerda amarela e metade direita azul ou metade esquerda azul e metade direita amarela (configurações de não matching). Os sujeitos dos grupos $\mathrm{M}$ e $\mathrm{N}$ foram divididos em dois subgrupos (Subgrupo MN, MM, NM e NN). Para os Subgrupos MM e NM, as respostas de bicar eram seguidas de reforço em VI 60 na presença das configurações de matching e de extinção na presença das configurações de não matching. Para os Subgrupos $\mathrm{NN}$ e MN, as respostas de bicar eram seguidas de reforço em VI 60 na presença das 
configurações de não matching e de extinção na presença das configurações de matching. Portanto, para os Subgrupos MM e NN, na Fase 5, era mantida a tarefa de responder na presença das configurações de matching (ensinadas na Fase 4) e para os Subgrupos MN e NM foi trocada a tarefa na Fase 5 em relação à Fase 4. Na Fase 5 foram realizadas 12 sessões. As demais características dessa fase foram idênticas às da Fase 4. Os resultados foram descritos em termos de razões discriminativas, obtidas pela divisão do total de respostas aos estímulos não correlacionados com o reforço pelo total de respostas aos estímulos correlacionados com o reforço. Dessa maneira, quanto menor o número de respostas nos "incorretos" e quanto maior o número de respostas nos "corretos", menor o valor da razão. O cálculo de cada razão foi apresentado por meio da média de respostas emitidas pelos sujeitos de cada subgrupo. $\mathrm{Na}$ primeira sessão da Fase 4 (primeira sessão do treino discriminativo), a razão do Grupo $M$ foi de 1,2 e a razão do Grupo $\mathrm{N}$ foi de 0,61 . Os valores das razões decresceram até a última sessão, na qual as razões foram menores do que 0,2 para os dois grupos. Isso indica que os sujeitos do Grupo M responderam mais na presença das configurações de matching do que diante das configurações de não matching e os sujeitos do Grupo $\mathrm{N}$ responderam mais na presença das configurações de não matching do que diante das configurações de matching. $\mathrm{Na}$ primeira sessão da Fase 5 (teste), as razões discriminativas dos Subgrupos MM e MN foram, aproximadamente, 1, a razão do Subgrupo NN foi 0,4 e a do Subgrupo NM foi 1,76. Os valores das razões decresceram até a última sessão, na qual as razões foram menores do que 0,2 para os quatro subgrupos. Segundo Zentall e Hogan (1975), esses resultados apontam que os sujeitos que foram mantidos na Fase 5 no mesmo tipo de tarefa em relação à Fase 4 (Subgrupos MM e NN) aprenderam mais rapidamente a segunda tarefa. Isso indicaria que foi estabelecido o conceito de "matching" e de "não matching". Contudo, essa conclusão não parece considerar que os Subgrupos MM e MN tiveram o mesmo valor de razão.

Zentall e Hogan (1975) planejaram um segundo experimento com o objetivo de verificar a emergência das relações de identidade e singularidade com estímulos com propriedades ortogonais às propriedades dos estímulos do treino. Doze pombos ingênuos passaram pelas mesmas fases do Experimento 1. A única alteração foi com relação a Fase 5 que envolveu configurações formadas por duas metades com brilho, duas metades sem brilho, metade esquerda com brilho e metade direita sem brilho e metade esquerda sem brilho e metade direita com brilho.. Na primeira sessão da Fase 4 (treino discriminativo), a razão do Grupo M foi 1,11 e a razão do Grupo $\mathrm{N}$ foi 0,75 . Os valores das razões decresceram até a última sessão, na qual as razões foram menores do que 0,2 para os dois grupos. Isso indica que os sujeitos do Grupo M passaram a responder mais na presença das configurações de matching e os sujeitos 
do Grupo $\mathrm{N}$ responderam mais na presença das configurações de não matching. Esses resultados replicaram os resultados do Experimento 1. Na primeira sessão da Fase 5, as razões discriminativas dos Grupos MM, MN e NN foram aproximadamente de 1 e a razão do Grupo NM foi 1,23. Os valores das razões decresceram até a última sessão, na qual as razões foram 0,4 para o Subgrupo MN, 0,3 para os Subgrupos NM e NN e 0,25 para o Subgrupo MM. Para Zentall e Hogan (1975), os sujeitos demonstraram um responder consistente com o que foi ensinado, mesmo quando foram apresentados estímulos com propriedades ortogonais aos estímulos do treino. Entretanto, na primeira sessão da Fase 5 (teste), para os quatro subgrupos o valor de razão foi aproximadamente o mesmo, indicando que não havia diferenças entre os subgrupos que mudaram e os que não mudaram de tarefa.

Segundo Carter e Werner (1978), os desempenhos dos sujeitos do estudo de Zentall e Hogan (1975) poderiam envolver discriminações simples e não relações condicionais emergentes que atestariam controle por relações de identidade e singularidade. $O$ controle discriminativo simples sobre o responder seria exercido pelo campo homogêneo, formado pelas configurações com metades iguais e o controle discriminativo simples sobre o não responder seria exercido pelo campo heterogêneo, formado pelas configurações com metades diferentes. Portanto, estudos que investigassem se o procedimento go/no-go utilizado por Zentall e Hogan (1975) gera controle condicional permitiriam que o procedimento mencionado fosse empregado como uma alternativa ao procedimento matching-to-sample. Uma possibilidade de impedir o estabelecimento de controle discriminativo simples pelo campo homogêneo ou pelo campo heterogêneo consiste em ensinar relações arbitrárias entre estímulos.

Um estudo que ensinou relações arbitrárias e testou a emergência de relações condicionais por meio do procedimento go/no-go com estímulos compostos em humanos foi o de Debert, Matos e McIlvane (2007). Nesse estudo, seis estudantes universitários foram submetidos a um treino, teste de simetria e testes de transitividade e de equivalência. Os participantes foram ensinados a responder diante de determinados estímulos compostos e não responder na presença de outros compostos por meio do procedimento go/no-go com estímulos compostos. Em cada tentativa, um estímulo composto, formado por um par de formas, era apresentado por quatro segundos. Nove formas, empregadas por Markham e Dougher (1993) foram utilizadas para compor os pares. Os estímulos compostos "corretos" eram: A1B1, A2B2, A3B3, B1C1, B2C2 e B3C3. Os estímulos compostos "incorretos" eram: A1B2, A1B3, A2B1, A2B3, A3B2, A3B1, B1C2, B1C3, B2C1, B2C3, B3C1 e B3C2. Os compostos eram apresentados sucessivamente a cada tentativa. Para que os estímulos 
"corretos" e os estímulos "incorretos" fossem apresentados o mesmo número de vezes, cada composto "correto" era apresentado uma vez e cada composto "incorreto" era apresentado duas vezes em cada bloco. A ordem de apresentação dos estímulos compostos era randômica, mas cada tipo de composto, "correto" ou "incorreto", era apresentado no máximo três vezes consecutivas em um bloco. Cada sessão era formada por 12 blocos de 24 tentativas cada, totalizando 288 tentativas. Cada resposta diante dos compostos "corretos" era seguida do acréscimo de dez pontos em um contador, um som e do total de pontos piscando por 1,5 segundo durante as 36 primeiras tentativas. Nas tentativas seguintes, respostas ao composto "correto" eram reforçadas em esquema conjuntivo FR1 e VT 2,5 segundos. Esse esquema era empregado com o objetivo de evitar que a consequência da resposta se estabelecesse como um estímulo discriminativo para o responder e que a não apresentação da consequência se estabelecesse como um estímulo discriminativo para o não responder. Respostas diante dos compostos "incorretos", bem como ausência de respostas diante dos compostos "corretos" não eram seguidas de consequência programada. As tentativas eram separadas por um IET de 2 segundos. A porcentagem de acertos em cada sessão foi calculada dividindo-se o número de respostas aos compostos "corretos" diante dos quais ocorreu pelo menos uma resposta e do número de compostos "incorretos" diante dos quais não ocorreram respostas pelo número de tentativas e multiplicando-se por 100. O critério de avanço para o teste de simetria consistia em os participantes responderem na presença de todos os compostos "corretos" e não responderem na presença de qualquer composto "incorreto" em uma sessão. O teste de simetria pretendeu verificar se os participantes responderiam sem um treino direto apenas na presença dos compostos "corretos" quando o elemento que era apresentado à esquerda no treino era apresentado no teste de simetria à direita e o elemento que era apresentado à direita durante o treino era apresentado no teste de simetria à esquerda. No teste de simetria, o mesmo balanceamento de tipo de tentativas no bloco empregado no treino foi empregado no teste de simetria. Cada sessão tinha seis blocos de 24 tentativas cada, totalizando 144 tentativas. Nenhuma resposta foi seguida de consequência programada. As demais características do teste de simetria foram idênticas às do treino. Em seguida, foram realizados testes de transitividade e equivalência. Esses testes pretenderam verificar se, sem treino direto, os participantes responderiam apenas na presença dos compostos formados por elementos que nunca foram apresentados juntos, mas que foram relacionados a um elemento em comum durante o treino. Nesse teste, eram apresentados os compostos: A1C1, A2C2, A3C3, A1C2, $\mathrm{A} 1 \mathrm{C} 3, \mathrm{~A} 2 \mathrm{C} 1, \mathrm{~A} 2 \mathrm{C} 3, \mathrm{~A} 3 \mathrm{C} 1, \mathrm{~A} 3 \mathrm{C} 2$ (teste de transitividade) e $\mathrm{C} 1 \mathrm{~A} 1, \mathrm{C} 2 \mathrm{~A} 2, \mathrm{C} 3 \mathrm{~A} 3, \mathrm{C} 1 \mathrm{~A} 2$, C1A3, C2A1, C2A3, C3A1, C3A2 (teste de equivalência). As demais características do teste 
de transitividade e equivalência eram idênticas às do teste de simetria. Os resultados revelaram que a relação de simetria emergiu para todos os participantes. Cinco participantes demonstraram a emergência de transitividade e equivalência e apenas um não apresentou emergência dessas duas relações. Portanto, os resultados de cinco dos seis participantes demonstraram que os elementos dos compostos puderam ser separados e recombinados em novos compostos que continuaram a controlar o responder de uma forma consistente com o treino, indicando o estabelecimento de discriminação condicional. Segundo Debert et al. (2007), o procedimento go/no-go com estímulos compostos pode ser uma alternativa ao matching-to-sample para estabelecer relações condicionais emergentes.

Segundo Debert et al. (2007), o mesmo procedimento poderia ser empregado em estudos com populações com as quais têm sido encontradas dificuldades na produção de relações emergentes, sendo uma dessas populações os sujeitos não-humanos.

O procedimento go/no-go com estímulos compostos teria possíveis vantagens em relação ao procedimento matching-to-sample quando se visa o estabelecimento de relações condicionais arbitrárias emergentes com não-humanos. O procedimento go/no-go com estímulos compostos apresenta uma única localização para o responder, evitando que se estabeleça controle inadvertido pela localização do responder (Iversen, 1997; Iversen et al., 1986; Kamil \& Sacks, 1972; Sidman, 1992; Sidman et al., 1982). Ainda, não permite que se estabeleça um controle inadvertido pela ordem temporal de apresentação dos estímulos (Frank \& Wasserman, 2005), já que os estímulos são apresentados no mesmo momento. Em adição, se comparado ao estudo de Frank e Wasserman (2005), não seriam necessários treinos da relação de identidade para que a ordem temporal dos estímulos não se torne uma propriedade controladora do responder, o que tornaria o treino mais rápido.

O presente estudo decorreu dessas considerações e pretendeu avaliar se o procedimento go/no-go com estímulos compostos, analisado por Debert et al. (2007), produziria relações emergentes de simetria, transitividade e equivalência em pombos. 


\section{MÉTODO}

\section{Sujeitos}

Participaram do estudo, três pombos (Columba livia) sem história experimental, mantidos a $85 \%$ do peso ad lib com acesso livre à água. $\mathrm{O}$ alimento fornecido no biotério e durante as sessões foi constituído de grãos de girassol, milho, ervilha, lentilha e arroz.

Os sujeitos foram alojados em gaiolas individuais de metal de $44 \mathrm{~cm}$ de largura por 46 $\mathrm{cm}$ de comprimento por $50,5 \mathrm{~cm}$ de altura, alocadas no biotério de pombos do Instituto de Psicologia da Universidade de São Paulo (USP). A iluminação da sala seguiu um ciclo de doze horas de claridade e escuridão.

Esta pesquisa foi aprovada pelo Comitê de Ética em Pesquisa com Animal do Instituto de Psicologia da USP, sob o número 007.2008.

\section{Equipamentos}

As sessões foram conduzidas em uma sala no Instituto de Psicologia da USP que media $2,5 \mathrm{~m}$ por $2,4 \mathrm{~m}$ e foram observadas em uma sala ao lado que media $2,5 \mathrm{~m}$ por 4,8 $\mathrm{m}$.

Foi utilizada uma tela sensível ao toque e a bicadas de 15 polegadas, com tecnologia APR (Acoustic Pulse Recognition), modelo 1515L da marca Elo TouchSystems, na qual foram apresentados os estímulos, permitindo que os sujeitos pudessem emitir as respostas de bicar.

Um computador controlou a apresentação dos estímulos e o registro das respostas de bicar. O monitor desse computador e a tela sensível a bicadas foram conectados ao computador por meio de um cabo Y. Esse cabo realiza a duplicação da imagem gerada por um monitor em outro monitor, o que permitiu a observação dos estímulos apresentados aos sujeitos e a emissão ou não de respostas de bicar a tela.

Uma caixa de condicionamento operante para pombos Med Associates modelo Env-007, medindo $25,5 \mathrm{~cm}$ de largura por $32 \mathrm{~cm}$ de comprimento por $33 \mathrm{~cm}$ de altura foi utilizada, como apresentada na Figura 1. A caixa foi colocada dentro de outra caixa de madeira que media $63 \mathrm{~cm}$ de largura por $73,5 \mathrm{~cm}$ de comprimento por $73 \mathrm{~cm}$ de altura. A caixa experimental apresentou, em uma das paredes laterais, uma abertura de $7,5 \mathrm{~cm}$ por $8 \mathrm{~cm}$, na parte superior central, na qual foi exposta uma parte da tela sensível a bicadas. Abaixo da tela, na parte inferior central da parede, esteve localizado o comedouro, iluminado por uma lâmpada quando acionado. 


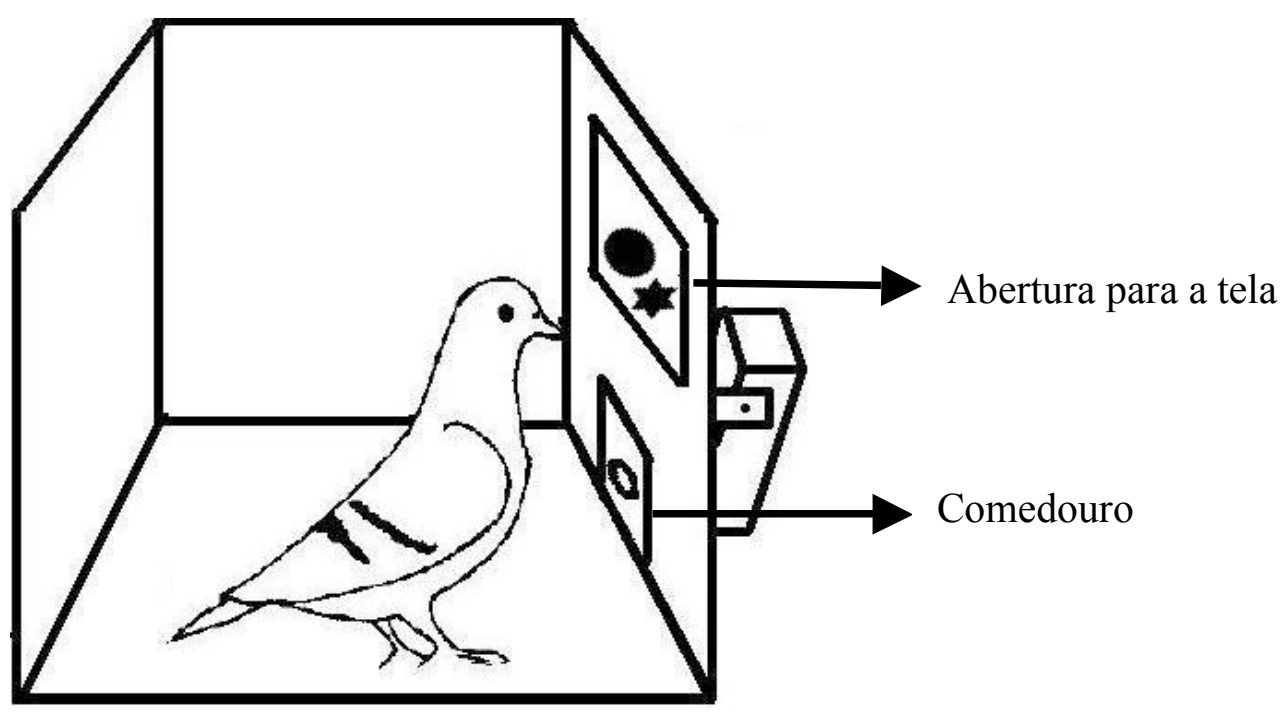

Figura 1. Ilustração da caixa durante as sessões experimentais.

Um programa desenvolvido por meio do software Visual Basic versão 6.0 para Windows controlou a apresentação dos estímulos compostos, o intervalo entre tentativas (IET), o sorteio dos valores do esquema de reforçamento intervalo variável (VI), o acionamento do comedouro e forneceu uma planilha no programa Excel referente a cada sessão que conteve:

a) a sequência dos estímulos compostos apresentada durante a sessão;

b) o número de respostas diante de cada composto na sequência de apresentação;

c) a latência da resposta de bicar em cada estímulo composto;

d) o lado (direito ou esquerdo) do composto no qual cada resposta de bicar, para cada composto, foi emitida;

e) o número de respostas de bicar durante os intervalos entre tentativas;

f) o valor sorteado do esquema de reforçamento VI para cada composto diante dos quais as respostas foram seguidas de reforço;

g) o tempo no qual foi emitida cada resposta;

h) o total de respostas de bicar diante de cada composto;

i) um índice de acertos diante dos compostos "corretos", calculado pela soma das tentativas de compostos "corretos" diante dos quais pelo menos uma resposta de bicar foi emitida dividido pelo total de compostos "corretos" apresentados;

j) um índice de acertos diante dos compostos "incorretos", calculado pela soma das tentativas de compostos "incorretos" diante dos quais as respostas não foram emitidas sobre o total de compostos "incorretos" apresentados;

k) as taxas de respostas por segundo para cada composto; 
1) um gráfico de frequência acumulada do número de respostas pela ordem de apresentação dos compostos;

m) um gráfico da latência das respostas de bicar pela ordem de apresentação dos compostos;

n) um gráfico de frequência acumulada do número de respostas durante o IET pela ordem de apresentação dos IETs;

o) um gráfico das taxas de respostas por segundo para cada composto;

p) o valor da razão discriminativa para cada composto.

Uma placa de controle KPORT - Central de automação foi acionada pelo programa criado por meio do software Visual Basic e controlou o acionamento do comedouro.

Foram utilizados como elementos dos compostos quatro das nove formas desenvolvidas por Markham e Dougher (1993) e utilizadas por Debert et al. (2007) (A1, A2 e C1 e C2). Outras duas formas (B1 e B2) foram desenvolvidas pela autora do presente estudo com o critério de que as formas apresentassem simetria bilateral. O objetivo foi apresentar formas não complexas.

Os elementos dos estímulos, apresentados na Figura 2, foram referidos como A1, B1, C1 (Conjunto 1) e A2, B2, C2 (Conjunto 2).

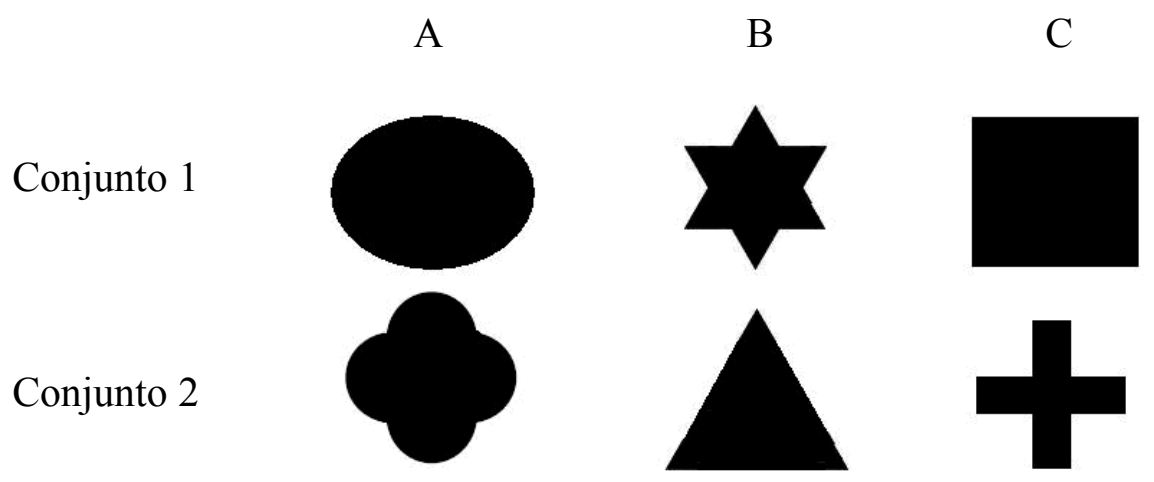

Figura 2. Formas apresentadas de acordo com suas identificações. As formas A1, A2 e C1 e C2 foram desenvolvidas por Markham e Dougher (1993) e utilizadas por Debert et al. (2007). As formas B1 e B2 foram desenvolvidas pela autora do presente estudo.

Cada forma teve $3 \mathrm{~cm}$ de altura por $4 \mathrm{~cm}$ de largura e foi elaborada no programa Paint. Essas formas foram apresentadas na cor preta com fundo branco na tela através da abertura da caixa que deu acesso à tela. 


\section{Procedimento}

O procedimento foi conduzido em quatro fases: Fase I - Pré-treino; Fase II - Treino; Fase III - Teste de simetria; e Fase IV - Teste de transitividade e equivalência.

Os dados foram coletados sete dias por semana, no mesmo horário do dia, no período da manhã. $\mathrm{O}$ número de sessões às quais cada sujeito foi submetido em um dia dependeu do desempenho do sujeito em cada sessão e da quantidade de alimento ingerida nas sessões. A quantidade de alimento ingerida durante as sessões realizadas em um dia de coleta foi suficiente para manter o peso dos sujeitos em $85 \%$ do peso ad lib.

\section{Fase I - Pré-treino}

O objetivo dessa fase foi modelar e fortalecer a resposta de bicar.

Durante o treino ao comedouro, a tela esteve preta, a alavanca do comedouro levantada e a luz do mesmo acesa, o que permitiu ao sujeito ter acesso ao alimento. O equipamento foi mantido desse modo até que o sujeito se alimentasse. Transcorridos 15 segundos após o sujeito se dirigir ao comedouro e se alimentar, a alavanca do comedouro foi retraída, impedindo que o sujeito tivesse acesso ao alimento. Em seguida, o período no qual a alavanca ficou levantada diminuiu dois segundos por acionamento do comedouro até atingir três segundos, tempo que foi utilizado nas fases seguintes. Os acionamentos do comedouro foram separados por um intervalo de 4 segundos.

Durante as sessões seguintes foram modeladas as respostas de bicar por meio do procedimento de aproximações sucessivas. Nessa fase, a tela esteve branca. Essa etapa foi encerrada quando o pombo emitiu uma resposta de bicar. Em seguida teve início a fase de fortalecimento da resposta.

Durante a fase de fortalecimento, foram apresentados apenas os compostos "corretos" A1B1, A2B2, B1C1 e B2C2. Cada composto foi apresentado sucessivamente por 30 segundos. Respostas de bicar foram consequenciadas com três segundos de acesso ao comedouro em esquema CRF. O IET foi de 10 segundos, durante o qual a tela ficou preta. Durante o IET cada resposta de bicar foi consequenciada com a recontagem do tempo, de modo que ele somente foi encerrado após 10 segundos sem a emissão de respostas. $\mathrm{O}$ critério de encerramento dessa fase ocorreu quando os sujeitos responderam com frequência relativamente constante em uma sessão. 
Depois de fortalecidas em CRF, as respostas de bicar foram seguidas de reforço em esquema de intervalo variável (VI) na presença dos mesmos compostos. Os valores do VI foram aumentados progressivamente, iniciando em 5 segundos e aumentando de 5 em 5 , até atingir 60 segundos. $\mathrm{O}$ aumento do valor do VI ocorreu quando os sujeitos responderam com frequência relativamente constante em uma sessão.

Essa fase se encerrou quando os sujeitos responderam com frequência relativamente constante em uma sessão com o esquema VI 60 segundos em vigor.

\section{Fase II - Treino}

Essa fase teve o objetivo de reforçar a resposta de bicar a tela na presença de determinados compostos e não reforçar a resposta de bicar a tela na presença de outros compostos por meio do procedimento go/no-go com estímulos compostos.

Os estímulos compostos envolveram pares dos estímulos apresentados na Figura 2. A Tabela 1 apresenta os oito estímulos compostos apresentados no treino e que foram utilizados por Perez, Campos e Debert (2009): A1B1, A2B2, B1C1 e B2C2 (compostos designados como "corretos") e A1B2, A2B1, B1C2 e B2C1 (compostos designados como "incorretos").

Cada estímulo composto foi apresentado na tela com fundo branco por 30 segundos, independentemente das respostas emitidas pelo sujeito. Essa duração dos compostos foi a mesma utilizada por Zentall e Hogan (1975) $)^{5}$. Transcorridos os 30 segundos, a tela era escurecida e iniciava-se o IET. Este teve duração mínima de 10 segundos, no qual nenhum estímulo foi apresentado. Respostas de bicar a tela durante o IET tiveram como consequência o reinício da contagem de tempo de 10 segundos, de modo que o IET foi encerrado quando não foram emitidas respostas de bicar por 10 segundos. Esse critério de encerramento teve o objetivo de enfraquecer eventuais respostas de bicar durante o IET que poderiam ser mantidas inadvertidamente pela apresentação de um composto "correto". Respostas de bicar na presença dos compostos "corretos" foram consequenciadas com a apresentação do alimento por três segundos em um esquema VI 60 segundos. Os valores do VI que foram sorteados randomicamente e consistiram em 1, 2, 3, 4, (...), 120. Quando o intervalo sorteado foi menor do que a duração da tentativa, o intervalo posterior foi sorteado logo após a apresentação do

\footnotetext{
${ }^{5}$ Esse parâmetro e outros que serão apontados ao longo da seção Método foram empregados por Zentall e Hogan (1975) e escolhidos para serem utilizados no presente estudo porque se pretende avaliar um procedimento similar ao empregado pelos autores que foi efetivo em estabelecer um responder discriminado.
} 
alimento. Assim, o alimento pôde ser apresentado mais de uma vez em uma mesma tentativa. Caso o valor sorteado excedesse os 30 segundos da apresentação do estímulo, não haveria reforço naquela tentativa. Sempre que uma nova tentativa foi iniciada, um novo valor de VI foi sorteado. Respostas de bicar diante dos compostos "incorretos" não foram seguidas de consequência programada. Nesse sentido, o procedimento envolveu uma discriminação sucessiva com um múltiplo VI60 e extinção.

Tabela 1. Estímulos compostos de treino e testes, constituídos por formas, apresentados de acordo com suas identificações.

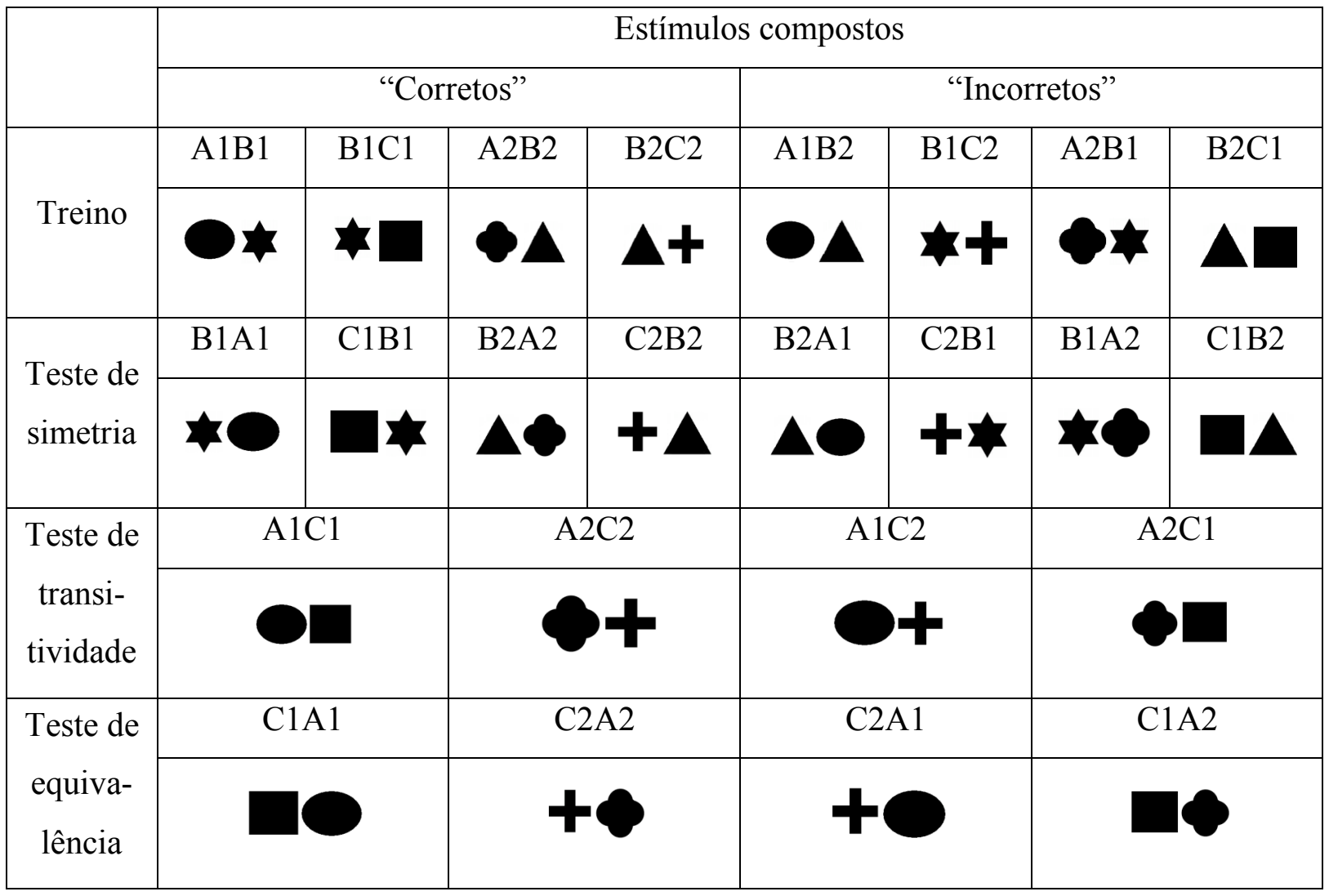

Os compostos foram distribuídos pseudo-randomicamente ao longo de 56 tentativas em cada sessão. Cada composto foi apresentado uma vez em cada bloco de oito tentativas e as tentativas com compostos "corretos" ou com "incorretos" foram apresentadas no máximo três vezes consecutivas.

Para passar para a próxima fase, os sujeitos deveriam apresentar uma razão discriminativa de até 0,2 (cf. Zentall e Hogan, 1975). A razão foi obtida a cada sessão dividindo-se o total de respostas nos compostos "incorretos" pelo total de respostas nos “corretos". Além disso, o sujeito não poderia emitir respostas em mais de uma apresentação 
de cada um dos quatro compostos "incorretos", bem como não poderia deixar de responder em mais de uma apresentação de cada um dos quatro compostos "corretos".

\section{Fase III - Teste de simetria}

O objetivo do teste de simetria foi verificar se, sem um treino direto, os sujeitos responderiam na presença dos compostos $\mathrm{B} 1 \mathrm{~A} 1, \mathrm{~B} 2 \mathrm{~A} 2, \mathrm{C} 1 \mathrm{~B} 1$ e $\mathrm{C} 2 \mathrm{~B} 2$ e não responderiam na presença de B2A1, B1A2, C2B1 e C1B2 (Debert et al., 2007). Os compostos do teste de simetria foram formados pela recombinação dos elementos dos compostos do treino. Ou seja, o estímulo que foi apresentado à direita no treino foi apresentado à esquerda no teste de simetria e o estímulo apresentado à esquerda no treino foi apresentado à direita durante o teste de simetria. Foram apresentados os compostos: B1A1, B2A2, C1B1 e C2B2 (“corretos") e B2A1, B1A2, C2B1 e C1B2 (“incorretos"), apresentados na parte central da Tabela 1.

As características do teste de simetria foram idênticas às da fase de treino, com exceção do que está descrito a seguir. A fase de teste de simetria ${ }^{6}$ iniciou-se com um bloco de oito tentativas, uma de cada composto do treino. A justificativa para o uso desse primeiro bloco foi prevenir que uma tentativa de teste, em extinção, iniciasse a fase de teste de simetria (Frank \& Wasserman, 2005), uma vez que repostas nas tentativas de treino com compostos “corretos" foram seguidas de alimento em VI 60 segundos. Esse primeiro bloco foi seguido de cinco blocos consecutivos de 24 tentativas cada: 16 tentativas de treino (duas vezes cada composto empregado no treino), acrescidas de oito tentativas de simetria (uma de cada composto de teste). Da mesma maneira que no estudo de Frank e Wasserman (2005), no teste de simetria, as tentativas de treino foram apresentadas intercaladamente de forma pseudorandômica com tentativas de teste de simetria, de modo que as sessões de teste não fossem conduzidas completamente em extinção. Por fim, um último bloco de 16 tentativas foi apresentado com cada um dos oito compostos de treino e cada um dos oito compostos de teste. Essas tentativas também foram apresentadas randomicamente de modo que cada composto fosse apresentado uma vez em cada bloco e que as tentativas com compostos "corretos" ou "incorretos" fossem apresentadas no máximo três vezes consecutivas. Cada sessão de teste de simetria totalizou 144 tentativas.

\footnotetext{
${ }^{6}$ A distribuição de tentativas de treino e teste durante o teste de simetria e outros parâmetros basearam-se no Experimento 1 de Frank e Wasserman (2005). Esses parâmetros foram escolhidos porque se pretendeu avaliar um procedimento (go/no-go) similar ao de Frank e Wasserman (2005).
} 
$\mathrm{O}$ reforço nas tentativas de treino foi disponibilizado da mesma maneira que durante a fase anterior. Respostas na presença dos compostos de teste de simetria não foram seguidas de consequência programada.

O teste de simetria foi aplicado uma vez.

\section{Fase IV - Teste de transitividade e de equivalência}

O objetivo do teste de transitividade e de equivalência foi verificar se os sujeitos, sem um treino direto, responderiam na presença dos compostos $\mathrm{A} 1 \mathrm{C} 1, \mathrm{~A} 2 \mathrm{C} 2, \mathrm{C} 1 \mathrm{~A} 1$ e $\mathrm{C} 2 \mathrm{~A} 2$ e não responderiam na presença de $\mathrm{A} 1 \mathrm{C} 2$, A2C1, C1A2 e C2A1 (Debert et al., 2007). Os compostos do teste de transitividade e de equivalência envolveram elementos que foram relacionados a um mesmo elemento no treino. Foram apresentados os compostos: A1C1, $\mathrm{A} 2 \mathrm{C} 2$, C1A1 e C2A2 ("corretos") e os compostos A1C2, A2C1, C1A2 e C2A1 (“incorretos"), que aparecem na parte inferior da Tabela 1.

As características do teste de transitividade e de equivalência foram idênticas às do teste de simetria, com exceção de que as tentativas de simetria foram substituídas pelas tentativas de transitividade e equivalência.

Foram conduzidas duas sessões de teste de transitividade e equivalência ${ }^{7}$, separadas por uma sessão de treino na qual o sujeito deveria atingir os critérios de acertos mencionados. Caso contrário, ele seria submetido ao treino até que atingisse os critérios em três sessões consecutivas.

\footnotetext{
${ }^{7}$ Estudos apontam que relações não ensinadas podem emergir quando os testes são conduzidos pela segunda vez (e.g., Sidman, 1994; da Hora, 2009; Debert et al., 2007; Perez et al., 2009).
} 


\section{RESULTADOS}

Nessa seção, serão descritos, separadamente, os resultados obtidos com os Sujeitos S9, $\mathrm{S} 10$ e S11 na sequência de fases às quais eles foram submetidos. Em virtude dos resultados obtidos, algumas alterações no procedimento apresentado no Método foram realizadas e serão descritas quando for apropriado.

\section{Sujeito S10}

Após modelagem e fortalecimento das respostas, conduzidos na Fase I, o Sujeito S10 foi submetido à Fase II.

Fase II - Treino

A Figura 3 apresenta as razões discriminativas, por sessão, obtidas por S10 durante o treino. Esta razão foi calculada pela soma do número de respostas aos quatro estímulos compostos "incorretos" dividida pela soma do número de respostas aos quatro compostos "corretos". Caso o número de respostas aos compostos "incorretos" e o número de respostas aos compostos "corretos" fosse idêntico, a razão discriminativa atingiria o valor 1. Esse resultado indicaria a ausência de um responder discriminado. Se o número de respostas aos compostos "incorretos" fosse maior do que o número de respostas aos compostos "corretos", a razão discriminativa alcançaria um valor superior a 1 . Se o número de respostas aos compostos "incorretos" for inferior ao número de respostas aos compostos "corretos", a razão discriminativa atingiria um valor inferior a 1. Pontos inexistentes na curva indicam que na respectiva sessão o sujeito não respondeu e, portanto, não foi possível calcular a razão discriminativa.

O Sujeito S10 foi submetido a 105 sessões de treino. Os valores das razões discriminativas variaram entre 0,66 (na Sessão 30) e 1,83 (Sessões 8 e 10). Até a Sessão 7, a razão discriminativa foi aproximadamente 1. Nas Sessões 8 e 10, a razão sofreu um aumento abrupto para 1,83. A partir da Sessão 13 até a Sessão 22 a razão discriminativa permaneceu acima de 1. Entre as Sessões 20 e 30, verifica-se uma queda na razão ficando em torno de 0,66 (Sessão 30). A partir da Sessão 31, há uma constante oscilação nos valores das razões que ficaram entre 0,71 (Sessão 63) e 1,39 (Sessão 31). Esses resultados indicam que mesmo 
após 105 sessões de treino, S10 não respondeu diferencialmente aos estímulos compostos "corretos" e "incorretos".

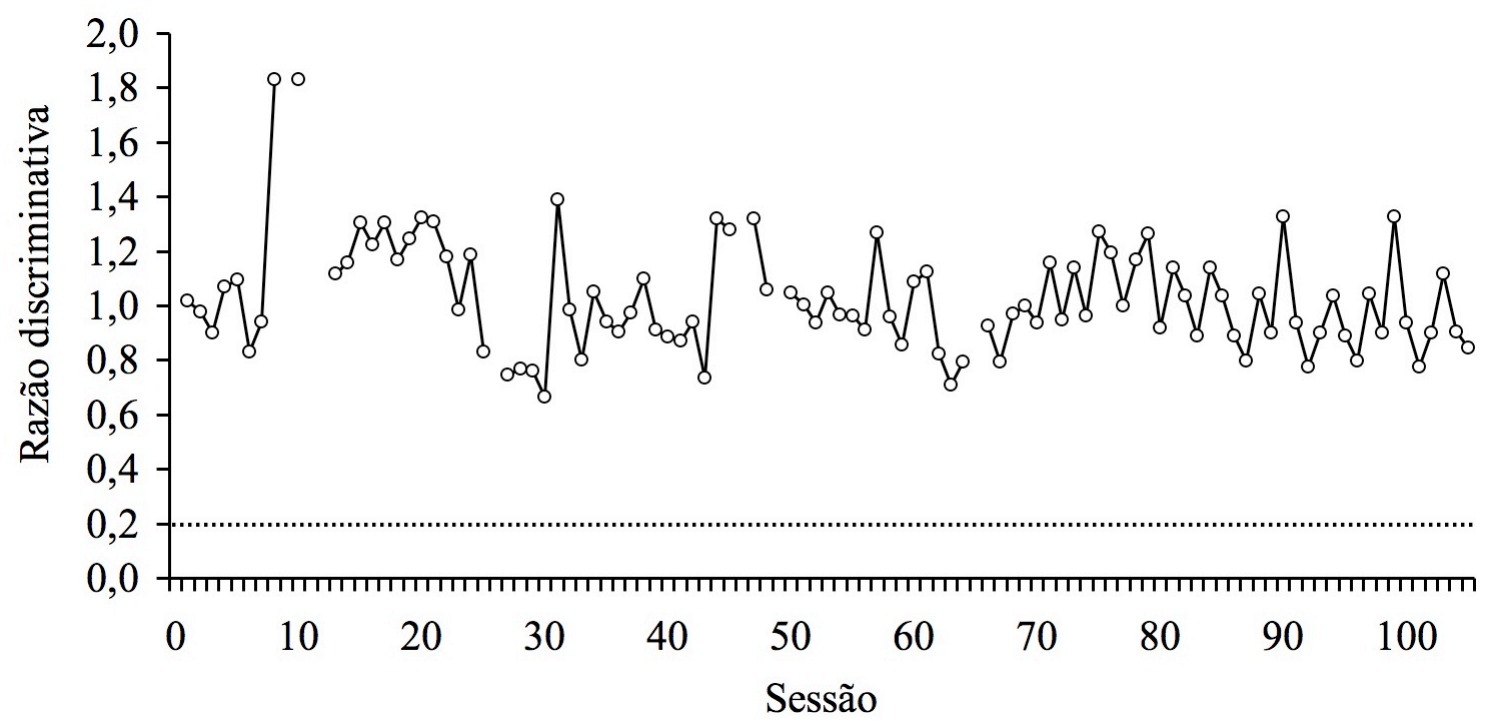

Figura 3. Razão discriminativa por sessão durante o treino para o Sujeito S10. A linha tracejada indica o valor 0,2 que foi utilizado como critério de aprendizagem. Pontos inexistentes na curva indicam que o sujeito não respondeu durante a sessão.

A partir da Sessão 105, passou a vigorar um procedimento denominado reset ou reinício da duração do tempo de apresentação do composto "incorreto". No procedimento de reset, cada resposta emitida diante dos compostos "incorretos" tinha como consequência o reinício da duração dos 30 segundos de apresentação daquele composto. Portanto, a tentativa somente se encerrava após 30 segundos sem a emissão da resposta de bicar. Esse procedimento teve o objetivo de diminuir o número de respostas emitidas na presença dos compostos "incorretos". Em adição, foi alterado o esquema de reforçamento para VI 60 segundos após ter sido verificado um erro na programação que havia gerado um esquema conjuntivo razão fixa (FR 1) e tempo variável (VT 60). Portanto, o reforço foi liberado em média 60 segundos após a ocorrência da primeira resposta. Os demais parâmetros foram mantidos em relação ao procedimento anterior.

A Figura 4 apresenta os valores da razão discriminativa, por sessão, durante o procedimento de treino das relações $\mathrm{AB}$ e $\mathrm{BC}$ e esquema de reforçamento VI 60 segundos e reset. 


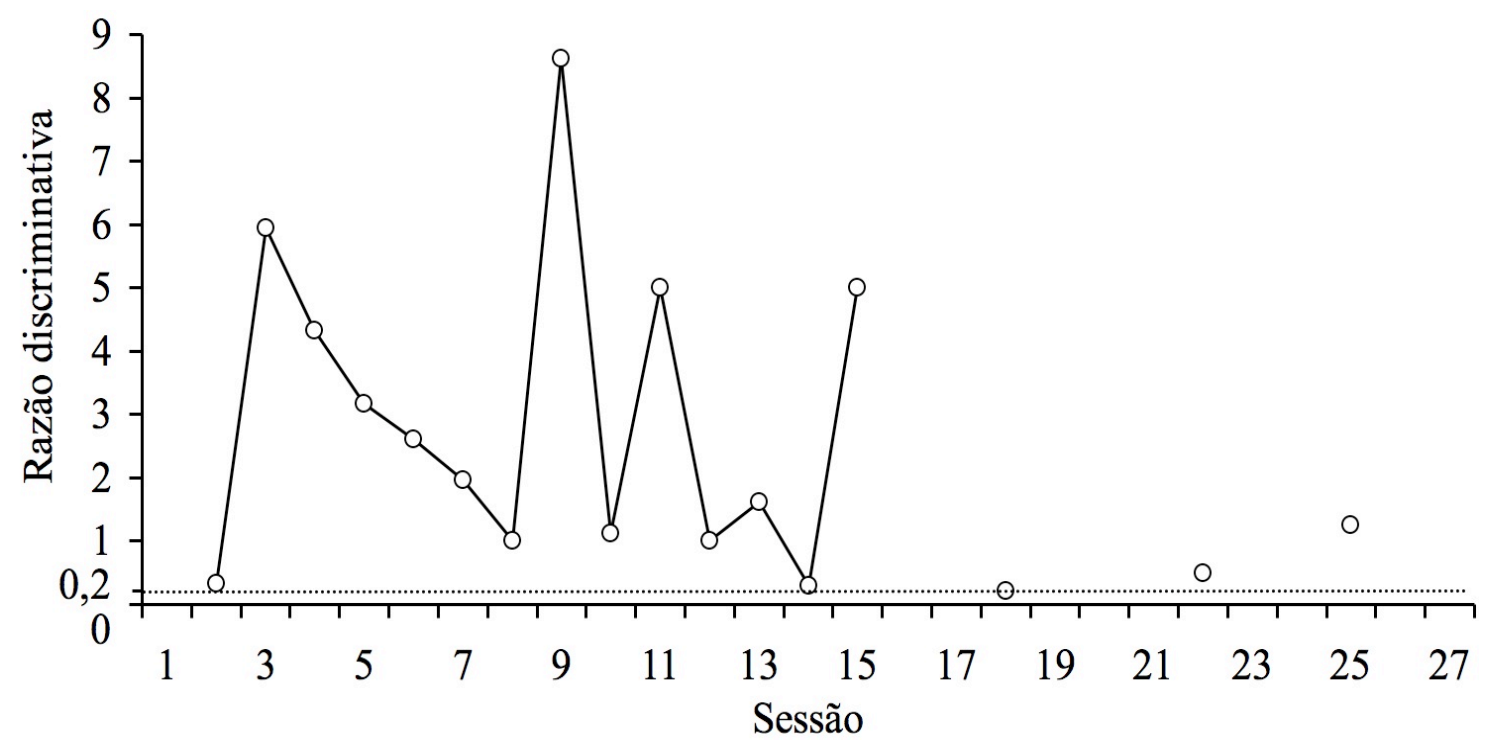

Figura 4. Razão discriminativa por sessão durante o treino $\mathrm{AB}$ e $\mathrm{BC}$ com esquema de reforçamento VI 60 segundos e reset para o Sujeito S10. A linha tracejada indica o valor 0,2 que foi utilizado como critério de aprendizagem. Pontos inexistentes na curva indicam que o sujeito não respondeu durante a sessão.

O Sujeito S10 foi submetido a 27 sessões nesse procedimento. Os valores das razões variaram entre 0,21 (Sessão 18) e 8,62 (Sessão 9). Na Sessão 1, S10 não emitiu respostas. Na Sessão 2, a razão atingiu o valor 0,33. Nessa sessão S10 emitiu quatro respostas, uma no composto "incorreto" A1B2, no composto "correto" A2B2 e uma no B1C1. Portanto, apesar do índice discriminativo ser baixo, ele não refletiu desempenhos discriminados. Na sessão 3, a razão atingiu o valor 5,94. A partir da Sessão 3, a razão foi diminuindo até atingir 1 na Sessão 8. Na Sessão 9, a razão sofreu um aumento abrupto para 8,62. A partir da Sessão 10 até a Sessão15, houve uma oscilação da razão entre os valores 0,3 (Sessão 14) e 5 (Sessões 11 e 15). Nas Sessões 16, 17, 19, 20, 21, 23, 24, 26 e 27, S10 não respondeu. Nas Sessões 18 e 22 os valores foram 0,22 e 0,5, respectivamente. Nessas sessões, S10 emitiu, respectivamente, apenas 11 respostas a $\mathrm{A} 1 \mathrm{~B} 1$, oito a $\mathrm{A} 2 \mathrm{~B} 2$ e quatro a $\mathrm{A} 2 \mathrm{~B} 1$ e uma resposta a $\mathrm{A} 1 \mathrm{~B} 1, \mathrm{~A} 2 \mathrm{~B} 2$ e A2B1. Portanto, apesar do índice discriminativo ser baixo, ele não refletiu desempenhos discriminados. Na Sessão 25, a razão aumentou para 1,25. Esses resultados indicam que o reset não foi efetivo para estabelecer um responder discriminado. Foi verificada a partir da introdução do reset uma grande diminuição do número de respostas a todos os compostos em algumas sessões ou um grande aumento do número de respostas aos compostos "incorretos" em outras sessões, uma vez que respostas a esses compostos tinham como consequência o aumento da duração de apresentação dos mesmos. 
Uma vez que S10 não apresentou responder discriminado nas sessões descritas, um novo procedimento foi conduzido com o objetivo de verificar se uma discriminação simples entre duas formas seria estabelecida. Foram apresentadas sucessivamente e randomicamente as formas A1 (estímulo designado como "correto") e a forma C2 (estímulo designado como “incorreto") - ver Figura 2. Cada estímulo foi apresentado 28 vezes, totalizando 56 tentativas na sessão. Nesse treino não foi aplicado o reset após respostas ao estímulo "incorreto", já que o reset não se mostrou efetivo no procedimento anterior. Os demais parâmetros foram mantidos em relação ao procedimento anterior.

A Figura 5 apresenta os valores da razão discriminativa, por sessão, com o procedimento de treino de discriminação simples com formas.

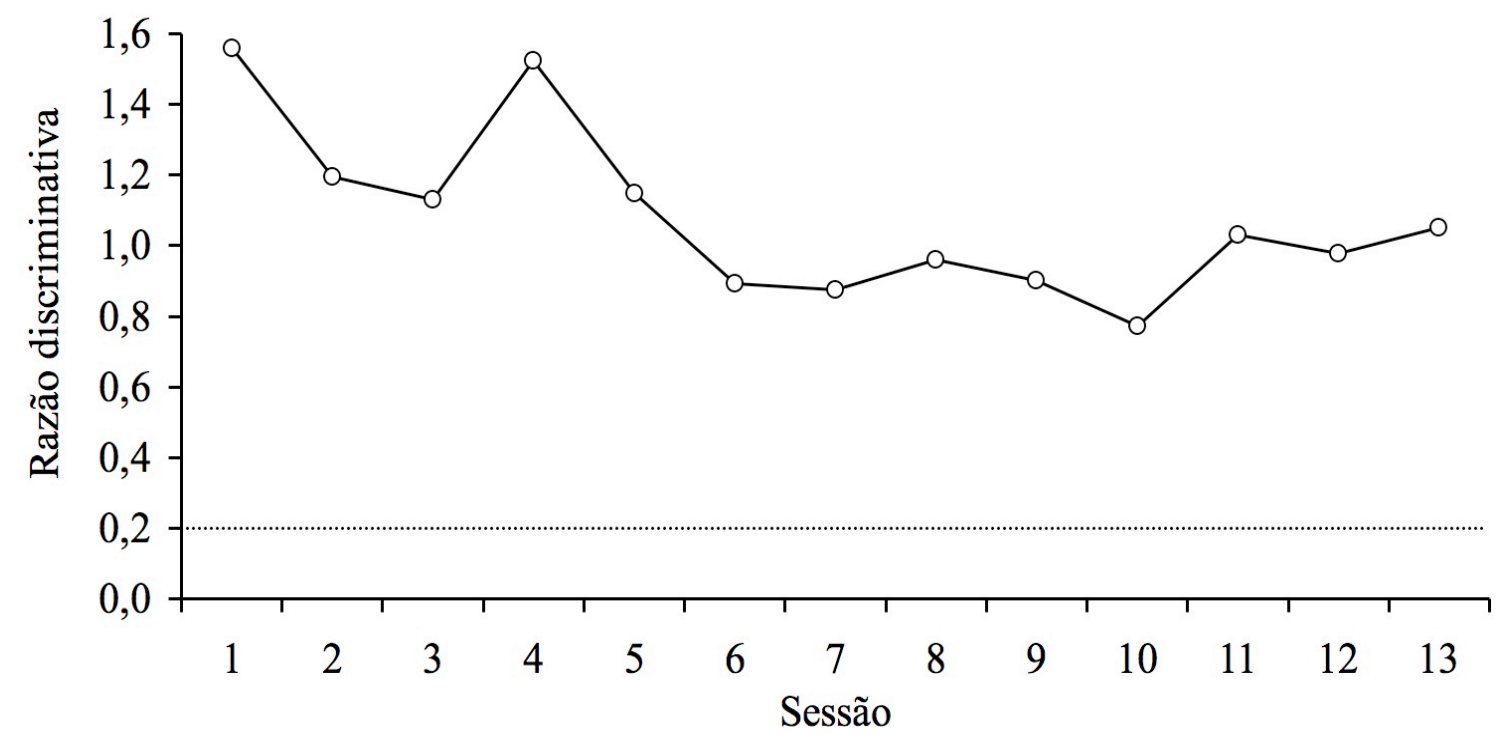

Figura 5. Razão discriminativa por sessão durante o treino de discriminação simples com formas para o Sujeito S10. A linha tracejada indica o valor 0,2 que foi utilizado como critério de aprendizagem.

O Sujeito S10 foi submetido a 13 sessões com esse procedimento. Os valores das razões variaram entre 0,77 (Sessão 10) e 1,55 (Sessão 1). A partir da Sessão 1, a razão decresceu até a Sessão 3, quando atingiu 1,13. Na Sessão 4, a razão aumentou para 1,52. A partir da Sessão 4 até a Sessão 6, a razão decresceu até atingir o valor 0,86. A partir da Sessão 7, a razão discriminativa se manteve em valores próximos a 1. Esses dados indicam que procedimento de treino de discriminação simples com formas não permitiu o estabelecimento de um responder discriminado. 
Como desempenhos discriminados não foram produzidos com o procedimento de discriminação simples, foi reintroduzido o procedimento reset com o objetivo de verificar se esse procedimento seria efetivo para diminuir o número de respostas emitidas na presença do estímulo "incorreto". Os demais parâmetros foram mantidos em relação ao procedimento anterior.

A Figura 6 apresenta os valores da razão discriminativa, por sessão, durante o procedimento treino de discriminação simples com formas e reset.

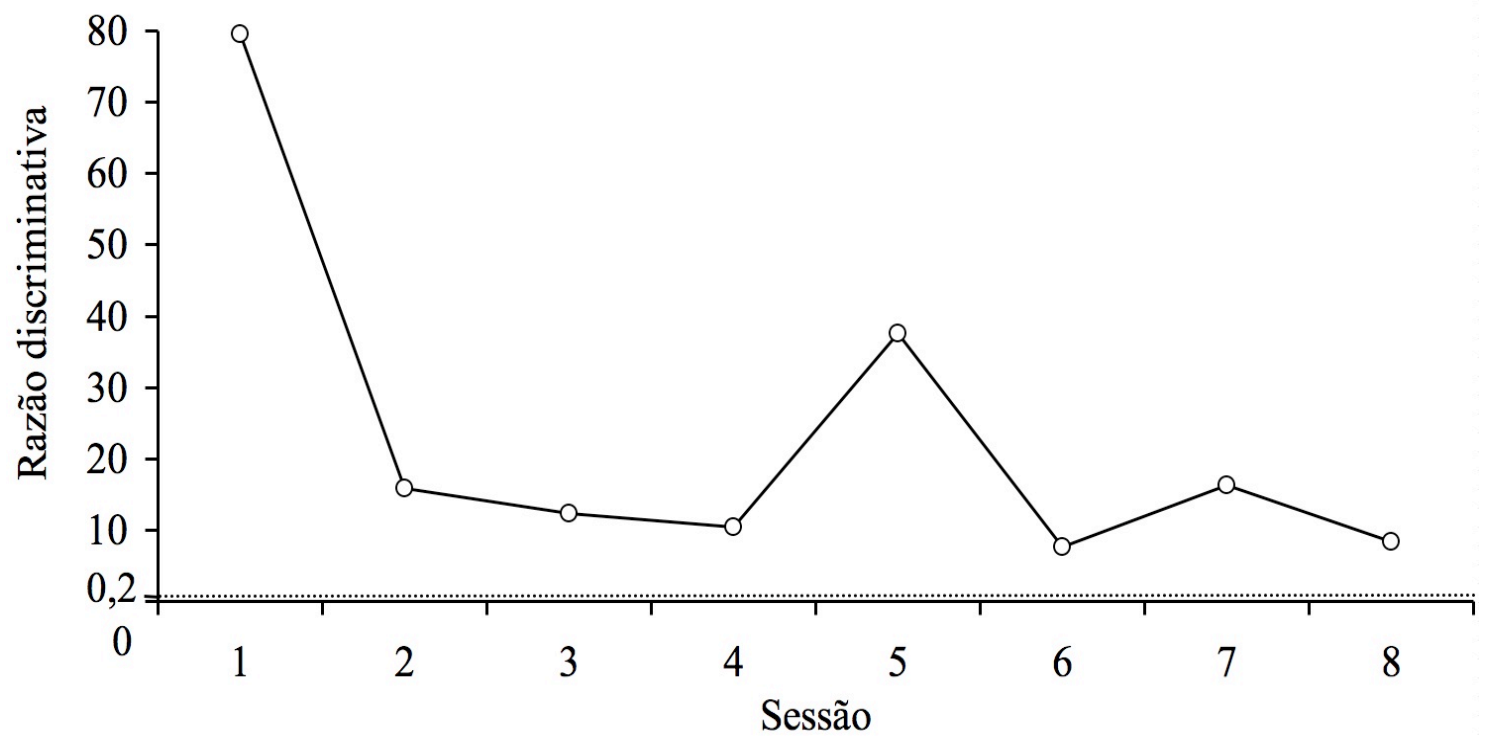

Figura 6. Razão discriminativa por sessão durante o treino de discriminação simples com formas e reset para o Sujeito S10. A linha tracejada indica o valor 0,2 que foi utilizado como critério de aprendizagem.

O Sujeito S10 foi submetido a oito sessões com esse procedimento. Os valores das razões variaram entre 79,63 (Sessão 1) e 7,64 (Sessão 6). Desde a Sessão 1, os valores da razão apresentam um decréscimo até atingir 8,3 na Sessão 8. A exceção ocorreu na Sessão 5, na qual a razão atingiu 37,57. Esses resultados indicam que a introdução do reset não permitiu o estabelecimento de um responder discriminado. Foi verificado a partir da introdução do reset um aumento do número de respostas aos dois estímulos, em relação ao procedimento anterior. Uma vez que S10 passou a responder nas sessões, esse procedimento foi mantido durante a fase seguinte.

Uma vez que S10 não apresentou responder discriminado com um procedimento de discriminação simples entre duas formas, levantou-se a possibilidade de que talvez os estímulos empregados não favorecessem a discriminação. Como o estudo de Carter e 
Eckerman (1975) demonstrou que pombos exibiram responder discriminado em um menor número de sessões quando eram apresentadas cores como estímulos, cores passaram a ser utilizadas como estímulos no presente estudo com o objetivo de verificar se desempenhos discriminados seriam estabelecidos com um procedimento de discriminação simples entre duas cores. Assim, as duas formas foram substituídas por duas cores (verde - estímulo designado como "correto" e vermelho - estímulos designado como "incorreto"). Cada cor foi apresentada em um círculo de $1 \mathrm{~cm}$ de diâmetro. Os demais parâmetros foram mantidos em relação ao procedimento anterior.

A Figura 7 apresenta os valores da razão discriminativa, por sessão, durante o procedimento de treino de discriminação simples com cores e reset.

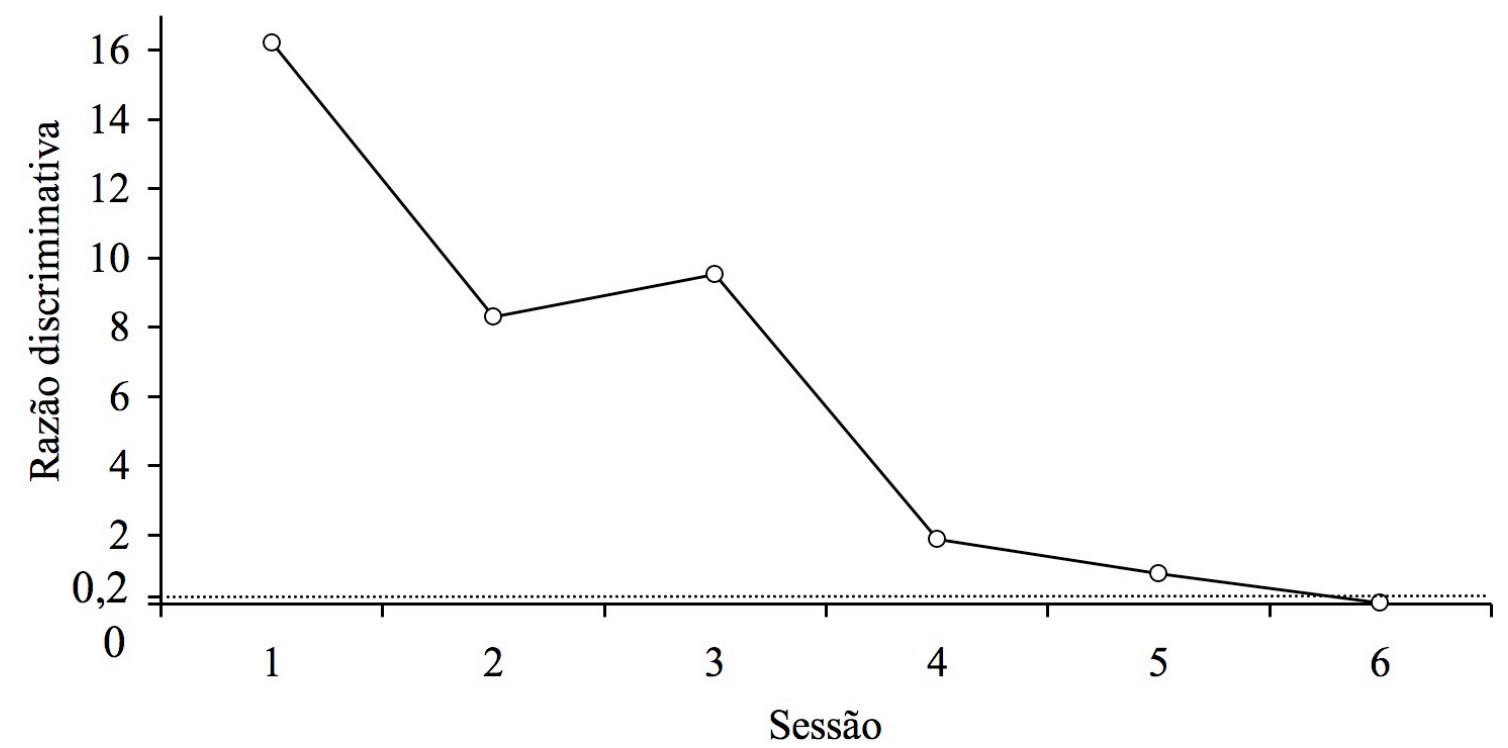

Figura 7. Razão discriminativa por sessão durante o procedimento de treino de discriminação simples com cores e reset para o Sujeito S10. A linha tracejada indica o valor 0,2 que foi utilizado como critério de aprendizagem.

O Sujeito S10 foi submetido a seis sessões com esse procedimento. Na Sessão 1, a razão foi 16,54. Ao longo das sessões, verifica-se uma queda nos valores da razão até atingir 0 na Sessão 6. Isso indica que a apresentação de cores como estímulos permitiu o estabelecimento de responder discriminado.

Em seguida, as formas utilizadas no treino foram substituídas por cores e os elementos dos estímulos compostos passaram a ser: vermelho (A1), azul (B1), verde (A2) e amarelo (B2). Cada uma dessas cores foi apresentada em uma das metades de um círculo dividido em duas metades iguais (ver Tabela 2). Os estímulos compostos foram: A1B1 e A2B2 (estímulos 
compostos "corretos") e A1B2 e A2B1 (compostos "incorretos") - ver Tabela 2. Cada estímulo foi apresentado 14 vezes, totalizando 56 apresentações na sessão. Dessa maneira, foram apresentados quatro compostos. O objetivo dessa alteração foi verificar se, por meio da apresentação de um menor número de compostos, S10 apresentaria um responder discriminado. Os demais parâmetros foram mantidos em relação ao treino AB com formas.

Tabela 2. Estímulos compostos de treino e testes, formados por cores, apresentados de acordo com suas identificações.

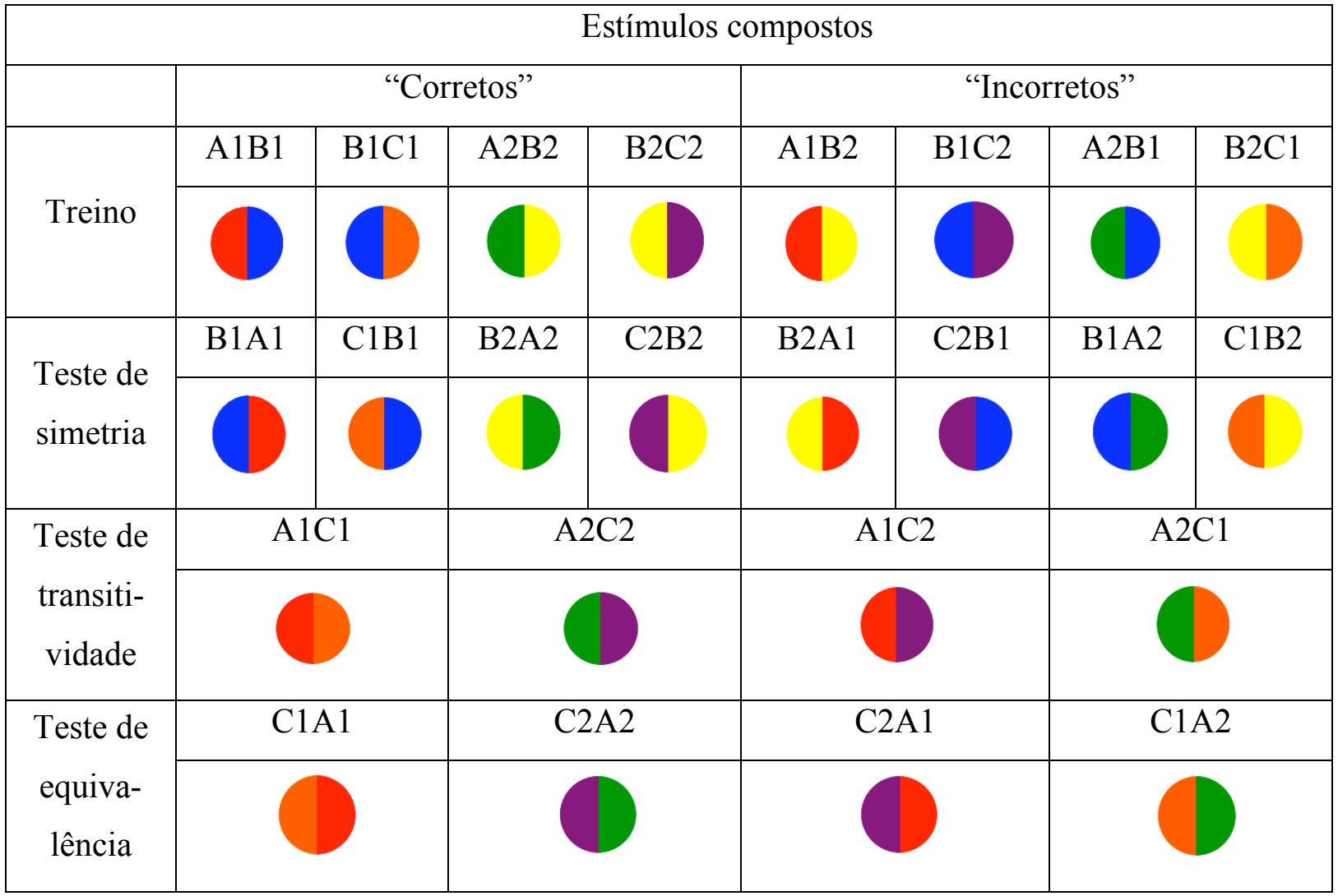

Na Figura 8 estão apresentados os valores da razão discriminativa, por sessão, durante o procedimento de treino $\mathrm{AB}$ com cores e reset.

O Sujeito S10 foi submetido a 19 sessões com esse procedimento. Na Sessão 1, a razão foi 16,92 . Ao longo das sessões, os valores da razão apresentam um decréscimo até atingir 0,02 (Sessões 17, 18 e 19). Esses resultados indicam que a apresentação dos compostos formados por cores permitiu o estabelecimento de um responder discriminado.

Após atingir o critério no procedimento de treino $\mathrm{AB}$ com cores, foi conduzido o treino BC com cores. Os elementos dos estímulos compostos consistiram nas cores: azul (B1), laranja (C1), amarelo (B2) e roxo (C2). Os estímulos compostos foram: B1C1 e B2C2 
(compostos "corretos") e B1C2 e B2C1 (compostos "incorretos") - ver Tabela 2. Os demais parâmetros foram mantidos em relação ao procedimento de treino $\mathrm{AB}$ com cores.

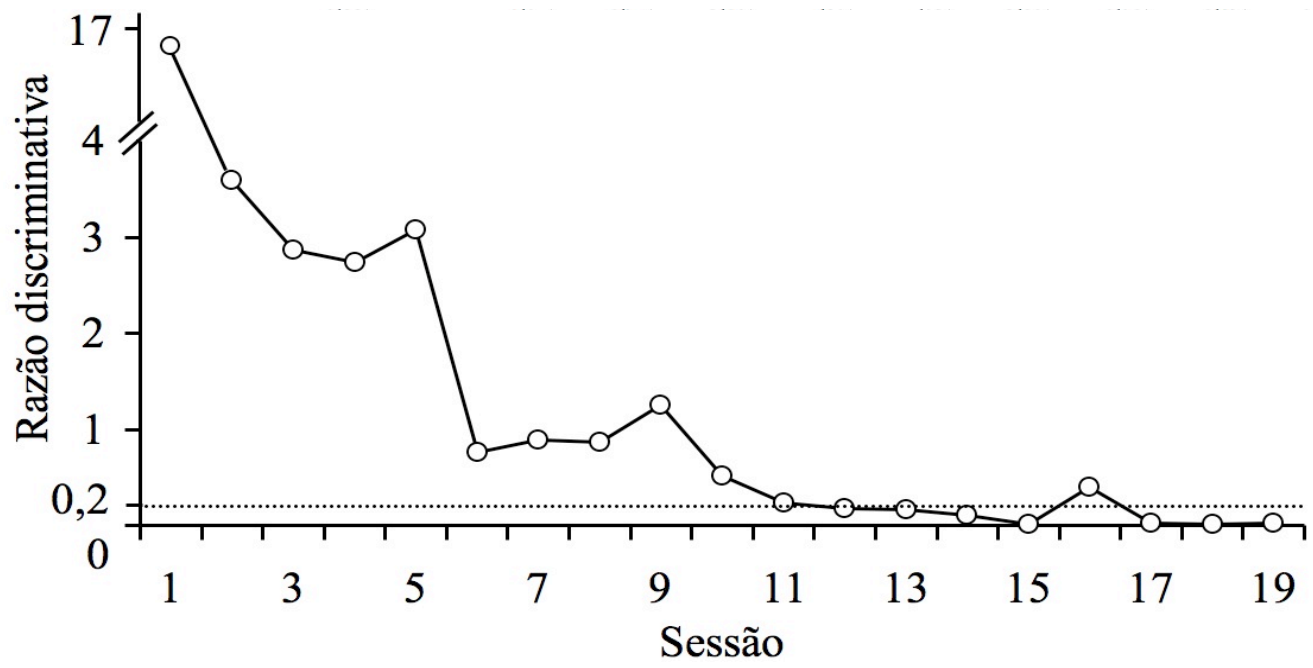

Figura 8. Razão discriminativa por sessão durante o procedimento de treino $\mathrm{AB}$ com cores e reset para o Sujeito S10. A linha tracejada indica o valor 0,2 que foi utilizado como critério de aprendizagem.

A Figura 9 apresenta os valores da razão discriminativa, por sessão, durante o procedimento de treino $\mathrm{BC}$ com cores e reset.

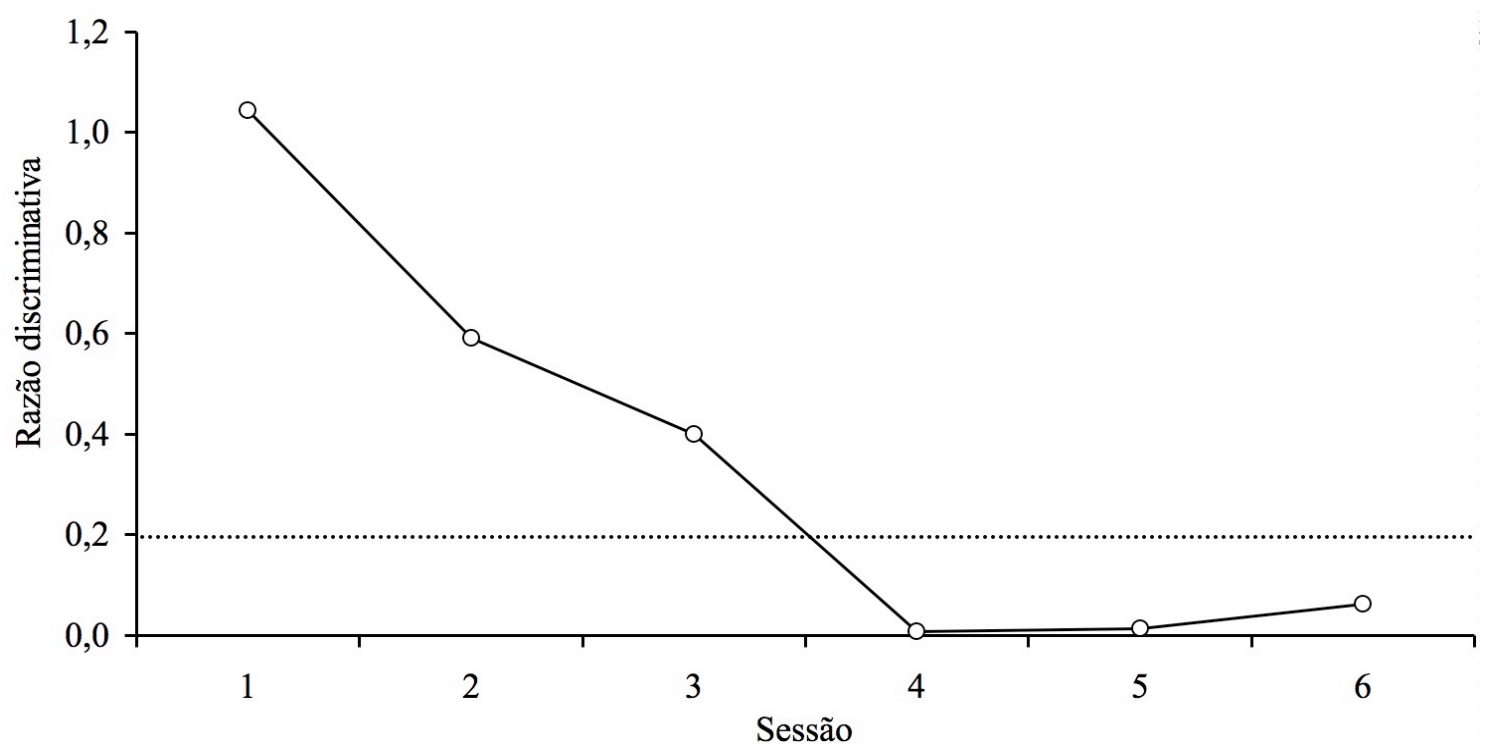

Figura 9. Razão discriminativa por sessão durante o procedimento de treino BC com cores e reset para o Sujeito S10. A linha tracejada indica o valor 0,2 que foi utilizado como critério de aprendizagem. 
O Sujeito S10 foi submetido a seis sessões com esse procedimento. Na Sessão 1, a razão foi 1,04. Nas seguintes, o valor da razão foi diminuindo até atingir menos de 0,2 nas Sessões 4, 5 e 6, indicando que S10 demonstrou um responder discriminado.

Comparando com os resultados obtidos no procedimento de treino $\mathrm{AB}$ com cores (Figura 8), nota-se um estabelecimento de um responder discriminado em um número inferior de sessões durante o treino BC (19 sessões no treino AB e 6 sessões no treino BC). Em adição, na Sessão 1 do treino $\mathrm{AB}$, o valor da razão 16,92, ao passo que na Sessão 1 do treino $\mathrm{BC}$, a razão foi 1,04. Isso indica que a aprendizagem foi mais rápida no treino $\mathrm{BC}$ provavelmente em função do treino prévio ao qual S10 foi submetido no treino AB.

Em seguida, foi conduzido um treino no qual foram apresentados os estímulos compostos do treino $\mathrm{AB}$ juntamente com os do treino $\mathrm{BC}$. O objetivo foi verificar se os desempenhos permaneceriam acurados em sessões nas quais os dois tipos de tentativas foram misturados. Os demais parâmetros foram mantidos em relação ao treino $\mathrm{AB}$ e $\mathrm{BC}$ com formas.

A Figura 10 mostra os valores da razão discriminativa, por sessão, durante o treino $\mathrm{AB}$ e BC com cores e reset.

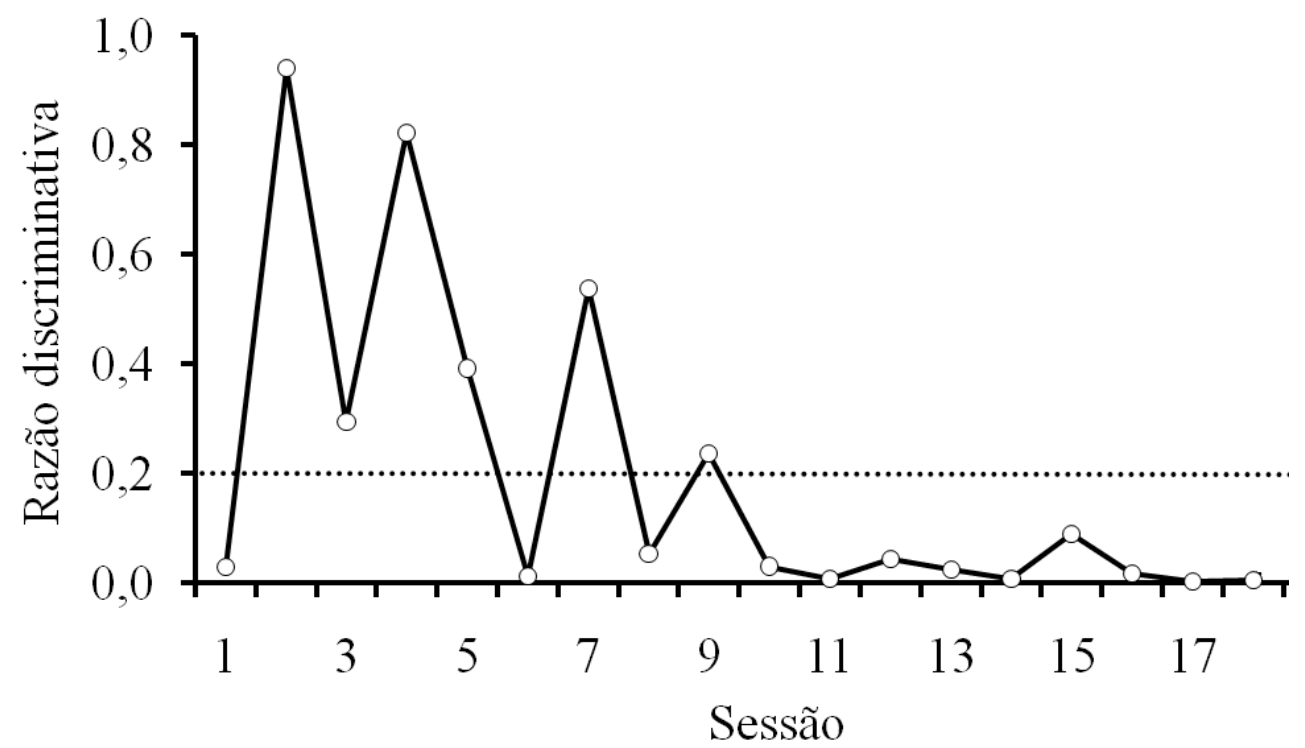

Figura 10. Razão discriminativa por sessão durante o treino $\mathrm{AB}$ e $\mathrm{BC}$ com cores e reset para o Sujeito S10. A linha tracejada horizontal indica o valor 0,2 que foi utilizado como critério de aprendizagem.

O Sujeito S10 foi submetido a 18 sessões com esse procedimento. Na Sessão 1, a razão foi aproximadamente $0 . \mathrm{Na}$ Sessão 2, a razão foi próxima a 1. Entre as Sessões 2 e 9 , 
nota-se uma oscilação nos valores da razão entre 0,01 (Sessão 6) e 0,94 (Sessão 2). Entre as Sessões 10 e 18 a razão foi próxima a 0 , indicando que S10 passou a responder quase exclusivamente na presença dos compostos "corretos". Entre as Sessões 10 e 15, ainda que a razão tenha atingido valores próximos a $0, \mathrm{~S} 10$ respondeu também na presença dos compostos “incorretos" e, por isso, foi mantido no treino. Esses resultados indicam que S10 não manteve o responder discriminado quando as tentativas $\mathrm{AB}$ e $\mathrm{BC}$ foram apresentadas conjuntamente.

Fase III - Teste de simetria

A Figura 11 apresenta as taxas de respostas por segundo, por estímulo composto, durante o teste de simetria. As barras pretas indicam as taxas na presença dos compostos "corretos" e as barras brancas indicam a taxa na presença de um composto "incorreto".

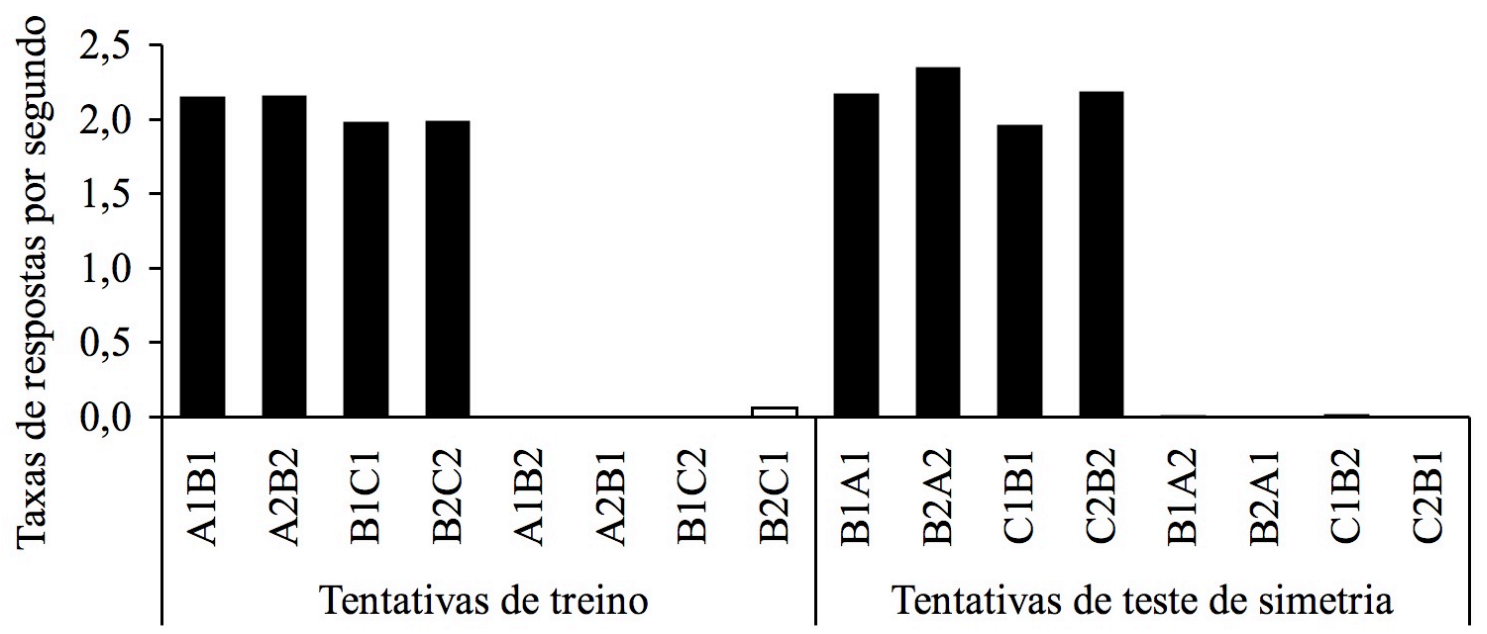

Figura 11. Taxas de respostas por segundo por estímulo composto de treino e de teste durante o teste de simetria para o Sujeito S10. As barras pretas indicam a taxa de respostas na presença dos compostos "corretos" e a barra branca indica a taxa na presença de um composto "incorreto".

Durante o teste de simetria, S10 respondeu quase exclusivamente na presença dos compostos "corretos" de treino e de teste. As taxas de respostas por segundo na presença dos compostos "corretos" de treino variaram entre 1,98 e 2,16 e na presença dos compostos "corretos" de teste, variaram entre 1,96 e 2,35. Na presença dos compostos "incorretos" de treino e de teste as taxas foram próximas a 0 . Portanto, as taxas diferenciais nos compostos "corretos" e "incorretos" foram muito similares nas tentativas de treino e teste. Esses resultados mostram a manutenção do responder discriminado de linha de base e indicam que 
durante o teste de simetria um desempenho condizente com o treino emergiu por meio do procedimento go/no-go com estímulos compostos.

\section{Fase IV - Teste de transitividade}

A Figura 12 mostra os valores da razão discriminativa, por sessão, durante as sessões de treino $\mathrm{AB}$ e $\mathrm{BC}$ com cores e reset conduzidas imediatamente antes do teste de transitividade e equivalência.

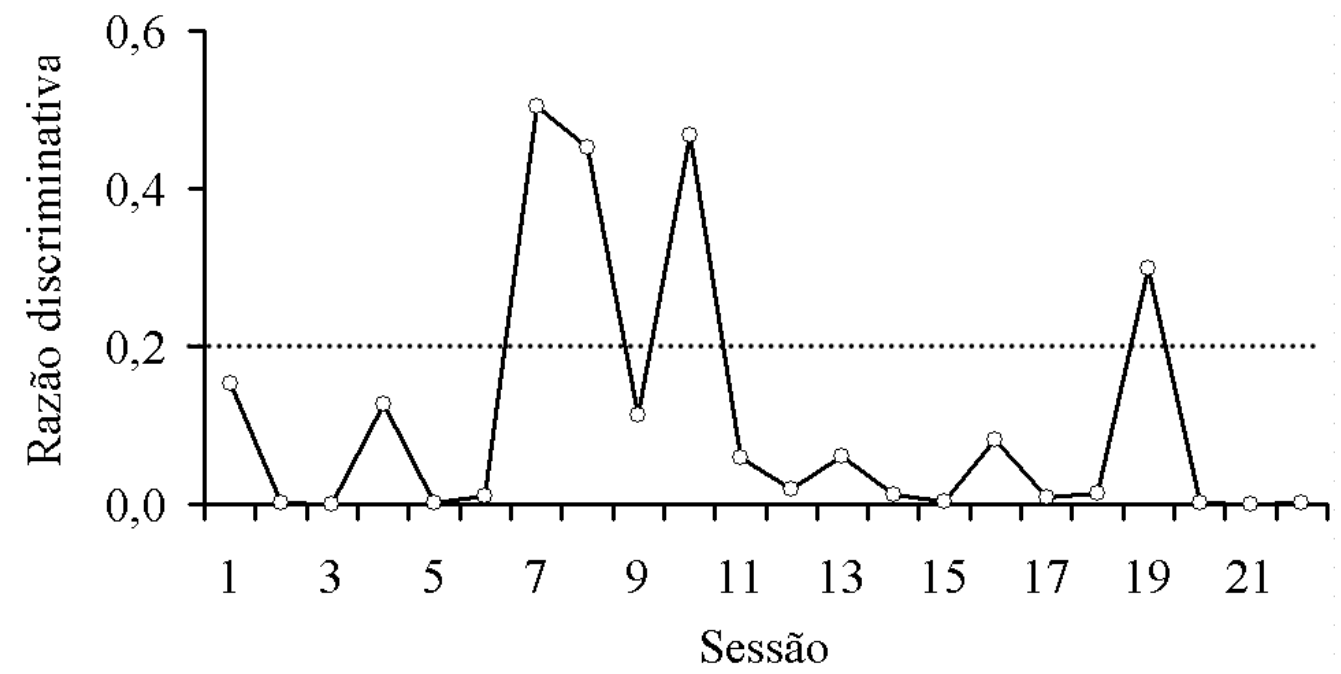

Figura 12. Razão discriminativa por sessão durante o treino $\mathrm{AB}$ e $\mathrm{BC}$ com cores e reset para $\mathrm{o}$ Sujeito S10. A linha tracejada horizontal indica o valor 0,2 que foi utilizado como critério de aprendizagem.

O Sujeito S10 foi submetido a 22 sessões com esse procedimento. Entre as Sessões 1 e 6, os valores da razão foram próximos a 0 . $\mathrm{Na}$ Sessão 7 , a razão aumentou para 0,5 . Entre as Sessões 8 e 10, a razão variou entre 0,11 (Sessão 9) e 0,47 (Sessão 10). Entre as Sessões 11 e 22 , os valores da razão foram próximos a 0 , exceto na Sessão 19 , cuja razão foi 0,3 , indicando que S11 passou a responder quase exclusivamente na presença dos compostos "corretos". Nas Sessões 11 a 18, ainda que a razão tenha atingido valores próximos a 0, S10 respondeu também na presença dos compostos "incorretos" e, por isso, foi mantido no treino. Nota-se que S10 não manteve o responder discriminado após o teste de simetria.

Em virtude do Sujeito S11 não demonstrar a emergência das relações de transitividade e equivalência condizentes com o treino, os testes dessas relações para o Sujeito S10 foram conduzidos separadamente em duas sessões para cada tipo de teste. 
A Figura 13 apresenta as taxas de respostas por segundo, por estímulo composto, durante o primeiro de transitividade.

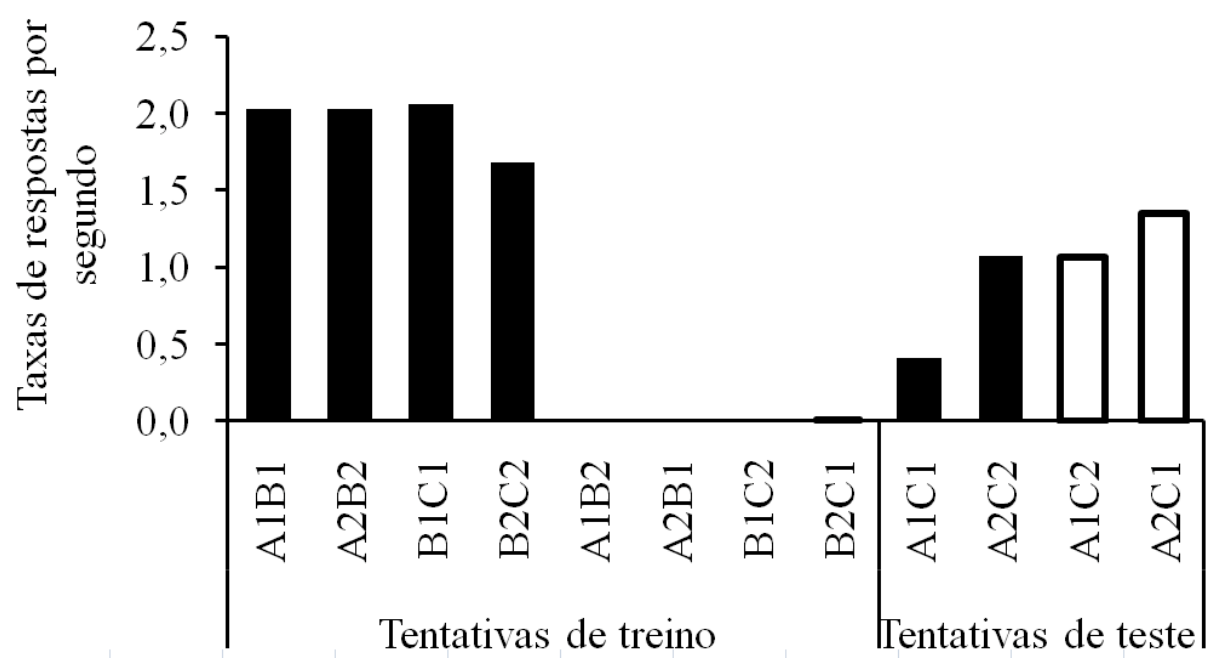

Figura 13. Taxas de respostas por segundo, por estímulo composto, de treino e de teste, durante o primeiro teste de transitividade para o Sujeito S10. As barras pretas indicam a taxa de respostas na presença dos estímulos compostos "corretos" e as barras brancas, as taxas na presença dos "incorretos".

Durante o primeiro teste de transitividade, na presença dos compostos "corretos" de treino, as taxas variaram entre 1,68 e 2,06. Na presença dos compostos "incorretos", as taxas foram próximas a 0 . Isso indica que houve manutenção do responder discriminado de linha de base.

$\mathrm{Na}$ presença dos compostos de teste $\mathrm{A} 1 \mathrm{C} 1, \mathrm{~A} 2 \mathrm{C} 2, \mathrm{~A} 1 \mathrm{C} 2$ e $\mathrm{A} 2 \mathrm{C} 1$, as taxas foram, respectivamente, 0,41, 1,07, 1,07 e 1,35. Esses resultados mostram que S10 respondeu a todos os compostos de teste. As taxas maiores diante dos compostos A2C2, A1C2 e A2C1 podem indicar que o responder estava sob controle desses três estímulos e não de $\mathrm{A} 1 \mathrm{C} 1$, o que indicaria que foi estabelecido controle discriminativo simples sob o responder. Esses resultados indicam que a relação de transitividade condizente com o treino não emergiu por meio do procedimento go/no-go com estímulos compostos.

Após o primeiro teste de transitividade, foi conduzida uma sessão de treino $\mathrm{AB}$ e $\mathrm{BC}$ com cores e reset, na qual a razão foi próxima de 0 , indicando manutenção do responder discriminado de linha de base.

A Figura 14 apresenta as taxas de respostas por segundo, por estímulo composto, durante o segundo teste de transitividade. 


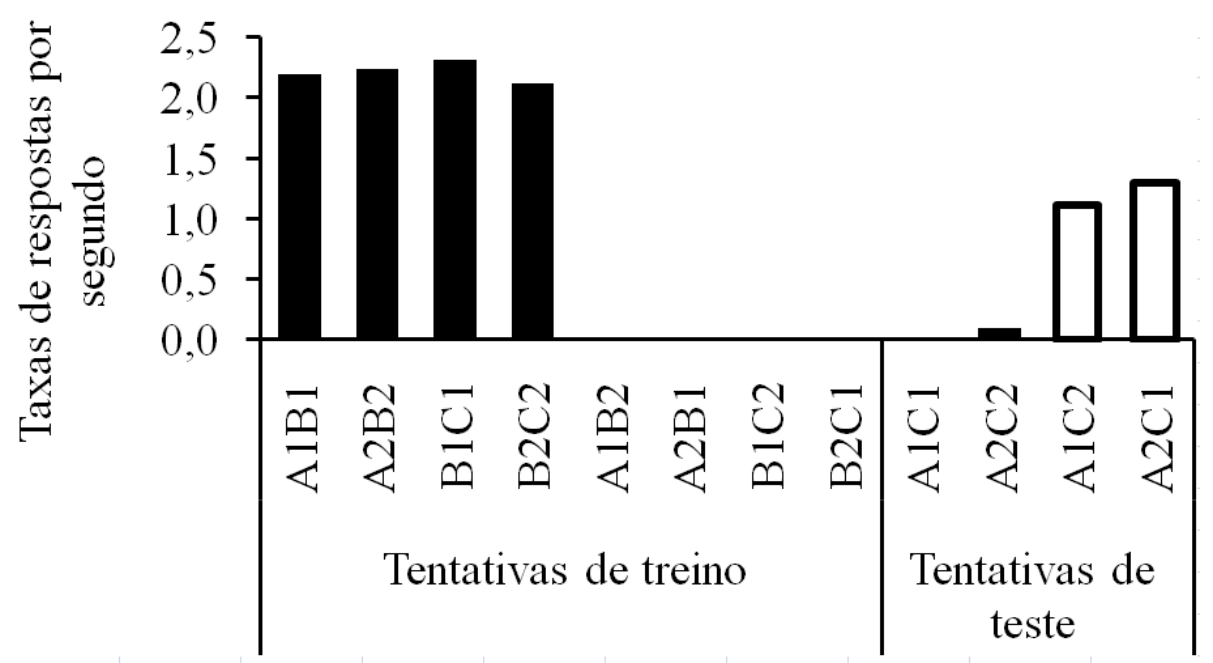

Figura 14. Taxas de respostas por segundo, por estímulo composto, de treino e de teste, durante o segundo teste de transitividade para o Sujeito S10. As barras pretas indicam a taxa de respostas na presença dos estímulos compostos "corretos" e as barras brancas, as taxas na presença dos “incorretos".

Durante o segundo teste, na presença dos compostos "corretos" de treino as taxas variaram entre 2,12 e 2,32. Na presença dos compostos "incorretos", as taxas foram 0. Esses resultados indicam manutenção do responder discriminado de linha de base após o primeiro teste de transitividade.

$\mathrm{Na}$ presença dos compostos $\mathrm{A} 1 \mathrm{C} 1, \mathrm{~A} 2 \mathrm{C} 2, \mathrm{~A} 1 \mathrm{C} 2$ e $\mathrm{A} 2 \mathrm{C} 1$ de teste, as taxas foram, respectivamente, 0,02, 0,09, 1,11 e 1,29. Esses resultados indicam que o responder ficou sob controle de $\mathrm{A} 1 \mathrm{C} 2$ e $\mathrm{A} 2 \mathrm{C} 1$ e que emergiram duas relações condicionais diferentes das especificadas pela experimentadora, o que não permitiria afirmar que a relação de transitividade condizente com o treino emergiu.

\section{Fase IV - Teste de equivalência}

Anteriormente ao teste de equivalência, foi conduzida uma sessão de treino $\mathrm{AB}$ e $\mathrm{BC}$ com cores e reset, na qual a razão foi próxima de 0 , indicando manutenção do responder discriminado de linha de base.

A Figura 15 apresenta as taxas de respostas por segundo, por estímulo composto, durante o primeiro teste de equivalência.

Durante o primeiro teste de equivalência, na presença dos compostos "corretos" de treino, S10 respondeu quase exclusivamente na presença dos compostos "corretos", de treino 
sendo que as taxas variaram entre 1,89 e 2,09. Na presença dos "incorretos", as taxas foram próximas a 0 . Esses resultados indicam manutenção do responder discriminado de linha de base.

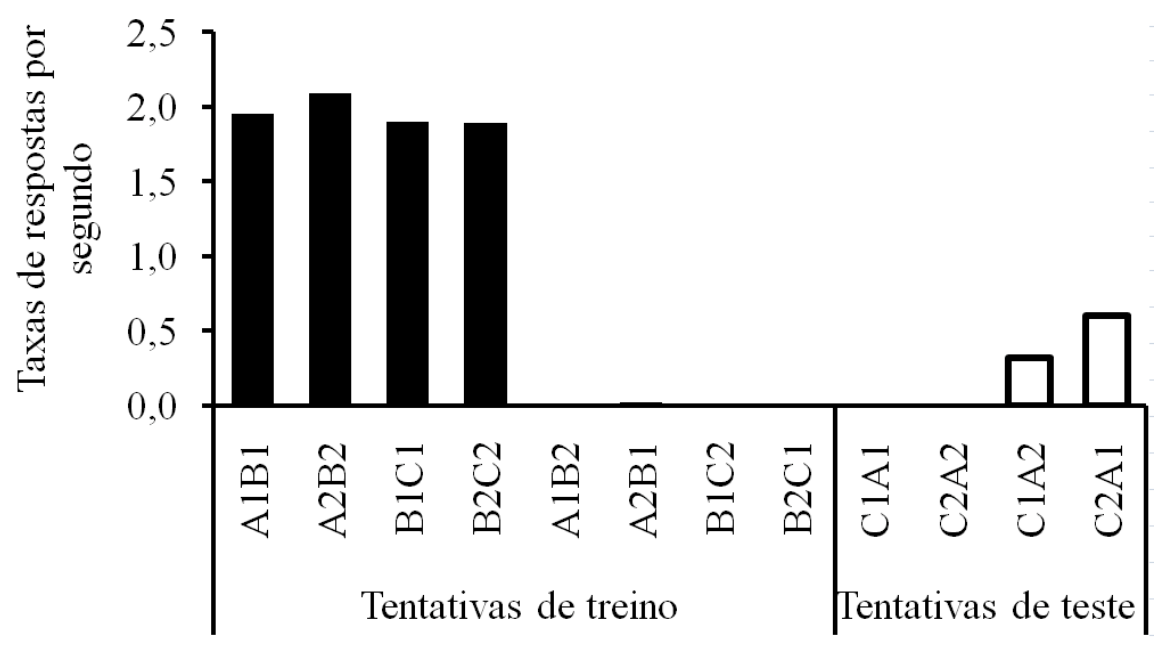

Figura 15. Taxas de respostas por segundo, por estímulo composto, de treino e de teste, durante o primeiro teste de equivalência para o Sujeito S10. As barras pretas indicam a taxa de respostas na presença dos estímulos compostos "corretos" e as barras brancas, as taxas na presença dos "incorretos".

$\mathrm{Na}$ presença dos compostos "corretos" de teste C1A1 e C2A2, não foram emitidas respostas. Na presença dos "incorretos" C1A2 e C2A1 as taxas foram, respectivamente, 0,32 e 0,61. Esses resultados indicam que o responder ficou sob controle de C1A2 e C2A1 e que emergiram duas relações condicionais diferentes das especificadas pela experimentadora, $\mathrm{o}$ que não permitiria afirmar que a relação de equivalência condizente com o treino emergiu. Cabe destacar que S10 respondeu na presença de $\mathrm{A} 1 \mathrm{C} 2$ e $\mathrm{A} 2 \mathrm{C} 1$ nos dois testes de transitividade e suas relações simétricas (equivalência): C1A2 e C2A1 no primeiro teste de equivalência.

Após o primeiro teste de equivalência, foi conduzida uma sessão de treino $\mathrm{AB}$ e $\mathrm{BC}$ com cores e reset, na qual a razão foi próxima de 0 , indicando manutenção do responder discriminado de linha de base.

A Figura 16 apresenta as taxas de respostas por segundo, por estímulo composto, durante o segundo teste de equivalência.

Durante o segundo teste de equivalência, na presença dos compostos "corretos" de treino, as taxas variaram entre 1,09 e 1,12. Na presença dos "incorretos", as taxas foram próximas a 0 . Esses resultados indicam manutenção do responder discriminado de linha de 
base após o primeiro teste de equivalência. Nota-se uma diminuição para 0 das taxas na presença dos quatro compostos do segundo teste de equivalência com relação ao primeiro teste de equivalência. Isso mostra que não emergiu a relação de equivalência condizente com o treino.

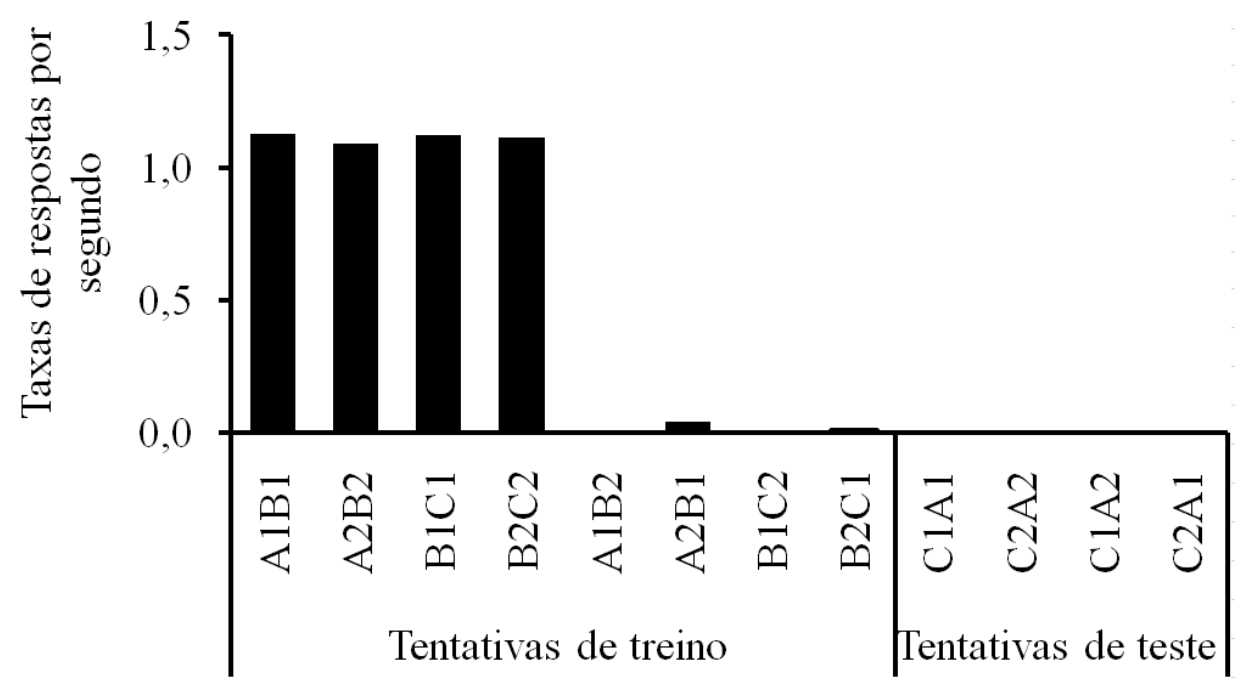

Figura 16. Taxas de respostas por segundo, por estímulo composto, de treino e de teste, durante o segundo teste de equivalência para o Sujeito S10.

\section{Sujeito S11}

Após modelagem e fortalecimento das respostas, conduzidos na Fase I, o Sujeito S11 foi submetido à Fase II.

Fase II - Treino

A Figura 17 apresenta os valores da razão discriminativa do treino para o Sujeito S11.

O Sujeito S11 foi submetido a 143 sessões de treino. Nessas sessões, os valores das razões discriminativas variaram entre 0,56 (Sessão 27) e 3,34 (Sessão 50). Ao longo das sessões, a razão foi, aproximadamente, 1. A partir da Sessão 112, verifica-se que a razão atingiu valores superiores a 1. Esses resultados indicam que S11 ao longo do treino não exibiu um responder discriminado.

Em seguida, foi realizada uma alteração no procedimento que consistiu na diminuição do número de relações ensinadas. O objetivo dessa alteração foi verificar se, por meio da apresentação de um menor número de compostos, S11 apresentaria um responder 
discriminado. Foi ensinada a relação $\mathrm{AB}$ e os estímulos compostos foram: A1B1, A2B2, A1B2 e A2B1. Os demais parâmetros foram mantidos em relação à fase anterior.

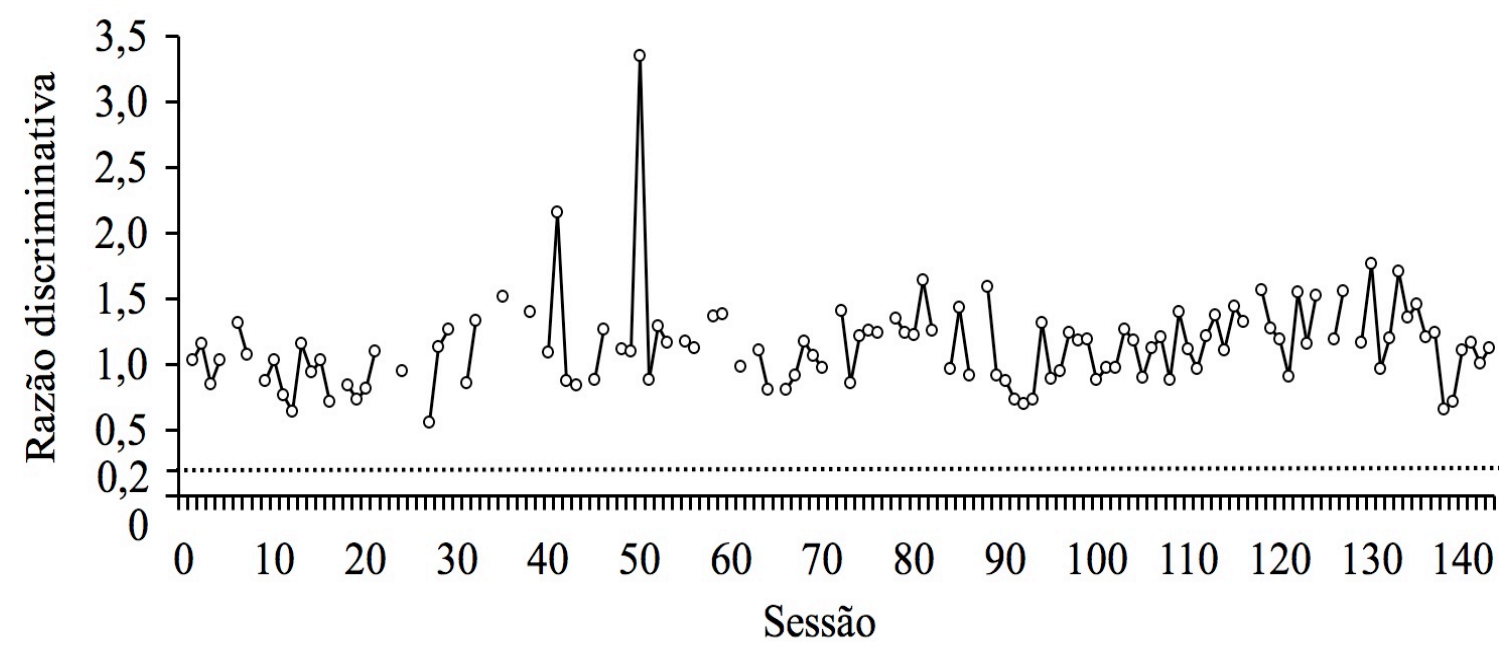

Figura 17. Razão discriminativa por sessão durante o treino para o Sujeito S11. A linha tracejada indica o valor 0,2 que foi utilizado como critério de aprendizagem. Pontos inexistentes na curva indicam que o sujeito não respondeu durante a sessão.

A Figura 18 apresenta os valores da razão discriminativa com o procedimento de treino AB e esquema de reforçamento FR 1 e VT 60 segundos para o Sujeito S11.

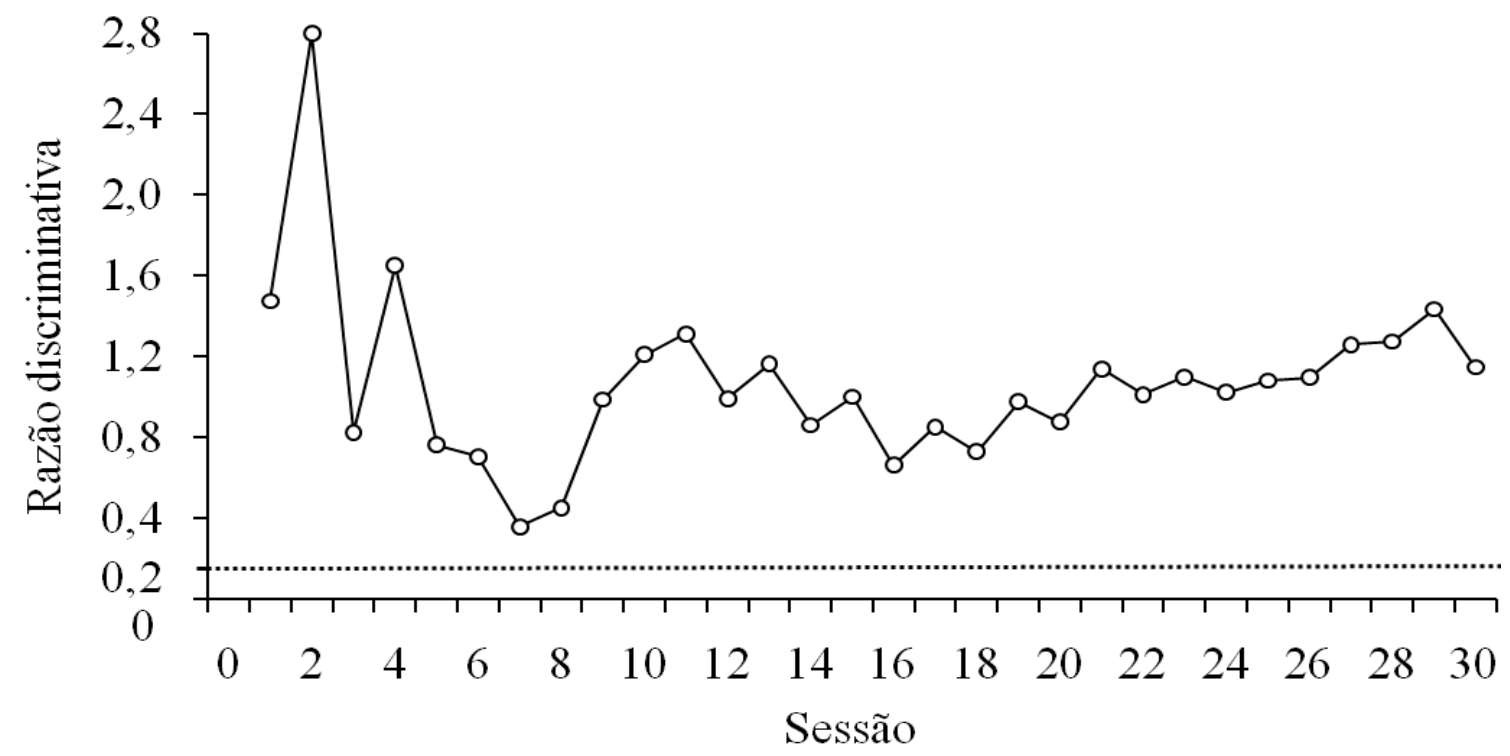

Figura 18. Razão discriminativa por sessão durante o procedimento de treino $\mathrm{AB}$ e esquema de reforçamento FR 1 e VT 60 segundos para o Sujeito S11. A linha tracejada indica o valor 0,2 que foi utilizado como critério de aprendizagem. 
O Sujeito S11 foi submetido a 30 sessões com esse procedimento, nas quais os valores das razões discriminativas variaram entre 0,3 (Sessão 7) e 2,8 (Sessão 2). Entre as Sessões 1 a 4, a razão foi superior ou igual a 0,8 . A partir da Sessão 4 os valores da razão caíram até atingir 0,35 na Sessão 7. A partir da Sessão 8, os valores da razão voltaram a aumentar até atingir 1,31 na Sessão 11. A partir da Sessão 12, os valores da razão oscilaram entre 0,66 (Sessão 16) e 1,43 (Sessão 29). Esses resultados indicam que a apresentação de apenas quatro compostos não permitiu o estabelecimento de um responder discriminado.

Após a Sessão 30 desse procedimento, verificou-se o erro na programação do esquema de reforçamento, até então um esquema conjuntivo razão fixa (FR) 1 e tempo variável (VT) 60 segundos. Os demais parâmetros foram mantidos em relação ao procedimento anterior.

A Figura 19 apresenta os valores da razão discriminativa do treino $\mathrm{AB}$ e esquema de reforçamento VI 60 segundos para o Sujeito S11.

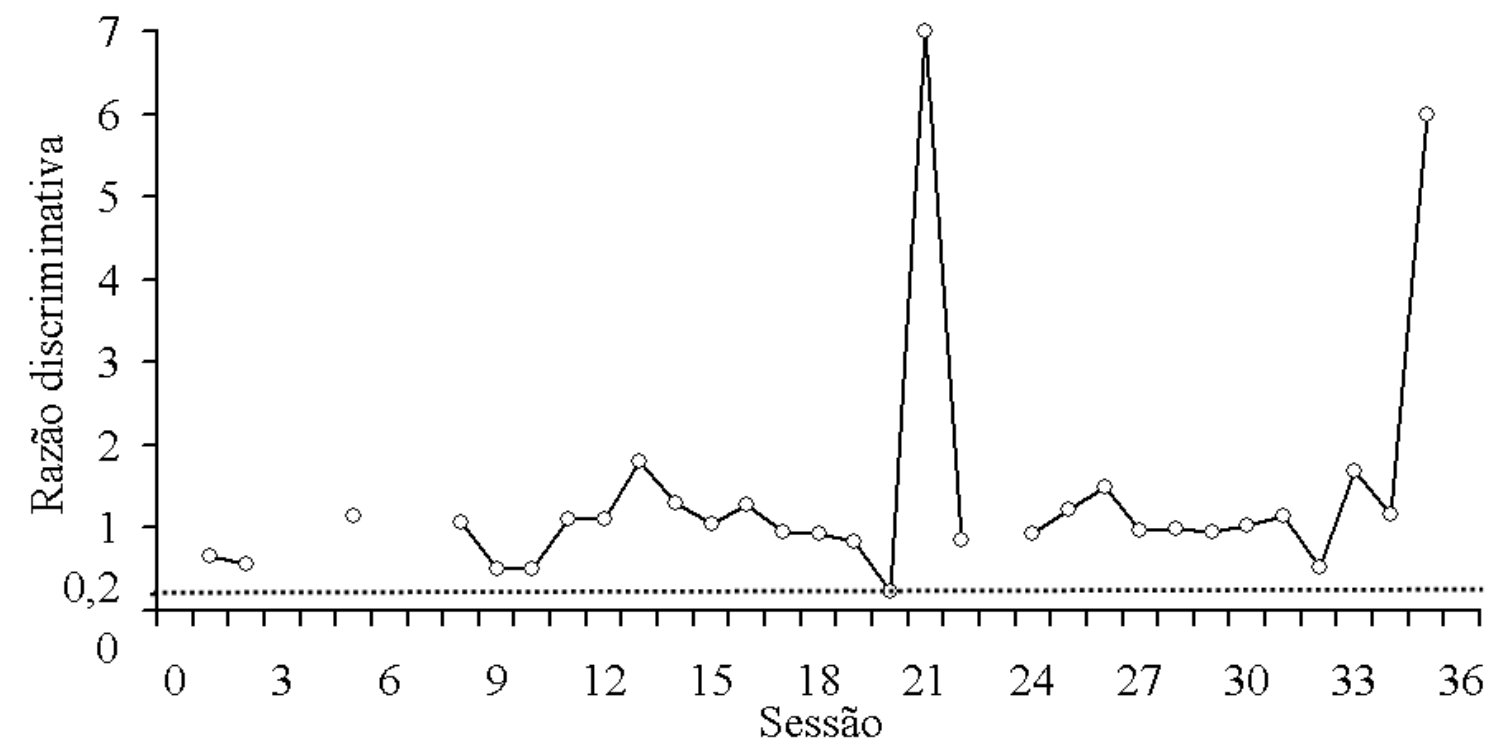

Figura 19. Razão discriminativa por sessão durante o procedimento de treino $A B$ com esquema VI 60 segundos para o Sujeito S11. A linha tracejada indica o valor 0,2 que foi utilizado como critério de aprendizagem. Pontos inexistentes na curva indicam que o sujeito não respondeu durante a sessão.

O Sujeito S11 foi submetido a 36 sessões com esse procedimento. Os valores da razão variaram entre 0,2 (Sessão 20) e 7 (Sessão 21). Ao longo das sessões, a razão ficou próxima a 1. Exceções ocorreram nas Sessões 21 e 35, cujos valores da razão foram, aproximadamente, 6. Esses resultados apontam que a apresentação de um menor número de compostos não produziu um responder discriminado. 
Em seguida, foi manipulado o esquema de reforçamento, que se alterou de VI 60 segundos para VI 15. Isso porque os valores desse esquema $(1,2,3,4, \ldots 30)$ eram menores ou iguais à duração da tentativa (30 segundos). Portanto, o VI 30 permitiria maior densidade de reforço. Os demais parâmetros foram mantidos em relação ao procedimento anterior

Na Figura 20 estão apresentados os valores da razão discriminativa, por sessão, durante o procedimento de treino $\mathrm{AB}$ com esquema VI 15 segundos.

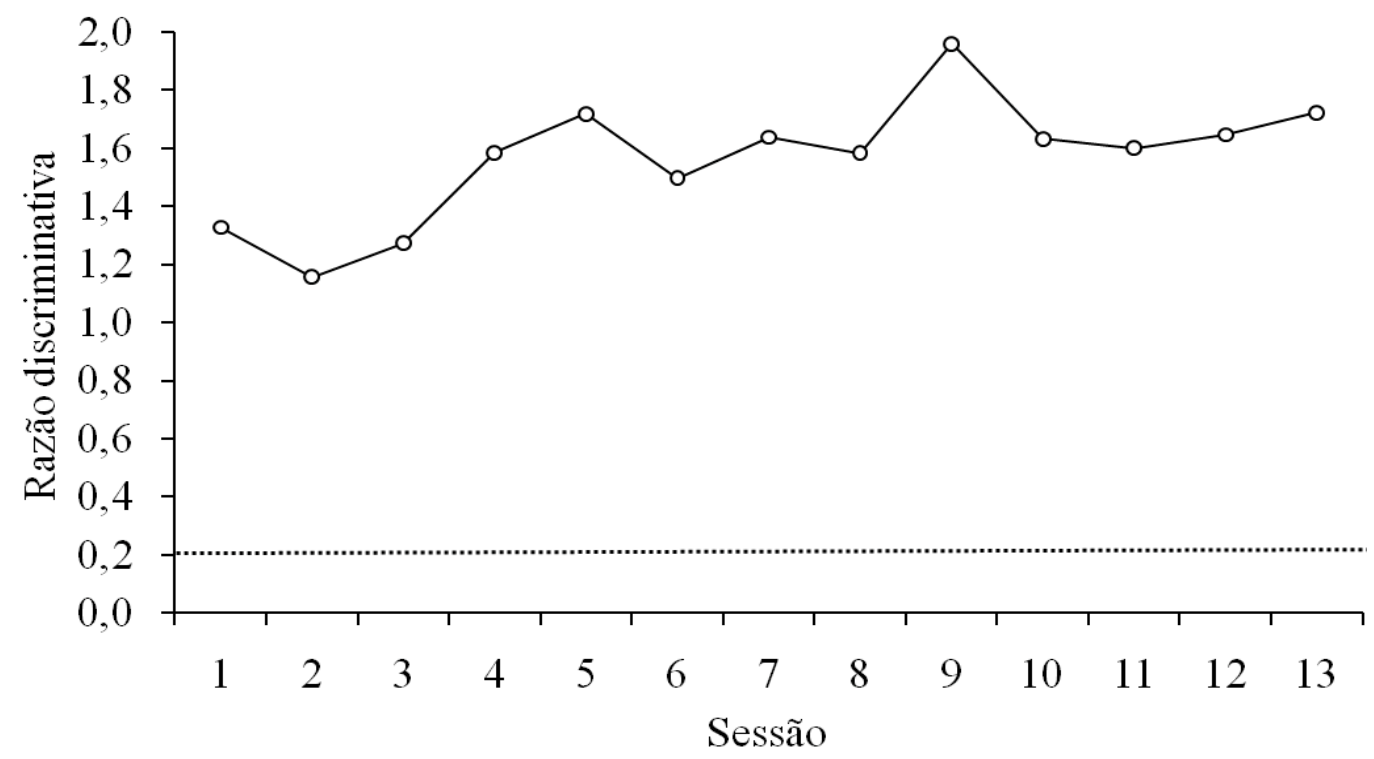

Figura 20. Razão discriminativa por sessão durante o procedimento de treino $A B$ com esquema VI 15 segundos para o Sujeito S11. A linha tracejada indica o valor 0,2 que foi utilizado como critério de aprendizagem.

O Sujeito S11 foi submetido a 13 sessões com esse procedimento. Os valores da razão variaram entre 1,16 (Sessão 2) e 1,96 (Sessão 9). Desde a Sessão 1, cujo valor da razão foi 1,33, os valores das razões sofreram aumento até atingir o valor 1,72 (Sessão 13). Esses dados indicam que a diminuição do valor do VI não permitiu o estabelecimento de um responder discriminado.

Em seguida, foi introduzido o procedimento reset, descrito anteriormente com o objetivo de diminuir o número de respostas emitidas na presença dos compostos "incorretos". Os demais parâmetros foram mantidos em relação ao procedimento anterior.

Na Figura 21 estão apresentados os valores da razão discriminativa, por sessão, durante o procedimento de treino $\mathrm{AB}$ com esquema VI 15 segundos e reset.

O Sujeito S11 foi submetido a nove sessões com esse procedimento. Na Sessão 1, a razão foi 165. Nas demais sessões, a razão apresentou um decréscimo até atingir 8,33, (Sessão 
9). Provavelmente a introdução do reset foi responsável pelos altos valores da razão nas sessões iniciais. Ainda que a razão tenha diminuído ao longo dos treinos, o reset não permitiu que se estabelecesse um responder discriminado.

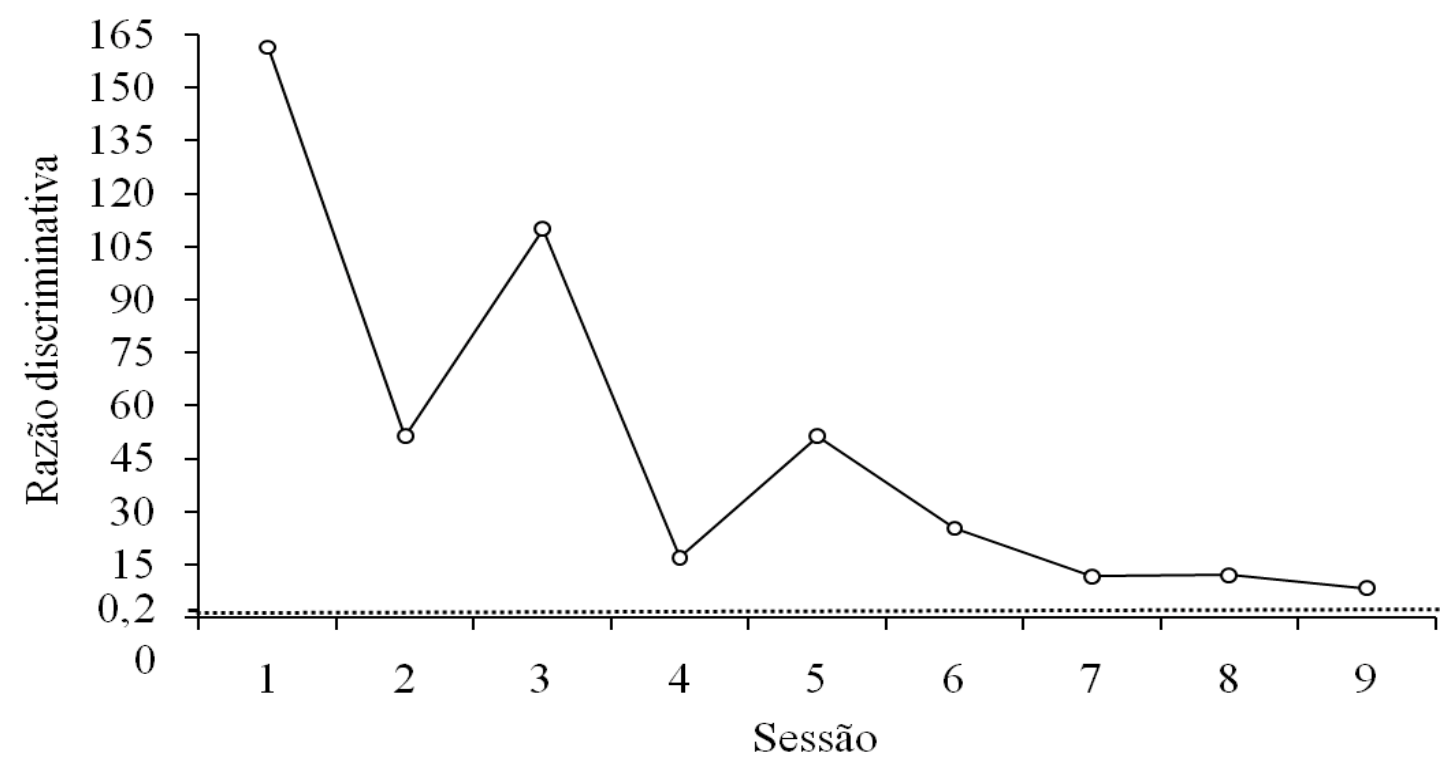

Figura 21. Razão discriminativa por sessão durante o procedimento de treino $A B$ com esquema VI 15 segundos e reset para o Sujeito S11. A linha tracejada indica o valor 0,2 que foi utilizado como critério de aprendizagem.

Em seguida, as formas utilizadas no procedimento de treino AB foram substituídas por cores com o objetivo de verificar se um responder discriminado seria estabelecido quando cores fossem apresentadas como estímulos. Esse procedimento foi idêntico ao conduzido com o Sujeito S10.

Na Figura 22 estão apresentados os valores da razão discriminativa, por sessão, durante o procedimento de treino AB com esquema VI 15 segundos, reset com cores.

O Sujeito S11 foi submetido a nove sessões com esse procedimento. Na Sessão 1 a razão foi 12,04. Nas Sessões 1, 2 e 3, os valores da razão aumentaram até atingir 15,7 (Sessão 3). Verifica-se ao longo das Sessões 3 a 9, um decréscimo nos valores da razão até o valor 0 (Sessões 6 a 9). Esses resultados indicam que, assim como verificado com o Sujeito S10, a apresentação dos compostos formados por cores permitiu o estabelecimento de um responder discriminado.

Na Figura 23 estão apresentados os valores da razão discriminativa, por sessão, durante o procedimento de treino BC com esquema VI 15 segundos, reset e cores. 


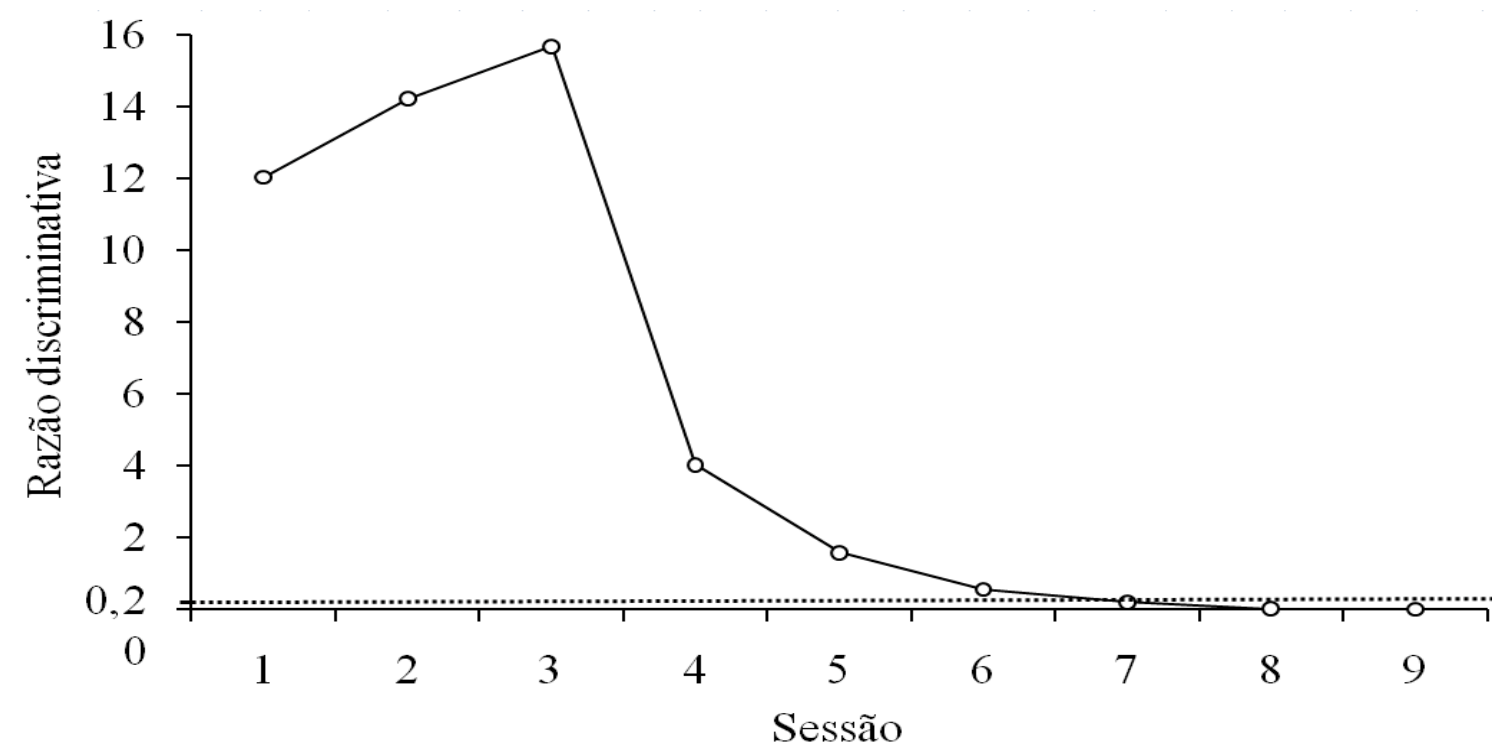

Figura 22. Razão discriminativa por sessão durante o procedimento de treino $A B$ com esquema VI 15 segundos, reset com cores para o Sujeito S11. A linha tracejada indica o valor 0,2 que foi utilizado como critério de aprendizagem.

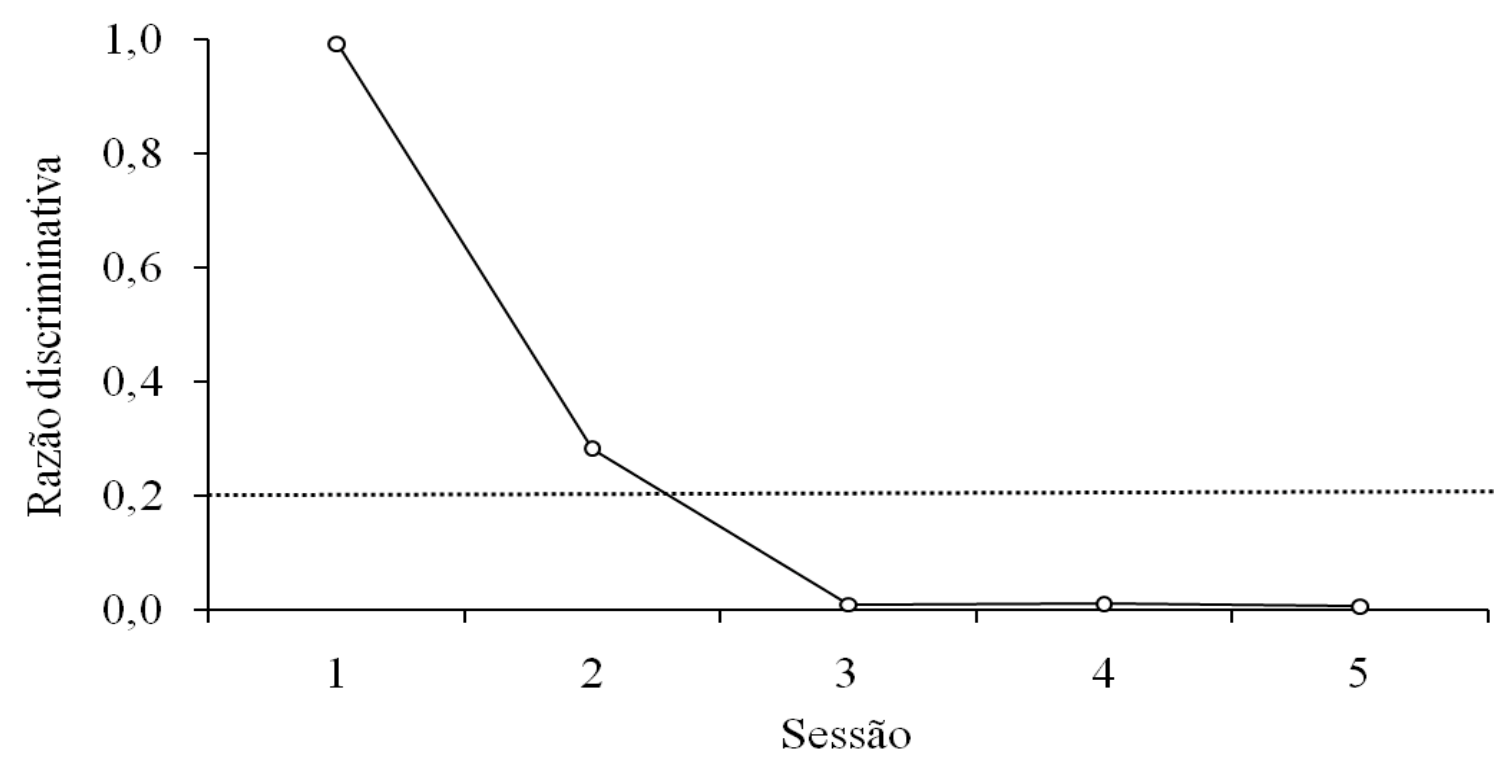

Figura 23. Razão discriminativa por sessão durante o procedimento de treino BC com esquema VI 15 segundos, reset com cores para o Sujeito S11. A linha tracejada indica o valor 0,2 que foi utilizado como critério de aprendizagem.

O Sujeito S11 foi submetido a cinco sessões com esse procedimento. Os valores da razão decresceram de 0,99 (Sessão 1) para 0 (Sessões 3 a 5). Isso indica o estabelecimento de um responder discriminado. 
Comparando esse resultado com o procedimento de treino AB com cores (Figura 22), nota-se o estabelecimento de responder discriminado em um número inferior de sessões durante o treino $\mathrm{BC}$ ( 9 sessões no treino $\mathrm{AB}$ e 5 sessões no treino $\mathrm{BC}$ ). Além disso, na Sessão 1 do treino $\mathrm{AB}$, o valor da razão 12,04, ao passo que na Sessão 1 do treino $\mathrm{BC}$, a razão foi 0,99. Isso indica que a aprendizagem foi mais rápida no segundo treino $\mathrm{BC}$ provavelmente em função do treino prévio ao qual S11 foi submetido no treino AB.

O Sujeito $\mathrm{S} 11$ foi submetido a sete sessões com o procedimento de treino $\mathrm{AB}$ e $\mathrm{BC}$ com cores e reset, nas quais a razão foi próxima de 0, indicando que S11 respondeu quase exclusivamente na presença dos compostos "corretos". Entre as Sessões 1 e 4, ainda que a razão tenha atingido valores próximos a $0, \mathrm{~S} 11$ respondeu também na presença dos compostos “incorretos" e, por isso, foi mantido no treino. Diferentemente de S10, o Sujeito S11 manteve o responder discriminado desde a primeira sessão quando as tentativas $\mathrm{AB}$ e $\mathrm{BC}$ foram misturadas.

Fase III - Teste de simetria

A Figura 24 apresenta as taxas de respostas, por estímulo composto, durante o teste de simetria.

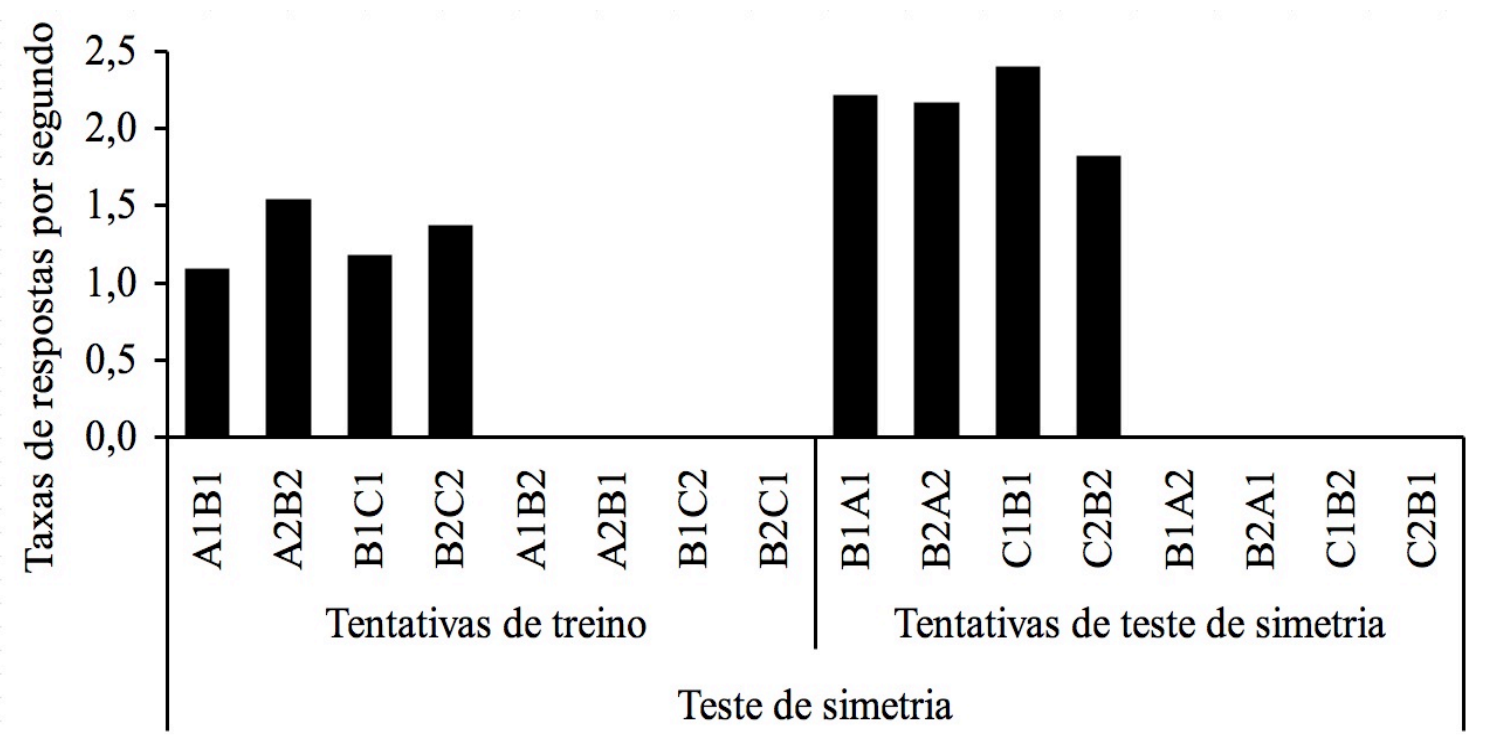

Figura 24. Taxas de respostas por segundo, por estímulo composto, de treino e de teste, durante o teste de simetria para o Sujeito S11. 
Durante o teste de simetria, S11 respondeu somente na presença dos compostos "corretos" de treino e de teste. As taxas de respostas por segundo na presença dos compostos "corretos" de treino variaram entre 1,09 e 1,55 e na presença dos compostos de teste "corretos", variaram entre 1,82 e 2,40. Portanto, as taxas diferenciais nos compostos "corretos" e "incorretos" foram similares nas tentativas de treino e teste. Esses resultados mostram a manutenção do responder discriminado de linha de base e indicam que, da mesma forma como verificado com o Sujeito S10, durante o teste de simetria um desempenho condizente com o treino emergiu por meio do procedimento go/no-go com estímulos compostos.

Fase IV - Teste de transitividade e equivalência

Anteriormente ao teste de transitividade e equivalência, foram conduzidas duas sessões de treino $\mathrm{AB}$ e $\mathrm{BC}$ com cores e reset, nas quais a razão foi próxima de 0 . Isso indica que houve manutenção do responder discriminado de linha de base, diferentemente ao verificado com o Sujeito S10. A Sessão 2 foi conduzida porque S11 estava acima do peso e optou-se por não submetê-lo a outro teste e, sim, ao treino.

A Figura 25 apresenta as taxas de respostas por segundo, por estímulo composto, durante o teste de transitividade e equivalência.

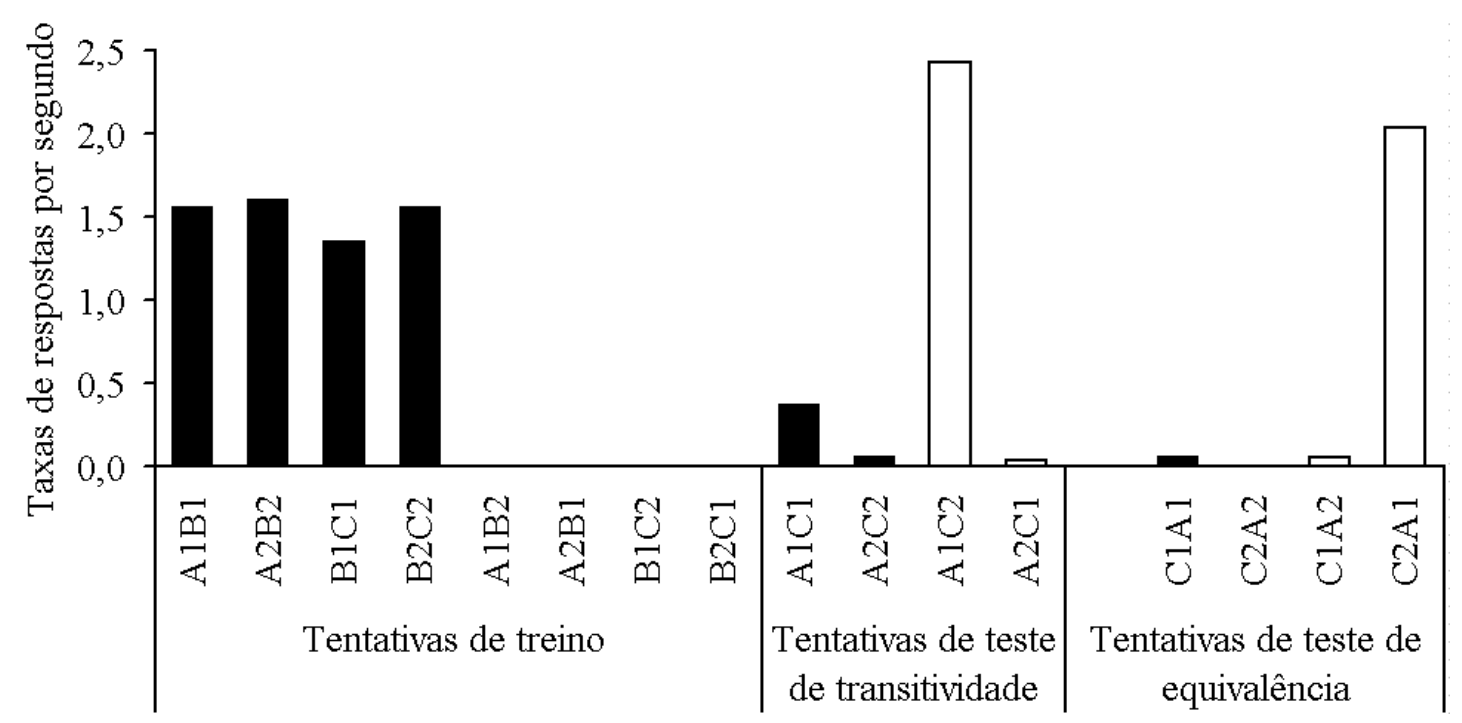

Figura 25. Taxas de respostas por segundo, por estímulo composto, durante o teste de transitividade e equivalência para o Sujeito S11. As barras pretas indicam a taxa de respostas na presença dos estímulos compostos "corretos" e as barras brancas, as taxas na presença dos "incorretos". 
Durante o teste de transitividade e equivalência, na presença dos compostos de treino, S11 respondeu exclusivamente aos "corretos", sendo que as taxas variaram entre 1,36 e 1,61. $\mathrm{Na}$ presença dos "incorretos", as taxas foram 0. Esses resultados indicam manutenção do responder discriminado de linha de base.

$\mathrm{Na}$ presença dos compostos "corretos" de teste de transitividade $\mathrm{A} 1 \mathrm{C} 1$ e $\mathrm{A} 2 \mathrm{C} 2$ as taxas foram, respectivamente, 0,37 e 0,07 . Na presença dos "incorretos" A1C2 e A2C1 as taxas foram, respectivamente, 2,43 e 0,04. Esses resultados indicam que o responder ficou sob controle do composto $\mathrm{A} 1 \mathrm{C} 2$, sugerindo o estabelecimento de controle discriminativo simples, assim como verificado no desempenho do Sujeito S10 no primeiro teste de transitividade. Isso indica que a relação de transitividade condizente com o treino não emergiu por meio do procedimento go/no-go com estímulos compostos.

Na presença dos compostos "corretos" de teste de equivalência C1A1 e C2A2 as taxas foram próximas a 0 . $\mathrm{Na}$ presença dos "incorretos" $\mathrm{C} 1 \mathrm{~A} 2$ e $\mathrm{C} 2 \mathrm{~A} 1$ as taxas foram, respectivamente, 0,06 e 2,04. Esses resultados mostram que o responder foi controlado pelo composto C2A1. Nota-se que este composto (de equivalência) consiste na relação simétrica de A1C2. Isso indica o estabelecimento de controle discriminativo simples, diferentemente do verificado com o Sujeito S10 no primeiro teste de equivalência que exibiu duas relações condicionais. Além disso, parece que foram aprendidas relações não condizentes com o treino e que, portanto, a relação de equivalência condizente com o treino não emergiu por meio do procedimento go/no-go com estímulos compostos.

Uma vez que as relações de transitividade e equivalência não emergiram no primeiro teste, foi conduzida mais uma sessão de teste de transitividade separada da sessão de teste de equivalência.

Anteriormente ao teste de transitividade, foi conduzida uma sessão de treino $\mathrm{AB}$ e $\mathrm{BC}$ com cores e reset, na qual a razão foi próxima de 0 , indicando manutenção do responder discriminado de linha de base.

A Figura 26 apresenta as taxas de respostas por segundo, por estímulo composto, durante o teste de transitividade.

Durante o segundo teste de transitividade, na presença dos compostos de treino, S11 respondeu quase exclusivamente aos "corretos", sendo que as taxas variaram entre 0,63 e 0,81 . Na presença dos "incorretos", as taxas foram próximas a 0. Esses resultados indicam manutenção do responder discriminado de linha de base após o primeiro teste de transitividade. 


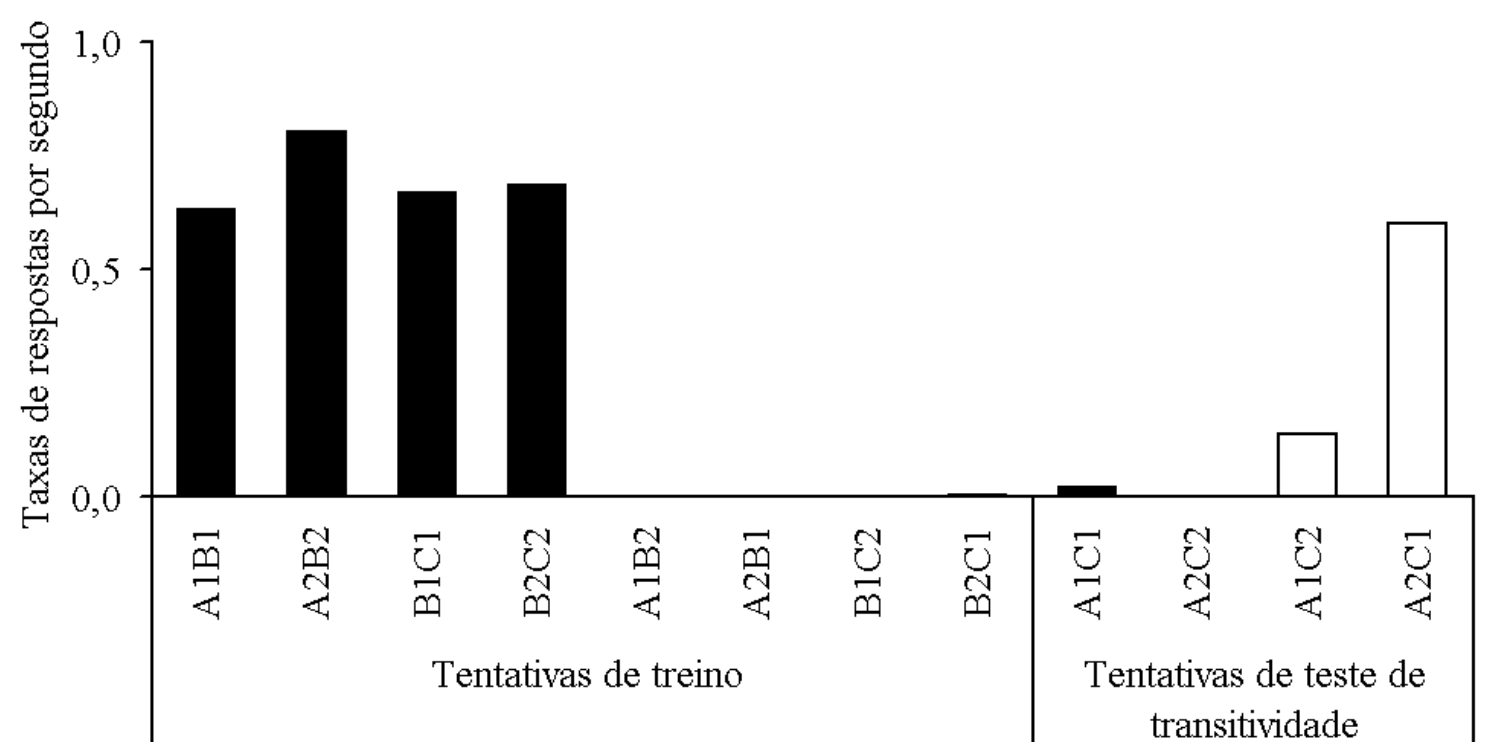

Figura 26. Taxas de respostas por segundo, por estímulo composto, durante o segundo teste de transitividade para o Sujeito S11. As barras pretas indicam a taxa de respostas na presença dos estímulos compostos “corretos" e as barras brancas, as taxas na presença dos "incorretos".

$\mathrm{Na}$ presença dos compostos "corretos" de teste de transitividade $\mathrm{A} 1 \mathrm{C} 1$ e A2C2, as taxas foram próximas a 0 . $\mathrm{Na}$ presença dos "incorretos" $\mathrm{A} 1 \mathrm{C} 2$ e $\mathrm{A} 2 \mathrm{C} 1$ as taxas foram, respectivamente, 0,14 e 0,6 . Isso indicaria que o responder ficou sob controle do composto A2C1. Nota-se também uma diminuição dos valores das taxas nos compostos A1C1, A2C2 e A1C2 do primeiro para o segundo teste de transitividade. Esses resultados indicam que não se manteve o desempenho do teste de transitividade anterior, sugerindo o estabelecimento de controle discriminativo simples, o que não permitiria afirmar que a relação de transitividade condizente com o treino emergiu.

Após o teste de transitividade, foi conduzida uma sessão de treino $\mathrm{AB}$ e $\mathrm{BC}$ com cores e reset, na qual a razão foi próxima de 0 , indicando manutenção do responder discriminado de linha de base.

A Figura 27 apresenta as taxas de respostas por segundo, por estímulo composto, durante o segundo teste de equivalência.

Durante o segundo teste de equivalência, na presença dos compostos de treino, S11 respondeu exclusivamente na presença dos "corretos", sendo que as taxas variaram entre 1,38 e 1,66. Na presença dos "incorretos", as taxas foram 0. Esses resultados indicam manutenção do responder discriminado de linha de base.

$\mathrm{Na}$ presença do estímulo de teste de equivalência C2A1 a taxa foi 0,81 e nos demais compostos, foi, aproximadamente, 0. Esses resultados indicam que o responder ficou sob 
controle de $\mathrm{C} 2 \mathrm{~A} 1$, sugerindo o estabelecimento de controle discriminativo simples. Nota-se uma queda no valor da taxa na presença de C2A1 do primeiro para o segundo teste, similarmente ao que foi verificado no desempenho do Sujeito S10. Isso mostra que, assim como verificado com o Sujeito S10, não emergiu a relação de equivalência condizente com o treino.

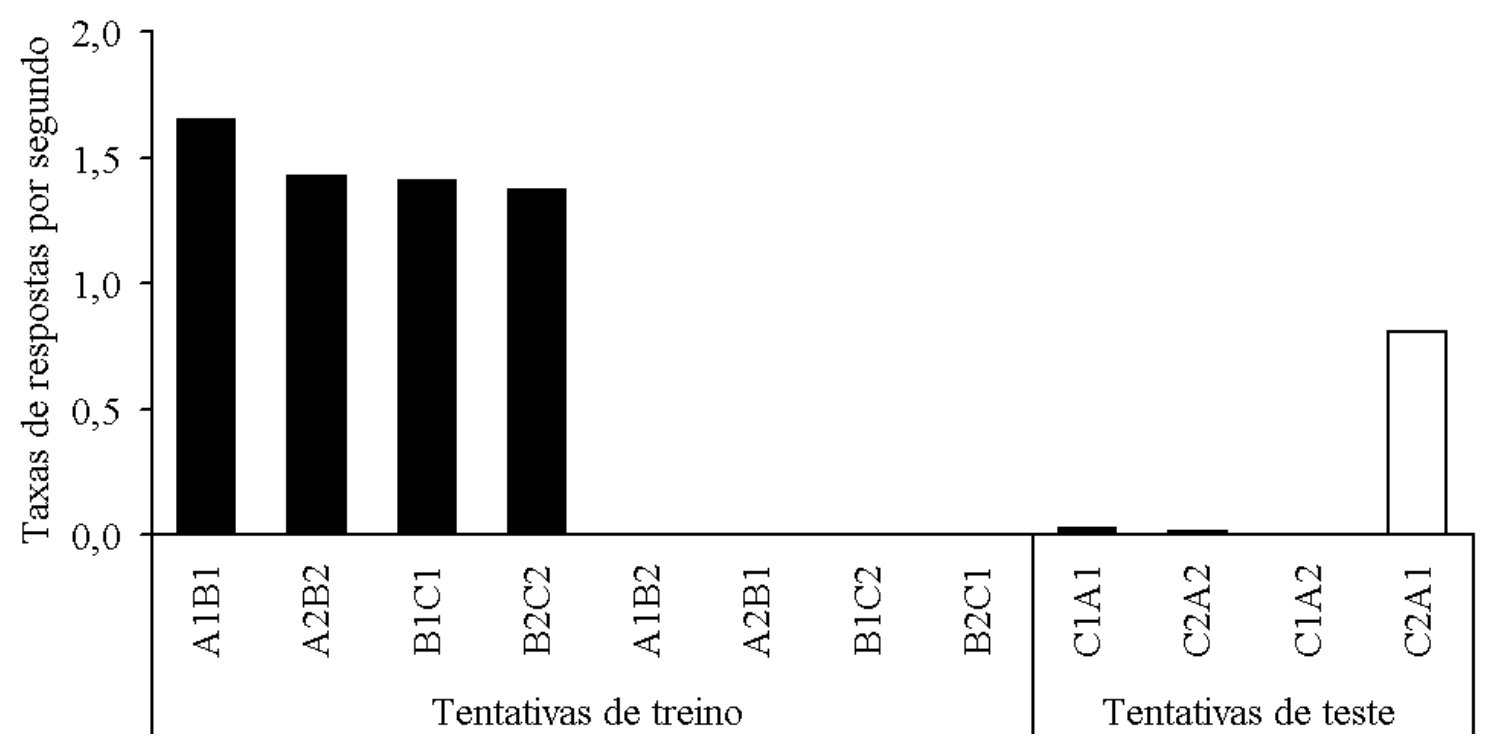

Figura 27. Taxas de respostas por segundo, por estímulo composto, durante o segundo teste de equivalência para o Sujeito S11. As barras pretas indicam a taxa de respostas na presença dos estímulos compostos "corretos" e as barras brancas, as taxas na presença dos "incorretos".

\section{Sujeito S9}

Após modelagem e fortalecimento das respostas, conduzidos na Fase I, o Sujeito S9 foi submetido à Fase II. Ele iniciou o treino com os estímulos compostos formados por cores devido aos resultados obtidos com os Sujeitos S10 e S11 que mostraram um responder discriminado quando foram apresentados os compostos formados por cores.

Fase II - Treino AB com cores, reset e VI 60

Na Figura 28 estão apresentados os valores da razão discriminativa, por sessão, durante o procedimento de treino $\mathrm{AB}$.

O Sujeito S9 foi submetido a 23 sessões com esse procedimento. Na Sessão 1 a razão foi 8,4. Nas Sessões 2 e 3 os valores da razão aumentaram até 43,5. Na Sessão 4 o valor 
decresceu para 2. Nas Sessões 5 a 8 , nota-se um aumento nos valores da razão até 9,85. A partir da Sessão 9 até o final do procedimento de treino, os valores decresceram até atingir 0 . Entre as Sessões 15 e 20, ainda que a razão tenha atingido valores próximos a 0, S9 respondeu também na presença dos compostos "incorretos" e, por isso, foi mantido no treino. Esses resultados indicam que, assim como verificado com os Sujeitos S10 e S11, a apresentação dos compostos formados por cores permitiu o estabelecimento de um responder discriminado.

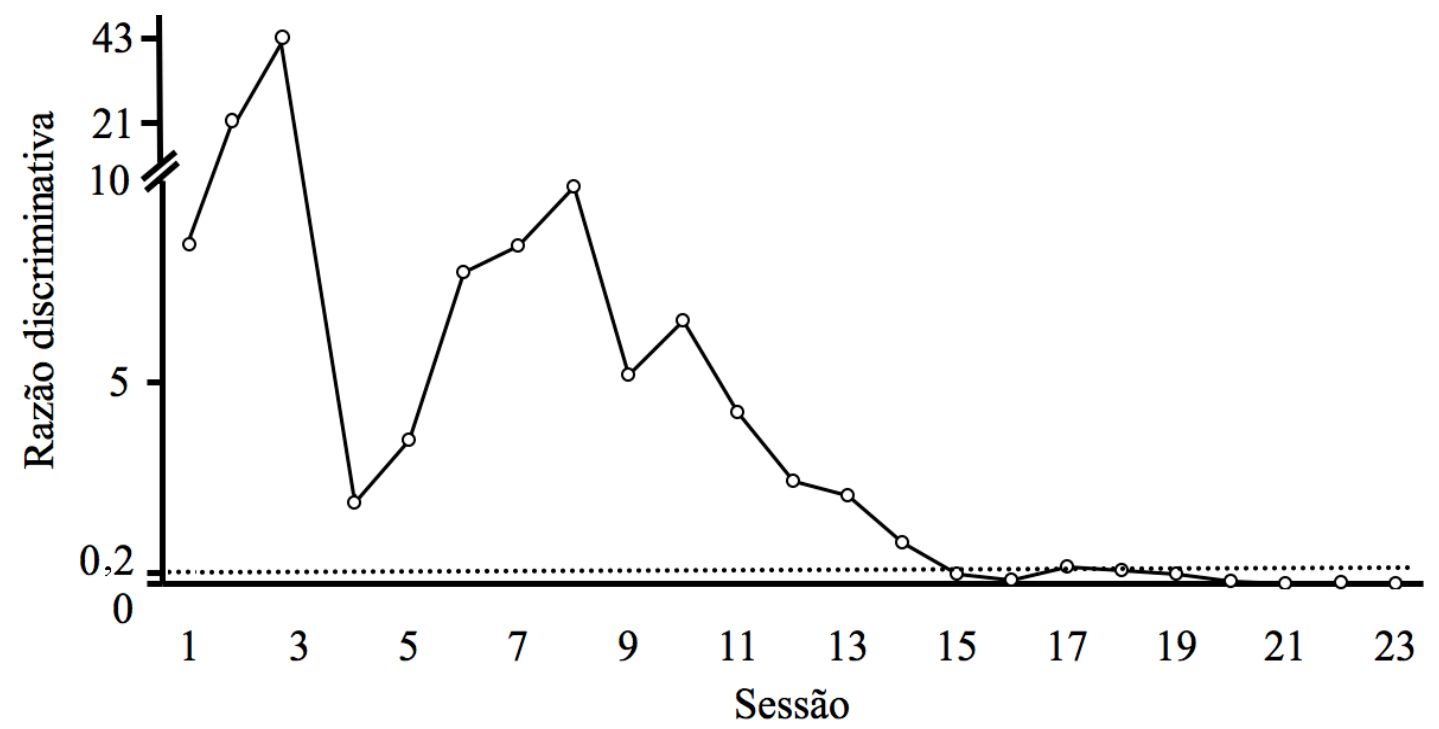

Figura 28. Razão discriminativa por sessão durante o procedimento de treino $A B$ para o Sujeito S9. A linha tracejada indica o valor 0,2 que foi utilizado como critério de aprendizagem.

Na Figura 29 estão apresentados os valores da razão discriminativa, por sessão, durante o treino BC com cores, reset e VI 60.

O Sujeito S9 foi submetido a 18 sessões com esse procedimento. Na Sessão 1 a razão foi 0,39 . Ao longo das Sessões 1 a 7 os valores da razão decresceram até 0,16 . Nas Sessões 8 e 9 nota-se um aumento da razão até 0,7 . A partir da Sessão 9 até o final do treino a razão decresceu até 0 . Entre as Sessões 10 e15, ainda que a razão tenha atingido valores próximos a 0 , S9 respondeu também na presença dos compostos “incorretos" e, por isso, foi mantido no treino. Esses resultados indicam que S9 apresentou responder discriminado na presença de cores como estímulos no treino BC.

Comparando os resultados com o treino AB (Figura 28), verifica-se o estabelecimento de responder discriminado em um menor número de sessões durante o procedimento de treino BC (23 sessões no treino $\mathrm{AB}$ e 18 sessões no treino $\mathrm{BC}$ ). Em adição, na Sessão 1 do treino $\mathrm{AB}$, o valor da razão 8,4 , ao passo que na Sessão 1 do treino $\mathrm{BC}$, a razão foi 0,39 . Isso indica 
que a aprendizagem foi mais rápida no segundo treino $\mathrm{BC}$ provavelmente em função do treino prévio ao qual S9 foi submetido no treino $\mathrm{AB}$.

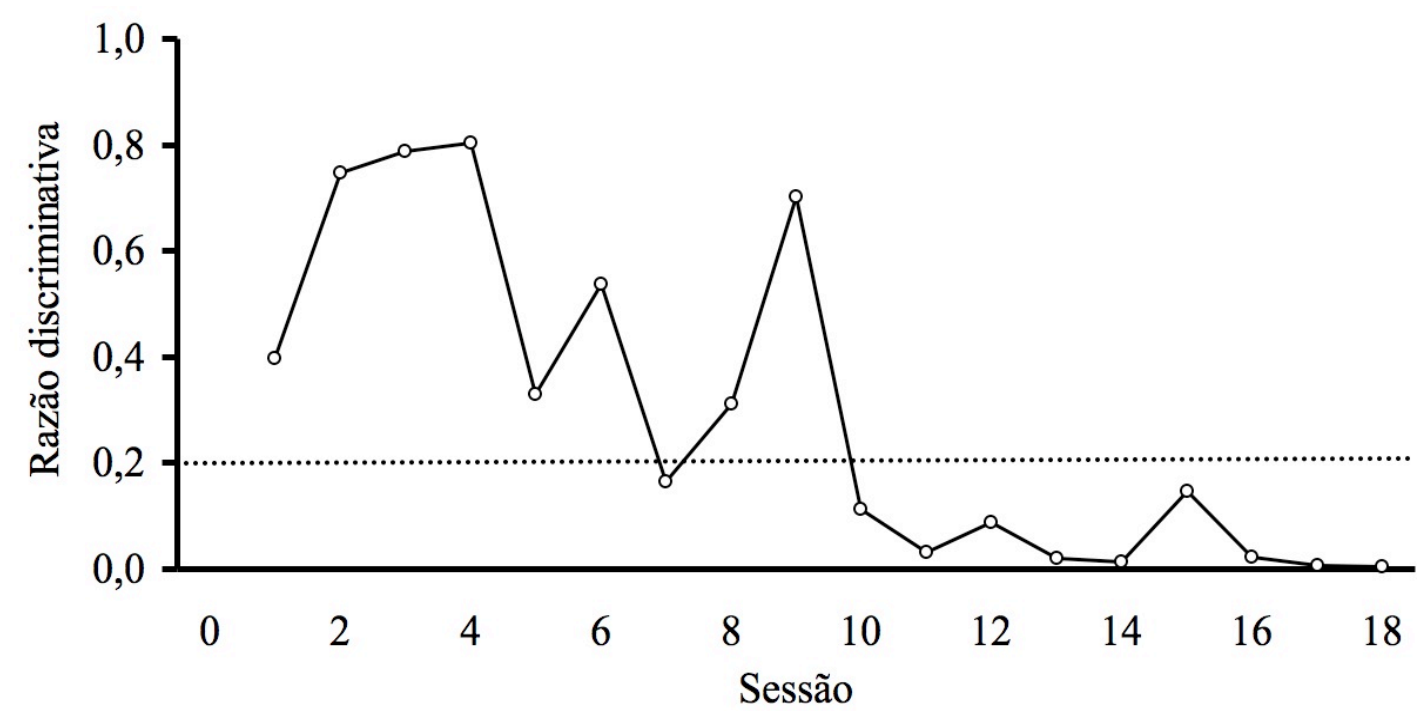

Figura 29. Razão discriminativa por sessão durante o procedimento de treino $\mathrm{BC}$ para o Sujeito S9. A linha tracejada indica o valor 0,2 que foi utilizado como critério de aprendizagem.

Na Figura 30 estão apresentados os valores da razão discriminativa, por sessão, durante o treino $\mathrm{AB}$ e $\mathrm{BC}$ com cores, reset e VI 60.

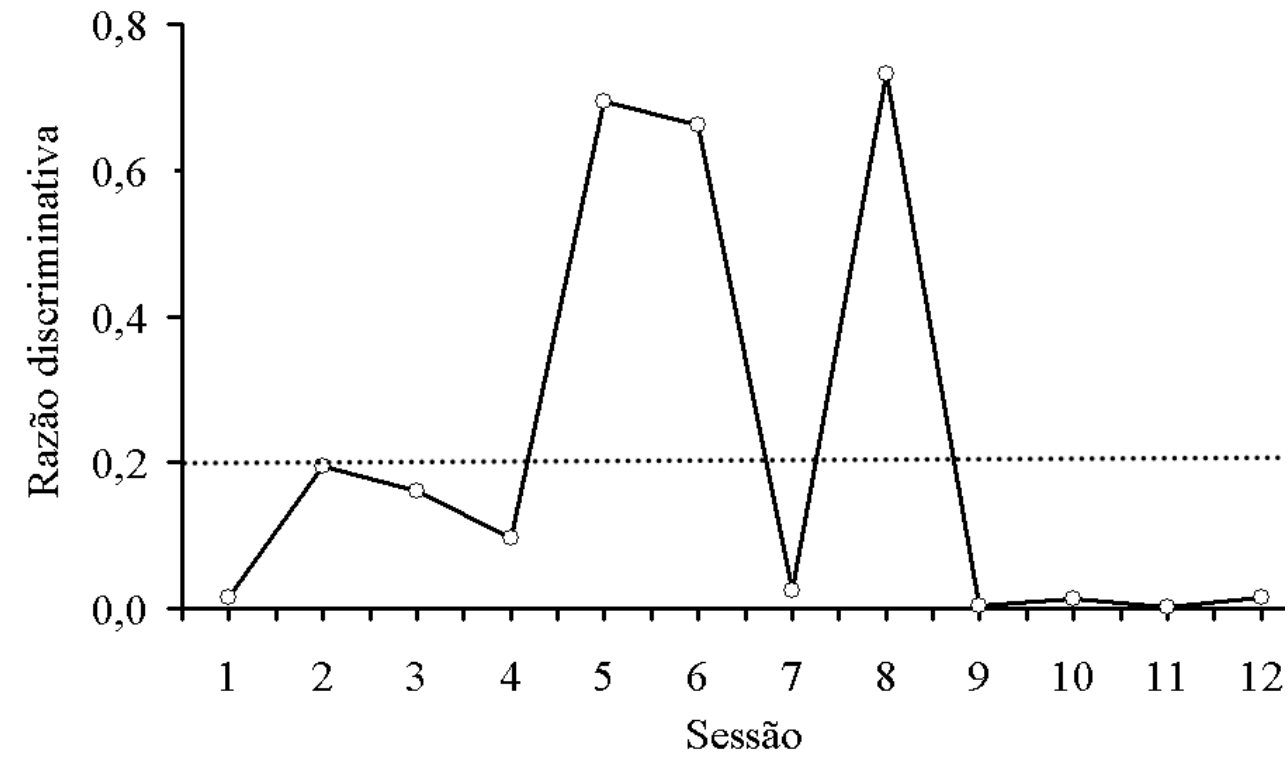

Figura 30. Razão discriminativa por sessão durante o procedimento de treino $\mathrm{AB}$ e $\mathrm{BC}$ com esquema VI 15 segundos, reset com cores para o Sujeito S9. A linha tracejada indica o valor 0,2 que foi utilizado como critério de aprendizagem. 
O Sujeito S9 foi submetido a 12 sessões com esse procedimento. Os valores da razão foram próximos a 0, exceto nas Sessões 5, 6 e 8, cujos valores foram, aproximadamente, 0,7, indicando que S9 passou a responder quase exclusivamente na presença dos compostos “corretos". Similarmente ao Sujeito S10, S9 não manteve o responder discriminado quando as tentativas $\mathrm{AB}$ e $\mathrm{BC}$ foram apresentadas conjuntamente. Esse resultado é diferente ao verificado no desempenho de S11.

\section{Fase III - Teste de simetria}

A Figura 31 apresenta as taxas de respostas, por estímulo composto, durante o teste de simetria.

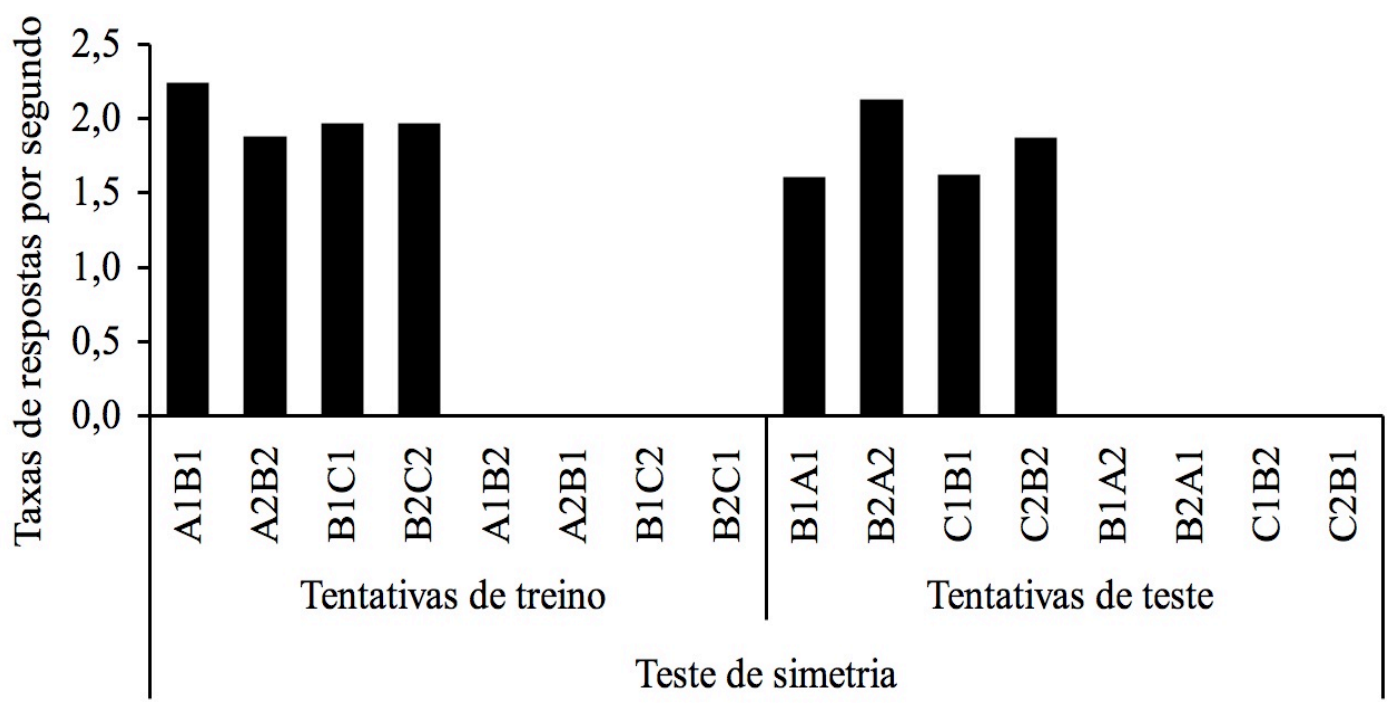

Figura 31. Taxas de respostas por segundo, por estímulo composto, de treino e de teste, durante o teste de simetria para o Sujeito S9.

Durante o teste de simetria, S9 respondeu somente na presença dos compostos "corretos" de treino e de teste. As taxas na presença dos compostos "corretos" de treino variaram entre 1,88 e 2,24 e na presença dos compostos "corretos" de teste variaram entre 1,61 a 2,13. Portanto, as taxas diferenciais nos compostos "corretos" e "incorretos" foram similares nas tentativas de treino e teste. Esses resultados mostram a manutenção do responder discriminado de linha de base e indicam que, da mesma forma como verificado com os Sujeitos S10 e S11, durante o teste de simetria um desempenho condizente com o treino emergiu por meio do procedimento go/no-go com estímulos compostos. 
O Sujeito P9 foi submetido a duas sessões de teste de transitividade e, em seguida, a duas sessões de teste de equivalência.

Anteriormente ao primeiro teste de transitividade, foi conduzida uma sessão de treino $\mathrm{AB}$ e $\mathrm{BC}$ com cores e reset, na qual a razão foi próxima de 0 , indicando manutenção do responder discriminado de linha de base.

A Figura 32 apresenta as taxas de respostas por segundo, por estímulo composto, durante o primeiro teste de transitividade.

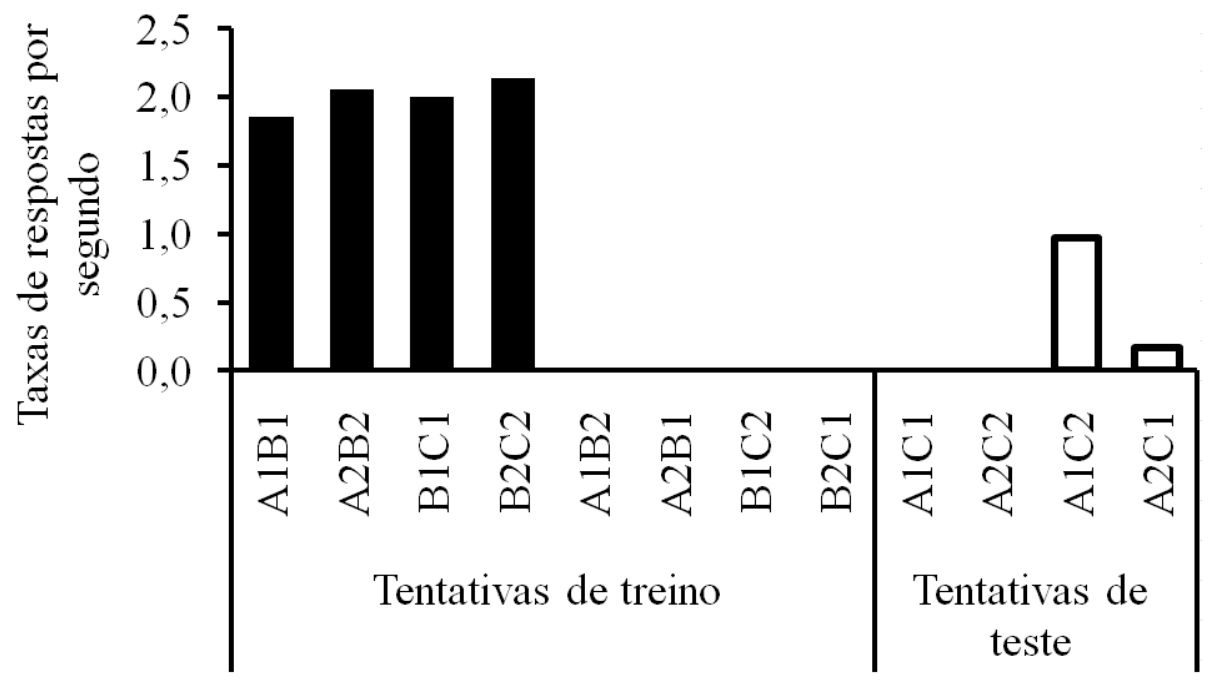

Figura 32. Taxas de respostas por segundo, por estímulo composto, de treino e de teste, durante o primeiro teste de transitividade para o Sujeito S9. As barras pretas indicam a taxa de respostas na presença dos estímulos compostos "corretos" e as barras brancas, as taxas na presença dos "incorretos".

Durante o primeiro teste de transitividade, na presença dos compostos de treino, S9 respondeu exclusivamente aos "corretos", sendo que as taxas variaram entre 1,85 e 2,13. Na presença dos "incorretos", as taxas foram 0. Esses resultados indicam manutenção do responder discriminado de linha de base.

Nas tentativas de teste de transitividade foram emitidas respostas apenas aos compostos "incorretos". As taxas foram, respectivamente, diante de A1C2 e A2C1, 0,97 e 0,17, indicando que o composto A1C2 controlou o responder. Esses resultados indicam o estabelecimento de controle discriminativo simples, assim como verificado nos desempenhos 
dos Sujeitos S10 e S11. Isso indica que a relação de transitividade condizente com o treino não emergiu por meio do procedimento go/no-go com estímulos compostos.

Anteriormente ao segundo teste de transitividade, foi conduzida uma sessão de treino $\mathrm{AB}$ e $\mathrm{BC}$ com cores e reset, na qual a razão foi próxima de 0 , indicando manutenção do responder discriminado de linha de base.

A Figura 33 apresenta as taxas de respostas por segundo, por estímulo composto, durante o segundo teste de transitividade.

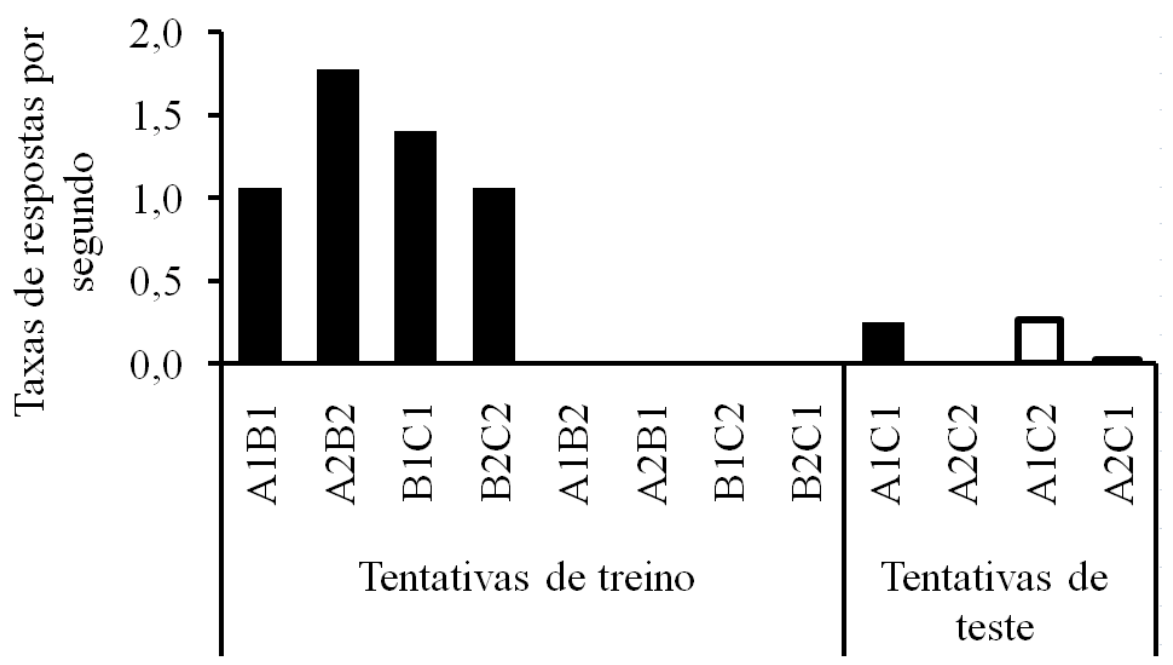

Figura 33. Taxas de respostas por segundo, por estímulo composto, de treino e de teste, durante o segundo teste de transitividade para o Sujeito S9. As barras pretas indicam a taxa de respostas na presença dos estímulos compostos "corretos" e as barras brancas, as taxas na presença dos "incorretos".

Durante o segundo teste de transitividade, na presença dos compostos de treino, S9 respondeu exclusivamente aos "corretos", sendo que as taxas variaram entre 1,77 e 1,06. Na presença dos "incorretos", as taxas foram próximas a 0. Esses resultados indicam manutenção do responder discriminado de linha de base após o primeiro teste de transitividade. Nota-se uma diminuição dos valores das taxas em relação ao primeiro teste de transitividade.

Durante o segundo teste de transitividade, na presença dos compostos de teste foram emitidas respostas quase exclusivamente na presença de $\mathrm{A} 1 \mathrm{C} 1 \mathrm{e} \mathrm{A} 1 \mathrm{C} 2$. As taxas foram, respectivamente, 0,25 e 0,26 , o que sugere o estabelecimento de um responder sob controle discriminativo simples pela presença do elemento A1. Na presença dos "incorretos", as taxas foram próximas a 0 . Observa-se uma diminuição dos valores das taxas dos compostos "incorretos" do primeiro para o segundo teste. Esses resultados indicam que, assim como 
verificado nos desempenhos de S10 e S11, a relação de transitividade condizente com o treino não emergiu por meio do procedimento go/no-go com estímulos compostos.

Fase IV-Teste de equivalência

Anteriormente ao primeiro teste de equivalência, foi conduzida uma sessão de treino $\mathrm{AB}$ e $\mathrm{BC}$ com cores e reset, na qual a razão foi próxima de 0 , indicando manutenção do responder discriminado de linha de base.

A Figura 34 apresenta as taxas de respostas por segundo, por estímulo composto, durante o primeiro teste de equivalência.

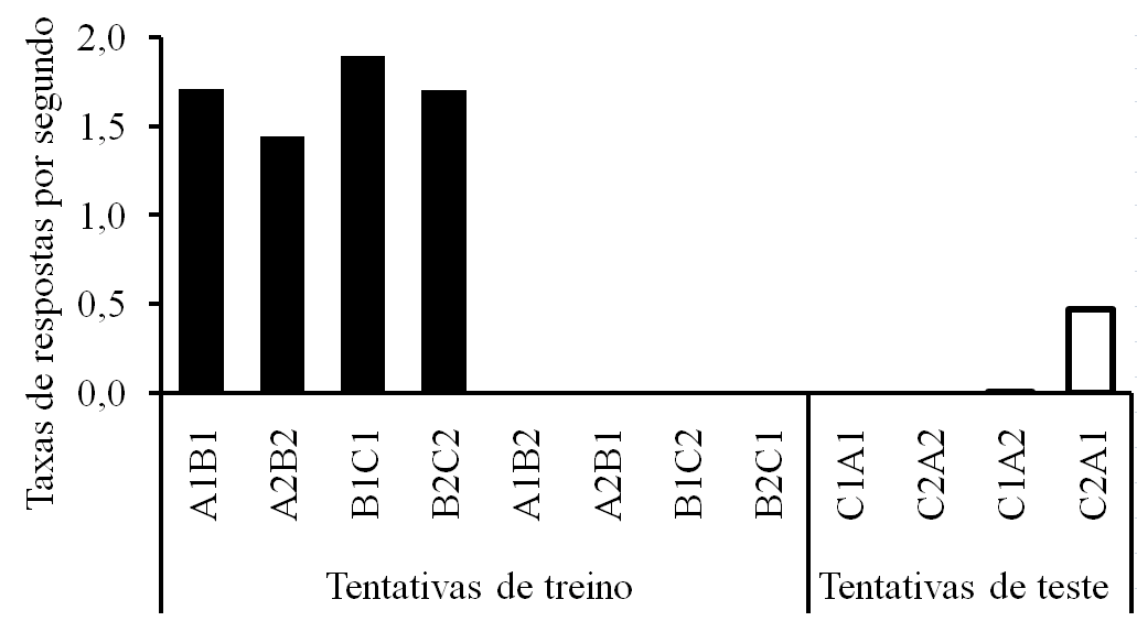

Figura 34. Taxas de respostas por segundo, por estímulo composto, de treino e de teste, durante o primeiro teste de equivalência para o Sujeito S9. As barras pretas indicam a taxa de respostas na presença dos estímulos compostos "corretos" e as barras brancas, as taxas na presença dos "incorretos".

Durante o primeiro teste de equivalência, na presença dos compostos de treino, S9 respondeu exclusivamente aos "corretos", sendo que as taxas variaram entre 1,44 e 1,89. $\mathrm{Na}$ presença dos "incorretos", as taxas foram 0. Isso indica manutenção do responder discriminado de linha de base.

$\mathrm{Na}$ presença dos compostos de teste, S9 respondeu quase exclusivamente a C2A1. A taxa foi 0,4 . Na presença dos demais estímulos de teste, as taxas foram próximas a 0 . Nota-se que durante o teste de transitividade $\mathrm{S} 9$ respondeu ao estímulo $\mathrm{A} 1 \mathrm{C} 2$, relação simétrica (de transitividade) do estímulo C2A1. Esses resultados sugerem que o responder estava sob controle discriminativo simples dos compostos formados por A1 e C2. Esses resultados 
indicam que, assim como verificado com os Sujeitos S10 e S11, a relação de transitividade condizente com o treino não emergiu por meio do procedimento go/no-go com estímulos compostos.

Anteriormente ao segundo teste de transitividade, foi conduzida uma sessão de treino $\mathrm{AB}$ e $\mathrm{BC}$ com cores e reset, na qual a razão foi próxima de 0 , indicando manutenção do responder discriminado de linha de base.

A Figura 35 apresenta as taxas de respostas por segundo, por estímulo composto, durante o segundo teste de equivalência.

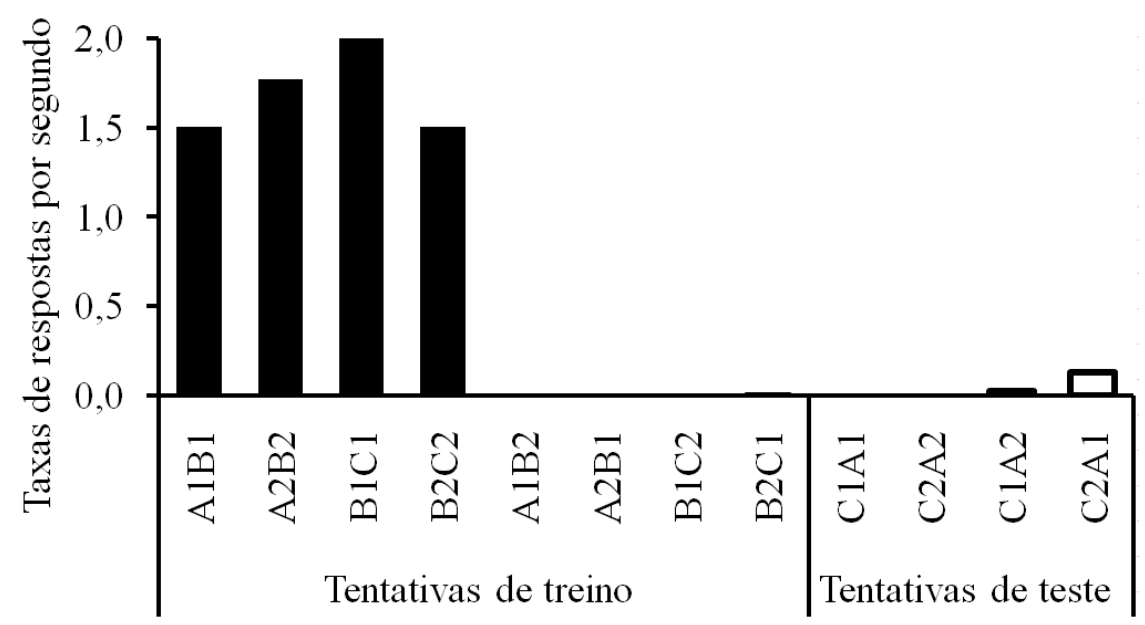

Figura 35. Taxas de respostas por segundo, por estímulo composto, de treino e de teste, durante o segundo teste de equivalência para o Sujeito S9. As barras pretas indicam a taxa de respostas na presença dos estímulos compostos "corretos" e as barras brancas, as taxas na presença dos "incorretos".

Durante o segundo teste de equivalência, na presença dos compostos de treino, S9 respondeu exclusivamente aos "corretos", sendo que as taxas variaram entre 1,5 e 2 . Na presença dos "incorretos", as taxas foram 0. Esses resultados indicam manutenção do responder discriminado de linha de base após o primeiro teste de transitividade.

$\mathrm{Na}$ presença dos compostos de teste, as taxas foram próximas a 0 . Isso mostra uma queda no valor das taxas do primeiro para o segundo teste. Esses resultados indicam que a relação de transitividade condizente com o treino não emergiu por meio do procedimento go/no-go com estímulos compostos, assim como verificado com os Sujeitos S10 e S11. 


\section{DISCUSSÃO}

O presente estudo pretendeu avaliar se o procedimento go/no-go com estímulos compostos produziria relações emergentes de simetria, transitividade e equivalência em pombos.

Durante o treino, foram manipulados separadamente os seguintes parâmetros do procedimento com o objetivo de estabelecer um responder discriminado: o número de relações ensinadas (redução de oito para quatro relações), o esquema de reforçamento (para um sujeito o esquema VI 60 foi alterado para VI 15), a dimensão física dos estímulos (as formas foram alteradas por cores) e a introdução do procedimento reset após respostas aos compostos "incorretos". Somente quando os compostos foram formados por cores foi verificado um responder discriminado no treino. Esses resultados indicam que o procedimento de treino go/no-go com estímulos compostos, analisado por Debert et al. (2007) com estudantes universitários, pode produzir responder discriminado em pombos desde que cores sejam apresentadas como estímulos. Futuros estudos com pombos utilizando o procedimento go/no-go com estímulos compostos devem privilegiar o uso de cores como estímulos.

Da mesma forma que no estudo de Debert et al. (2007), no presente estudo, os três sujeitos apresentaram nos testes de simetria desempenhos condizentes com o que foi ensinado durante o treino. Parece, então, que um procedimento que emprega uma única localização para o responder, como o procedimento go/no-go com estímulos compostos, permitiria a emergência de simetria em não-humanos. Isso porque essa característica do procedimento go/no-go com estímulos compostos não permite o estabelecimento de controle pela localização do responder como ocorre nos estudos que empregam o matching-to-sample (e.g., Iversen, 1997; Iversen et al., 1986; Kamil \& Sachs, 1972; Sidman, 1992; Sidman et al., 1982). Os resultados encontrados no teste de simetria do presente estudo corroboram os resultados encontrados por Frank e Wasserman (2005), que também utilizou uma única localização para o responder, e parece ter obtido emergência de simetria.

Os resultados com o procedimento go/no-go com estímulos compostos do presente estudo e os de Frank e Wasserman (2005) sugerem a possibilidade de produzir desempenhos no teste de simetria condizentes com o treino. A vantagem que parece envolver o procedimento go/no-go com estímulos compostos empregado no presente estudo, em relação ao procedimento go/no-go de Frank e Wasserman (2005), consiste no fato de que no presente estudo não foi necessário conduzir treinos de matching de identidade para evitar o controle 
pela ordem temporal de apresentação dos estímulos. Isso tornou o treino conduzido no presente estudo mais rápido.

Em relação ao estudo de Zentall e Hogan (1975), que também empregou uma única localização para o responder e sugere a emergência de relações não diretamente ensinadas (relação de identidade e de singularidade), o presente estudo indica a possibilidade de produzir relações condicionais emergentes e não discriminações simples, já que os estímulos "corretos" e "incorretos" não poderiam ser diferenciados em termos de campos homogêneos e heterogêneos que teriam controlado o responder como em uma discriminação simples.

Portanto, o procedimento go/no-go com estímulos compostos poderia se constituir uma alternativa ao procedimento matching-to-sample para a produção simetria em não-humanos.

Entretanto, os resultados verificados no teste de simetria do presente estudo poderiam envolver generalização (discriminação simples), uma vez que os estímulos nos testes de simetria envolveram as mesmas cores em posições diferentes. Isso porque desempenhos similares aos desempenhos produzidos no presente estudo foram considerados como generalização no estudo de Watanabe, Sakamoto e Wakita (1995). Esses autores submeteram pombos a um treino no qual, para alguns sujeitos, responder na presença de pinturas de Monet era seguido de alimento e responder na presença de pinturas de Picasso não era seguido de consequência programada. Para outros sujeitos, as contingências eram invertidas. Posteriormente, após o estabelecimento de responder discriminado, foi conduzido um teste, no qual as pinturas do treino eram apresentadas em posição revertida de lados ("left-right reversed") de forma similar às mudanças nos estímulos empregados nos testes do presente estudo. Como resultado, foi verificado que os sujeitos mantiveram o responder discriminado de treino quando as pinturas foram revertidas. Esses resultados foram interpretados pelos autores como envolvendo generalização e não simetria.

Entretanto, o mesmo questionamento poderia ser dirigido ao procedimento matching-tosample, uma vez que, nos testes de simetria com esse procedimento, os estímulos que eram apresentados no treino como modelo passam a ser apresentados como escolha nos testes e os estímulos que eram apresentados como escolha no treino passam a ser apresentados como modelos nos testes. Isso significa apenas uma mudança na localização dos estímulos (localização direita e esquerda, por exemplo). Portanto, as mesmas críticas que seriam apresentadas ao teste de simetria conduzido por meio do procedimento go/no-go com estímulos compostos empregado no presente estudo, bem como ao teste de simetria conduzido no estudo de Frank e Wasserman (2005), a respeito do suposto teste de simetria 
avaliar, na verdade, generalização, deveriam ser apresentadas aos testes de simetria conduzidos por meio do procedimento matching-to-sample.

De qualquer maneira, o fato dos resultados do presente estudo não indicarem emergência de relações de transitividade e equivalência sugerem que talvez não tenha sido produzida discriminação condicional e sim generalização nos testes de simetria. De acordo com Stromer, McIlvane e Serna (1993) e Debert et al. (2007), discriminações condicionais seriam atestadas apenas quando os elementos dos compostos de treino pudessem ser separados e recombinados em novos compostos que manteriam o controle do responder discriminado nos testes de transitividade e equivalência. Tendo em vista que essa separação e recombinação não foi detectada nos testes de transitividade e equivalência do presente estudo, talvez os resultados positivos nos testes de simetria poderiam refletir apenas generalização e não discriminação condicional.

Segundo Lionello-DeNolf (2009, p. 191), alguns estudos que empregaram o procedimento matching-to-sample demonstraram "resultados positivos de reflexividade (...) e transitividade (...) em não-humanos, mas os resultados que investigaram simetria são bem mais duvidosos". Sendo assim, têm-se dois procedimentos (matching-to-sample e go/no-go com estímulos compostos) que produzem resultados opostos nos testes de transitividade e de simetria. Resta saber se esses procedimentos medem desempenhos diferentes (discriminação condicional ou discriminação simples) ou se o fato do procedimento go/no-go com estímulos compostos por ter as possíveis vantagens anteriormente mencionadas, como uma única localização para o responder e ausência de diferenças na ordem temporal de apresentação dos estímulos, produziria emergência de simetria com não-humanos.

Futuros estudos poderiam investigar o tipo de controle estabelecido por meio do procedimento go/no-go com estímulos compostos em pombos e conduzir um treino no qual fosse ensinado aos sujeitos emitir uma resposta $\mathrm{R} 1$ na presença de A1B1, A2B2, B1C1 e B2C2 e a não emitir R1 na presença de A1B2, A2B1, B1C2 e B2C1. Em um treino posterior, seria ensinado aos sujeitos emitir uma resposta R2 na presença do elemento A1 e a emitir uma resposta R3 na presença do elemento A2. Em seguida, seria conduzido um teste, no qual seriam apresentados os elementos A1, B1, C1, A2, B2 e C2. Caso os sujeitos emitissem a resposta R2 exclusivamente na presença de A1, B1 e $\mathrm{C} 1$ e emitissem a resposta R3 exclusivamente na presença de A2, B2 e C2, poderia ser afirmado que foram formadas duas classes de estímulos equivalentes: Classe 1 (A1, B1 e C1) e Classe 2 (A2, B2 e C2), já que a transferência de R2 e R3 somente poderia ser explicada por meio da formação de classes de equivalência. 
Futuros estudos poderiam investigar também outros parâmetros do procedimento go/nogo com estímulos compostos que eventualmente permitiriam a produção de desempenhos emergentes nos testes de transitividade e equivalência para que uma avaliação mais pormenorizada do procedimento go/no-go com estímulos compostos pudesse ser conduzida. Isso seria relevante, tendo em vista os resultados do Sujeito S10 na segunda sessão de teste de transitividade, na qual há indícios da possibilidade de se estabelecer relações condicionais, apesar dessas relações serem diferentes daquelas especificadas pelo treino. 


\section{REFERÊNCIAS}

Barros, R. S., Galvão, O. F., \& McIlvane, W. (2002). Generalized identity matching-tosample in Cebus apella. Psychological Record, 52, 441-460.

Carter, D. E., \& Eckerman, D. A. (1975). Symbolic matching by pigeons: Rate of learning complex discriminations predicted from simple discriminations. Science, 187, 662-664.

Carter, D. E., \& Werner, T. J. (1978). Complex learning and information processing by pigeons: A critical analysis. Journal of the Experimental Analysis of Behavior, 29, 565601.

Cumming, W. W., \& Berryman, R. (1965). The complex discriminated operant: Studies of matching-to-sample and related problems. Em D. I. Mostofsky (Ed.), Stimulus generalization (pp. 284-330). Stanford, CA: Stanford University Press.

Da Hora, C. L. (2009). Procedimento go/no-go com estímulos compostos e relações condicionais emergentes em crianças com autismo. 189 f. Dissertação (Mestrado Instituto de Psicologia, Universidade de São Paulo, São Paulo.

Debert, P., Matos, M. A., \& McIlvane, W. (2007). Conditional relations with compound abstract stimuli using a go/no-go procedure. Journal of the Experimental Analysis of Behavior, 87, 89-96.

Frank, A., \& Wasserman, E. (2005). Associative symmetry in the pigeon after successive matching-to-sample training. Journal of the Experimental Analysis of Behavior, 84, 147-165.

Iversen, I. H. (1997). Matching-to-sample performance in rats: A case of mistaken identity? Journal of the Experimental Analysis of Behavior, 68, 27-45.

Iversen, I. H., Sidman, M., \& Carrigan, P. (1986). Stimulus definition in conditional discrimination. Journal of the Experimental Analysis of Behavior, 45, 297-304.

Kamil, A. C., \& Sacks, R. A. (1972). Three-configuration matching-to-sample in the pigeons. Journal of the Experimental Analysis of Behavior, 17, 483-488.

Lionello-DeNolf, K. M. (2009). A search for symmetry: 25 years in review. Learning and Behavior, 37, 188-203.

Mallot, R. W., Mallot, K., Svinicki, J. G., Kladder, F., \& Ponicki, E. (1971). An analysis of matching and nonmatching behavior using a single key, free operant procedure. The Psychological Record, 21, 545-564. 
Markham, M. R., \& Dougher, M. J. (1993). Compound stimuli in emergent stimulus relations: Extending the scope of stimulus equivalence. Journal of the Experimental Analysis of Behavior, 60, 529-542.

Perez, W. F., Campos, H. C., \& Debert, P. (2009). Procedimento go/no-go com estímulos compostos e a emergência de duas classes com três estímulos. Acta Comportamentalia, $17,191-210$.

Sidman, M. (1992). Adventitious control by the location of comparison stimuli in conditional discriminations. Journal of the Experimental Analysis of Behavior, 58, 176-182.

Sidman, M. (1994). Equivalences relations and behavior: A research story. Boston: Authors Cooperative.

Sidman, M., Rauzin, R., Lazar, R., Cunningham, S., Tailby, W., \& Carrigan, P. (1982). A search for symmetry in the conditional discriminations of rhesus monkeys, baboons, and children. Journal of the Experimental Analysis of Behavior, 37, 23-44.

Sidman, M., \& Tailby, W. (1982). Conditional discrimination vs. matching to sample: An expansion of testing paradigm. Journal of the Experimental Analysis of Behavior, 37, 522 .

Skinner, B. F. (1953). Science and human behavior. New York: Macmillan.

Stromer, R., McIlvane, W. J., \& Serna, R. W. (1993). Complex stimulus control and equivalence. The Psychological Record, 43, 585-598.

Watanabe, S., Sakamoto, J., \& Wakita, M. (1995). Pigeons' discrimination of paintings by Monet and Picasso. Journal of the Experimental Analysis of Behavior, 63, 165-174.

Zentall, T. R., \& Hogan, D. E. (1975). Concept learning in the pigeon: Transfer to new matching and nonmatching stimuli. American Journal of Psychology, 88, 233-244. 